\title{
Servidor web distribuído com diferenciação de serviços - implementação e avaliação de um protótipo
}

\author{
Valter Rogérios Messias
}

Prof. Dr. Marcos José Santana

Dissertação apresentada ao Instituto de Ciências Matemáticas e de Computação - ICMC-USP, como parte dos requisitos para obtenção do título de Mestre em Ciências - Ciências de Computação e Matemática Computacional.

\section{"VERSÃO REVISADA APÓS A DEFESA"}

Data da Defesa:

$19 / 10 / 2007$

Visto do Orientador:

USP - São Carlos

Novembro/2007 
Servidor web distribuído com diferenciação de serviços implementação e avaliação de um protótipo

Valter Rogério Messias 

À minha familia, em especial à minha mãe, Hilda Aparecida de Arruda e à minha avó, Catarina Melchior Arruda. 



\section{Agradecimentos}

Agradeço, primeiramente, a Deus, pelas oportunidades na minha vida.

À minha família, especialmente à minha mãe, Hilda Aparecida de Arruda e à minha avó, Catarina Melchior Arruda, pela educação, por estarem presentes na maioria dos momentos difíceis e felizes da minha vida, pelo apoio incondicional e pelo carinho.

A Universidade de São Paulo, USP - Campus São Carlos, pela oportunidade de realizar o curso de Pós-Graduação.

A Universidade Estadual Paulista, Unesp - Campus Rio Claro, pela base oferecida durante o curso de Graduação.

A meu orientador, Marcos José Santana, pela orientação e confiança durante o desenvolvimento do trabalho, além da amizade e dos ensinamentos transmitidos.

Ao meu amigo de graduação Gustavo Faria, pela ajuda e incentivo, especialmente no inicio do mestrado, além da amizade.

À Ana, pelo seu carinho e atenção, e pela sua disposição em ajudar.

A todos meus colegas e amigos do LaSDPC, da USP e de São Carlos, que não vou citar os nomes porque são muitos, e todos igualmente especiais, pela dedicação, ajuda, companheirismo, e por terem tornado os momentos que passei em suas companhias inesqueciveis.

Aos funcionários do ICMC-USP, Arli, Marcos, Roberto, Jô, Camilo, Aparecido, Emerson, Moacir, Adriano, Cláudio, pelo convívio amigo e descontraído, e pela disposição em sempre bem atender. 
Aos funcionários do STI do ICMC-USP, Dotta, Guilherme, Thiago, pela dedicação e suporte dados durante a realização deste projeto.

Às funcionárias da Pós-Graduação do ICMC-USP, Beth, Laura e Ana Paula, pela dedicação e disposição em sempre bem atender.

A CAPES e ao CNPQ, pelo apoio financeiro dado a este trabalho. 
"Todos os caminhos são mágicos, se nos levam aos nossos sonhos."

Paulo Coelho 



\section{Sumário}

1 Introdução 1

1.1 Contextualização . . . . . . . . . . . . . . . . . . . . 1

1.2 Motivação . . . . . . . . . . . . . . . . . . . 2

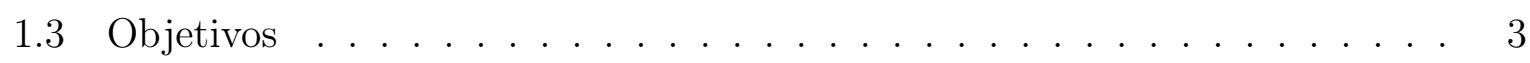

1.4 Estrutura da Monografia . . . . . . . . . . . . . . . . 3

2 Estrutura da $\mathrm{Web} \quad 5$

2.1 Considerações Iniciais . . . . . . . . . . . . . . . . . . . . . 5

2.2 Conjunto de Protocolos TCP/IP . . . . . . . . . . . . . . 5

2.2 .1 Arquitetura TCP $/ \mathrm{IP} \ldots \ldots \ldots$. . . . . . . . . . 6

2.2.2 Descrição das Camadas e seus Protocolos . . . . . . . . . . . . . . 6

2.3 A World Wide Web . . . . . . . . . . . . . . . . . . 8

2.3.1 Visão Geral do Protocolo HTTP . . . . . . . . . . . . . . . . . . . 9

2.3.2 Mensagens HTTP . . . . . . . . . . . . . . . . 9

2.3.3 Conexões HTTP . . . . . . . . . . . . . . . . . . . . . 11

2.4 Formas de Organização de servidores Web . . . . . . . . . . . . . . 12

2.5 Considerações Finais . . . . . . . . . . . . . . . . . . . . . . . 14

3 Serviços Diferenciados $\quad 17$

3.1 Considerações Iniciais . . . . . . . . . . . . . . . . . . . . . . . . . 17

3.2 Conceitos Básicos de QoS . . . . . . . . . . . . . . . . . 18

3.2.1 Classificação de aplicações quanto ao tipo de tráfego . . . . . . . 18

3.3 Arquiteturas para QoS . . . . . . . . . . . . . . . . . . . . . . 19

3.3.1 Serviços Integrados . . . . . . . . . . . . . . . . . . . . . . . 19

3.3.2 Serviços Diferenciados . . . . . . . . . . . . . . . 21

3.4 Serviços Diferenciados em Nível de Aplicação . . . . . . . . . . . . . . . . . 24

3.5 Considerações Finais . . . . . . . . . . . . . . . . . . . . 28 
4 Servidor Web com Diferenciação de Serviços (SWDS) 31

4.1 Considerações Iniciais . . . . . . . . . . . . . . . . . . . . . . 31

4.2 Modelo de Servidor Web com Diferenciação de Serviços . . . . . . . . . . . 32

4.3 Mecanismos de Diferenciação de Serviços . . . . . . . . . . . . . . . . . 35

4.3 .1 Reserva de Recursos . . . . . . . . . . . . . . . . . . . 35

4.3.2 Escalonamento Baseado em Prioridades . . . . . . . . . . . . 36

4.4 Cenários de Utilização . . . . . . . . . . . . . . . . . . . . . . . 37

4.5 Considerações Finais . . . . . . . . . . . . . . . . . . . . . . . . . . 38

5 Implementação de um protótipo do SWDS 39

5.1 Considerações Iniciais . . . . . . . . . . . . . . . . . . . . . . . 39

5.2 Arquitetura do Protótipo . . . . . . . . . . . . . . . . . . . . . . . . . 39

5.3 Algoritmos de Diferenciação de Serviços . . . . . . . . . . . . . . . . . 46

5.3.1 Algoritmos de Reserva de Recursos . . . . . . . . . . . . . . . . 46

5.3.2 Escalonamento Baseado em Prioridades . . . . . . . . . . . . . . . . 48

5.3.3 Mecanismos de Controle de Admissão . . . . . . . . . . . . . . . . . 49

5.4 Arquitetura de Testes . . . . . . . . . . . . . . . . . . 50

5.5 Considerações Finais . . . . . . . . . . . . . . . . . . . . . . . 52

6 Resultados Experimentais $\quad 53$

6.1 Considerações Iniciais . . . . . . . . . . . . . . . . . . . . . . 53

6.2 Algoritmos de Reserva de Recursos . . . . . . . . . . . . . . . . . . 54

6.2 .1 Introdução . . . . . . . . . . . . . . . . . . . . . . . . . 54

6.2.2 Planejamento dos Experimentos . . . . . . . . . . . . . . 54

6.2.3 Carga de trabalho sintética, composta majoritariamente por requisições estáticas . . . . . . . . . . . . . . . . . . 55

6.2.4 Carga de trabalho sintética, hipotética, composta $100 \%$ por requisições com alto consumo de CPU . . . . . . . . . . . . 57

6.2.5 Considerações sobre os algoritmos baseados em reserva de recursos . 64

6.3 Escalonamento Baseado em Prioridades . . . . . . . . . . . . . . . . 65

6.3 .1 Introdução . . . . . . . . . . . . . . . . . . . 65

6.3.2 Planejamento dos Experimentos . . . . . . . . . . . 65

6.3.3 Carga de trabalho sintética, composta majoritariamente por requisições estáticas . . . . . . . . . . . . . . . . 66

6.3.4 Carga de trabalho sintética, hipotética, composta $100 \%$ por requisições dinâmicas com alto consumo de CPU . . . . . . . . . . . 66

6.3.5 Considerações sobre o algoritmo . . . . . . . . . . . . . . 70

6.4 Mecanismos de Controle de Admissão . . . . . . . . . . . . . . . . . . . . . 70

6.4 .1 Introdução . . . . . . . . . . . . . . . . . . . . 70

6.4.2 Planejamento dos Experimentos . . . . . . . . . . . 70 
6.4.3 Carga de trabalho sintética, hipotética, composta $100 \%$ por requisições dinâmicas com alto consumo de CPU . . . . . . . . . . . 71

6.4.4 Considerações sobre o mecanismo de controle de admissão .... . 74

6.5 Considerações Finais . . . . . . . . . . . . . . . . . . . . . . . . 74

7 Conclusão $\quad 77$

7.1 Visão Geral . . . . . . . . . . . . . . . . . . . . . . . . . . . 77

7.2 Principais Resultados e Contribuições . . . . . . . . . . . . . . . . . . . 80

7.3 Trabalhos Futuros . . . . . . . . . . . . . . . . . . . 82

$\begin{array}{ll}\text { APENNDICE } & 85\end{array}$

A Demais Gráficos $\quad 85$

Referências Bibliográficas $\quad 95$ 



\section{Lista de Figuras}

2.1 Arquitetura do TCP $/$ IP. . . . . . . . . . . . . . . . . . 6

2.2 Exemplo de requisição HTTP. . . . . . . . . . . . . . . . . . . . . 10

2.3 Exemplo de resposta HTTP. . . . . . . . . . . . . . . . . . 11

2.4 Conexões TCP usando o protocolo HTTP 1.0 (a) e 1.1 (b) (Menascé \& Almeida, 2003) . . . . . . . . . . . . . . . . . . . 12

3.1 Funcionamento do protocolo RSVP (Zhao et al., 2000) . . . . . . . . . 20

3.2 Campo DS (Oyama \& de Lucena, 2002). . . . . . . . . . . . . . . . . 22

3.3 Valores recomendados para identificar os PHBs (Oyama \& de Lucena, 2002). 23

4.1 Arquitetura do SWDS (Teixeira, 2004) . . . . . . . . . . . . . 32

4.2 Controle de Admissão. . . . . . . . . . . . . . . . . . . . . . . . . 34

5.1 Operações de um Web Switch layer 4 (Esquerda) e layer 7 (Direita) (Cardellinni \& Casalicchio, 2002). . . . . . . . . . . . . . . . . . . 40

5.2 Visão geral da arquitetura do protótipo do SWDS. . . . . . . . . . . . . . 41

5.3 Arquitetura do Web Switch e interações com o cliente e o Web Server. . . . 43

5.4 Exemplo de utilização do mod_rewrite. . . . . . . . . . . . . . . . . . . . 44

5.5 Arquitetura do controle de admissão . . . . . . . . . . . . . . . . 45

5.6 Modelo preforking de atendimento de requisições (Gröne et al., 2004). . . . 49

5.7 Filas de prioridades para o atendimento das requisições. . . . . . . . . . . . 50

5.8 Arquitetura de Testes . . . . . . . . . . . . . . . . . . . . . . 51

6.1 Médias dos tempos de respostas para o algoritmo RSV . . . . . . . . . . 56

6.2 Porcentagem de requisições não completadas por ultrapassarem o tempo máximo de espera no cliente (timeout) com a utilização do algoritmo RSV. 56

6.3 Médias dos tempos de respostas para o algoritmo RSVadap. . . . . . . . . 58

6.4 Porcentagem de requisições não completadas por ultrapassarem o tempo máximo de espera no cliente (timeout) com a utilização do algoritmo RSVadap. . . . . . . . . . . . . . . . . . . 58 
6.5 Médias dos tempos de respostas para o algoritmo RSV com $20 \%$ de requisições de alta prioridade (carga hipotética) . . . . . . . . . . . . . 60

6.6 Porcentagem de requisições não completadas por ultrapassarem o tempo máximo de espera no cliente (timeout) com a utilização do algoritmo RSV com $20 \%$ de requisições de alta prioridade (carga hipotética) . . . . . . . . 60

6.7 Médias dos tempos de respostas para o algoritmo RSV com $30 \%$ de requisições de alta prioridade (carga hipotética) . . . . . . . . . . . . . . . 62

6.8 Porcentagem de requisições não completadas por ultrapassarem o tempo máximo de espera no cliente (timeout) com a utilização do algoritmo RSV com 30\% de requisições de alta prioridade (carga hipotética) . . . . . . . . . 62

6.9 Médias dos tempos de respostas para o algoritmo RSVadap com 50\% de requisições de alta prioridade e nível de diferenciação 0.5 (carga hipotética). 63

6.10 Porcentagem de requisições não completadas para o algoritmo RSVadap com $50 \%$ de requisições de alta prioridade e nível de diferenciação 0.5 (carga hipotética).

6.11 Médias dos tempos de respostas para o algoritmo PriProcess com 50\% de requisições de alta prioridade.

6.12 Porcentagem de requisições não completadas para o algoritmo PriProcess com $50 \%$ de requisições de alta prioridade. . . . . . . . . . . . . . . 67

6.13 Médias dos tempos de respostas para o algoritmo PriProcess com 50\% de requisições de alta prioridade (carga hipotética) . . . . . . . . . . . . 68

6.14 Porcentagem de requisições não completadas para o algoritmo PriProcess com 50\% de requisições de alta prioridade (carga hipotética). . . . . . . . . 68

6.15 Médias dos tempos de respostas para o algoritmo PriProcess com 50\% de requisições de alta prioridade e mecanismos de controle de admissão. . . 72

6.16 Porcentagem de requisições não completadas para o algoritmo PriProcess com $50 \%$ de requisições de alta prioridade e mecanismos de controle de admissão.

A.1 Médias dos tempos de respostas utilizando o algoritmo PriProcess com $10 \%$ de requisições de alta prioridade (carga hipotética).

A.2 Porcentagem de requisições não completadas utilizando o algoritmo PriProcess com $10 \%$ de requisições de alta prioridade (carga hipotética). . . . 86

A.3 Médias dos tempos de respostas utilizando o algoritmo PriProcess com $30 \%$ de requisições de alta prioridade (carga hipotética) . . . . . . . . . . 86

A.4 Porcentagem de requisições não completadas utilizando o algoritmo PriProcess com 30\% de requisições de alta prioridade (carga hipotética). . . . 87

A.5 Médias dos tempos de respostas utilizando o algoritmo PriProcess com $70 \%$ de requisições de alta prioridade (carga hipotética) . . . . . . . . . . . 87 
A.6 Porcentagem de requisições não completadas utilizando o algoritmo PriProcess com $70 \%$ de requisições de alta prioridade (carga hipotética). . . . 88

A.7 Médias dos tempos de respostas utilizando o algoritmo PriProcess com 90\% de requisições de alta prioridade (carga hipotética) . . . . . . . . . . . . 88

A.8 Porcentagem de requisições não completadas utilizando o algoritmo PriProcess com $90 \%$ de requisições de alta prioridade (carga hipotética). . . . 89

A.9 Médias dos tempos de respostas utilizando o algoritmo PriProcess com 10\% de requisições de alta prioridade e mecanismos de controle de admissão. . 89

A.10 Porcentagem de requisições descartadas utilizando o algoritmo PriProcess com $10 \%$ de requisições de alta prioridade e mecanismos de controle de admissão.

A.11 Médias dos tempos de respostas utilizando o algoritmo PriProcess com 30\% de requisições de alta prioridade e mecanismos de controle de admissão. . 90

A.12 Porcentagem de requisições descartadas utilizando o algoritmo PriProcess com 30\% de requisições de alta prioridade e mecanismos de controle de admissão. . . . . . . . . . . . . . . . . . . . . . . . . . 91

A.13 Médias dos tempos de respostas utilizando o algoritmo PriProcess com $70 \%$ de requisições de alta prioridade e mecanismos de controle de admissão. . . 91

A.14 Porcentagem de requisições descartadas utilizando o algoritmo PriProcess com $70 \%$ de requisições de alta prioridade e mecanismos de controle de admissão.

A.15 Médias dos tempos de respostas utilizando o algoritmo PriProcess com 90\% de requisições de alta prioridade e mecanismos de controle de admissão. . . 92

A.16 Porcentagem de requisições descartadas utilizando o algoritmo PriProcess com $90 \%$ de requisições de alta prioridade e mecanismos de controle de admissão. . . . . . . . . . . . . . . . . . . . . . 93 



\section{Lista de Tabelas}

2.1 Descrição dos métodos do protocolo HTTP 1.1. . . . . . . . . . . . . . . 10

2.2 Descrição das classes de respostas do protocolo HTTP. . . . . . . . . . . . 11

5.1 Modelo de carga utilizado no SURGE . . . . . . . . . . . . . . . . 52

6.1 Utilização dos recursos do sistema quando submetido a uma carga de trabalho real . . . . . . . . . . . . . . . . . . . 57

6.2 Utilização dos recursos do sistema quando submetido a uma carga de trabalho hipotética composta $100 \%$ por requisições com alto consumo de CPU 59

6.3 Comparação das médias dos tempos de respostas (segundos) utilizando o algoritmo PriPocess submetido a diferentes cargas de trabalho . . . . . . . 69

6.4 Comparação da porcentagem de requisições não completadas utilizando o algoritmo PriPocess submetido a diferentes cargas de trabalho . . . . . . . 69

6.5 Comparação das médias dos tempos de respostas (segundos) utilizando o mecanismo de controle de admissão submetido a diferentes cargas de trabalho 73

6.6 Comparação da porcentagem de requisições descartadas utilizando o mecanismo de controle de admissão submetido a diferentes cargas de trabalho 74 



\section{Lista de Símbolos}

$\begin{array}{ll}\text { ARP } & \text { Address Resolution Protocol } \\ \text { API } & \text { Application Programming Interface } \\ \text { CPU } & \text { Central Processing Unit } \\ \text { DoD } & \text { Department of Defense } \\ \text { DNS } & \text { Domain Name Server } \\ \text { DSCP } & \text { Differentiated Services CodePoint } \\ \text { FCFS } & \text { First Come First Served } \\ \text { FTP } & \text { File Transfer Protocol } \\ \text { HTML } & \text { HyperText Markput Language } \\ \text { HTTP } & \text { HyperText Transfer Protocol } \\ \text { IETF } & \text { Internet Engineering Task Force } \\ \text { ICMP } & \text { Internet Control Message Protocol } \\ \text { IIS } & \text { Internet Information Service } \\ \text { IP } & \text { Internet Protocol } \\ \text { ISP } & \text { Internet Service Provider } \\ \text { LAN } & \text { Local Area Network } \\ \text { LaSDPC } & \text { Laboratório de Sistemas Distribuídos e Programação Concorrente } \\ \text { MIME } & \text { Multiporpose Internet Mail Extension } \\ \text { MPLS } & \text { MultiProtocol Label Switching } \\ \text { PHB } & \text { Per-Hop Behavior } \\ \text { QoS } & \text { Quality of Service } \\ \text { RARP } & \text { Reverse Address Resolution Protocol } \\ \text { RFC } & \text { Request for Comments } \\ \text { RSVP } & \text { Resource Reservation Protocol } \\ \text { SLA } & \text { Service Level Agreements } \\ \text { SMTP } & \text { Simple Mail Transfer Protocol } \\ \text { SWDS } & \text { Servidor Web com Diferenciação de Serviços } \\ \text { TCP } & \text { Transmission Control Protocol } \\ & \end{array}$


TCP/IP Trasmission Control Protocol/Internet Protocol

UDP User Datagram Protocol

URI Uniform Resource Identifiers

URL Universal Resource Locator

VPN Virtual Private Network

W3C World Wide Web Consortium

WWW World Wide Web

SURGE Scalable URL Reference Generator 


\section{Resumo}

Este trabalho apresenta um estudo, implementação e avaliação em ambiente real de um protótipo de servidor Web com diferenciação de serviços (SWDS) para provisão de QoS relativa em servidores Web. Para tanto foram considerados algoritmos de reserva de recursos e escalonamento baseado em prioridades para prover diferenciação entre as classes de serviço, além de mecanismos de controle de admissão a fim de controlar a carga no sistema. A meta é oferecer melhor tratamento para requisições de maior prioridade, sem prejudicar em excesso as requisições de prioridade menor. Foi observado que os algoritmos de reserva de recursos (RSV e RSVadap) são eficientes para prover diferenciação entre as classes consideradas, no entanto seus desempenhos não foram satisfatórios em alguns casos, tanto devido a arquitetura em que foram implementados, como por motivos inerentes à própria natureza do algoritmo. O algoritmo de escalonamento baseado em prioridades considerado (PriProcess), mostrou-se eficiente tanto no sentido de prover diferenciação de serviços entre as classes, como na questão de desempenho, com a classe de maior prioridade sempre sendo melhor atendida em relação à classe de menor prioridade. Também foi alvo do estudo a criação de um mecanismo de controle de admissão com diferenciação de serviços. Os resultados alcançados sinalizam uma melhora em termos de tempos de respostas e número de requisições completadas para a classe de maior prioridade. 



\begin{abstract}
This work presents a study, implementation and evaluation in real environment of a Web server architecture with service differentiation (SWDS) for provision of relative QoS in Web servers. Algorithms of resources reservation and scheduling based on priorities were considered to provide service differentiation among the request classes, besides implementation of a mechanism for admission control in order to control the load in the system. The goal is to offer better treatment for higher priority requests without harming in excess lower priority ones. It was observed that the algorithms for resource reservation (RSV and RSVapap) are efficient to provide differentiation among the considered classes, however their performance was not satisfactory in some cases, due to both, the archtectures through which they were implemented and the specific features of the algorithm nature. The considered scheduling algorithm based on priorities (PriProcess) was efficient both in the sense of providing service differentiation among the classes and with regards to performance, with the higher priority class always being better served than the lower priority one. It was also studied the creation of a mechanism for admission control with service differentiation. The achieved results show an improvement in terms of response times and the number of completed requests for the higher priority class.
\end{abstract}





\section{Capítulo \\ 1 \\ Introdução}

\subsection{Contextualização}

Nos últimos anos, a Internet vem passando por um crescimento intenso e a tendência é que esse cenário se mantenha pelos próximos anos (Morrison, 2005). A World Wide Web tem sido um dos principais fatores que motivaram esse crescimento, pois foi a responsável pela popularização do uso da Internet, de tal forma que hoje em dia se confunde com a própria Internet e com serviços disponíveis há mais tempo, tais como o e-mail e o FTP (File Transfer Protocol), por exemplo.

Com isso, a Internet, que até a década de 90 era usada basicamente por pesquisadores, acadêmicos e estudantes universitários para se comunicar com outras cidades, transferirem arquivos locais para computadores remotos, trocar notícias e utilizar o correio eletrônico, passou a ser usada também para localizar e visualizar documentos baseados em hipertexto sobre uma diversidade de assuntos, conteúdo multimídia, entre outros. A tendência é que os serviços que funcionam sobre a estrutura da Internet sejam cada vez mais incrementados, como por exemplo: redes de telefonia, rádio e televisão (Mahonen et al., 2004).

Com a popularização e o crescente número de usuários, a Internet que originalmente transportava quase exclusivamente dados em formato textual, os quais lhe impunham pouca carga, começa a dar sinais de estrangulamento. Isso se deve ao fato da mesma não ter sido projetada para o tipo de conteúdo que trafega por ela atualmente (imagens, vídeos, transações comerciais, etc) e, nem para a grande quantidade de carga que lhe vem sendo imposta.

A Internet atual é baseada na pilha de protocolos TCP/IP, que fornece um serviço baseado no modelo de melhor esforço (best-effort), isto é, procura realizar a tarefa de 
envio, recebimento e transporte de informações da melhor maneira e no menor tempo possível. Entretanto, não há nenhuma garantia desse serviço às aplicações (Comer, 2000).

Uma possível solução para o problema mencionado tem sido o aumento da largura de banda da rede. Porém, essa é uma solução apenas parcial, pois com o crescente número de usuários, esse aumento pode ser rapidamente consumido e, assim, o problema voltar a existir.

Uma outra tentativa de melhorar a qualidade dos serviços na Internet é a utilização da abordagem de serviços diferenciados, que disponibiliza novos recursos ao tráfego. Embora essa seja uma boa alternativa, não resolve o problema por completo, pois cada vez mais surgem aplicações que exigem mais recursos tanto da rede como dos servidores $W e b$. Sendo assim, para resolver o problema por completo, é necessário que tal abordagem não fique restrita à rede, mas também se aplique aos servidores Web.

Entre os trabalhos que propõem o uso de serviços diferenciados em nível de aplicação pode ser citado o trabalho de Teixeira (2004), onde é proposto um modelo de um servidor Web com diferenciação de serviços (SWDS), o qual serve de base para este trabalho.

\subsection{Motivação}

A Web está se tornando cada vez mais uma mídia orientada a negócios (Lee et al., 2004) e a interface preferida para os mais recentes sistemas de informação (Andreolini et al., 2004). Conseqüentemente, torna-se mais importante projetar e implementar sistemas capazes de diferenciar o desempenho designado a usuários e serviços. Tais sistemas devem ser capazes de lidar com diferentes exigências de diversos tipos de aplicações e também com as diferentes expectativas dos usuários (Zhou et al., 2004), permitindo tratamento diferenciado de acordo com suas prioridades. Por exemplo, transações econômicas são geralmente mais importantes que uma simples visualização de um site de entretenimento e, usuários pagantes de um determinado serviço podem esperar melhor qualidade do mesmo em relação ao publico não pagante.

No entanto, o modelo de melhor esforço usado pela Internet, tanto em nível de rede através do protocolo IP, quanto em nível de aplicação, onde as requisições são atendidas pelos servidores na maioria dos casos de acordo com a política FCFS (First Come First Served) (Yeager \& McGrath, 1996), não é adequado para prover a qualidade de serviço exigida por usuários e aplicações na atualidade.

Uma quantidade significante de pesquisas sobre Qualidade de serviço (QoS) tem sido focada sobre a infra-estrutura da rede, tais como protocolos, roteadores, entre outros. Também já foram desenvolvidas sob a coordenação da IETF (Internet Engineering Task Force), várias especificações para a provisão de qualidade de serviço sobre redes IP, dentre elas destacam-se as arquiteturas de Serviços Integrados (IntServ) (Braden et al., 1994) e de Serviços Diferenciados (DiffServ) (Blake et al., 1998). 
Entretanto, QoS em nível de rede isoladamente não é suficiente pra garantir qualidade de serviço fim a fim, capaz de atender as necessidades de usuários e aplicações. Para evitar a situação onde um tráfego de alta prioridade chega ao servidor e é descartado, ou fica esperando indefinidamente na fila, pois o servidor não está preparado para tratar esse tráfego de maneira diferenciada, vários trabalhos foram propostos com o objetivo de oferecer QoS também em nível de aplicação, entre os quais, um modelo de servidor Web com diferenciação de serviços (SWDS), proposto por Teixeira (2004).

O SWDS é composto por três módulos: Um módulo Classificador responsável por classificar as requisições; um Controle de Admissão responsável por aceitar ou rejeitar uma requisição que chega ao sistema, de acordo com a carga deste; e um cluster de servidores responsáveis por tratar as requisições. O modelo foi avaliado através de simulação. O principal objetivo deste trabalho é implementar características desse modelo e verificar o desempenho alcançado em ambiente real.

\subsection{Objetivos}

O objetivo central deste trabalho é dar continuidade ao trabalho iniciado por Teixeira (2004), através da implementação de um protótipo que aglutine não apenas as considerações iniciais do modelo apresentado em (Teixeira, 2004) mas, também, inclua outros elementos apontados por Teixeira como trabalhos futuros. Alguns desses elementos já foram implementados ou estão em fase de estudos e implementação em outros trabalhos (Traldi et al., 2006), (Estrella et al., 2006) e outros estão ainda em aberto. No caso desses trabalhos, a técnica utilizada é sempre modelagem e simulação. Dentre os objetivos específicos deste trabalho destacam-se:

- Estudar o modelo de servidor Web com diferenciação de serviços (SWDS) proposto em (Teixeira, 2004);

- Implementar um protótipo do SWDS em um sistema distribuído, com base em elementos de processamento de propósito geral disponíveis;

- Analisar o protótipo em ambiente real (com clientes simulados);

- Comparar os resultados obtidos com e sem a utilização dos algoritmos de diferenciação de serviços implementados no SWDS.

\subsection{Estrutura da Monografia}

O Capítulo 2 desta monografia apresenta a infra-estrutura da Internet, seus protocolos e principais serviços, destacando-se a Web, com especial atenção ao protocolo HTTP e suas 
aplicações. São apresentadas também as principais formas de organização de servidores Web.

No Capítulo 3, aborda-se o tópico de diferenciação de serviços na Internet e discutem-se as limitações do seu modelo atual de atendimento a clientes. São apresentados conceitos da área de qualidade de serviço e detalhadas as arquiteturas de serviços integrados e diferenciados. É introduzida a necessidade de se fornecer qualidade de serviço na Internet, em nível de aplicação, particularmente nos servidores Web, sendo feita uma revisão dos principais trabalhos na área.

O Capítulo 4 apresenta o modelo de servidor Web com provisão de serviços diferenciados proposto em (Teixeira, 2004), onde são descritos os principais componentes do modelo, e é fornecida uma visão geral dos algoritmos de diferenciação de serviços e de controle de admissão implementados. Finalmente, são apontados alguns cenários de utilização de serviços diferenciados na $W e b$.

No capítulo 5, descreve-se a arquitetura do protótipo a ser implementado, especificando-se como foi feito o mapeamento dos componentes do modelo de servidor Web com diferenciação de serviços (SWDS) para o protótipo, assim como as ferramentas utilizadas para o desenvolvimento do projeto.

O Capítulo 6 apresenta os resultados obtidos através dos experimentos realizados com o protótipo através da submissão de carga sintética e, uma análise desses resultados, comparando-os com os resultados obtidos sem a utilização de mecanismos de diferenciação de serviços.

Finalmente, o Capítulo 7 apresenta as conclusões e principais contribuições desta dissertação, bem como, algumas sugestões para trabalhos futuros. 


\section{Capítulo \\ 2 \\ Estrutura da Web}

\subsection{Considerações Iniciais}

Embora o uso da Internet tenha se disseminado apenas recentemente, principalmente em termos comerciais, as pesquisas visando à criação de tecnologia que permitisse a interligação de computadores em redes começaram bem antes disso, no início dos anos 70, quando não era imaginado que a Internet tomasse as proporções que tem hoje.

A Internet tornou-se muito maior do que seus criadores poderiam prever e cada vez mais vem sendo usada para fins comerciais e não apenas para pesquisas acadêmicas, transferência de arquivos, troca de mensagens e outros serviços para os quais ela foi originalmente projetada. Entretanto, esse crescimento não se deu impunemente, pois, atualmente, nota-se que a rede está sobrecarregada, apresentando sérios problemas de desempenho.

Neste capítulo, será apresentada uma visão geral da Internet, destacando seus serviços mais comuns e os protocolos da arquitetura TCP/IP que constituem sua infra-estrutura. Será abordada também a World Wide Web, sua forma de organização e o protocolo HTTP. Aborda-se, ainda, algumas arquiteturas mais comumente utilizadas na organização de servidores Web.

\subsection{Conjunto de Protocolos TCP/IP}

Criado pelo Departamento de Defesa dos Estados Unidos (DoD), com o objetivo de conectar varias redes ao mesmo tempo e, evitar a perda de comunicação entre dois computadores caso alguns hosts, roteadores ou gateways fossem destruídos por possíveis ataques, o modelo de referência TCP/IP surgiu para ser um conjunto de protocolos roteáveis e, 
capaz de se adaptar a aplicações com necessidades divergentes. Hoje esse conjunto de protocolos é amplamente utilizado por todos os tipos de redes, mesmo as que usam sistemas operacionais proprietários, como o Windows NT, que antes só utilizava seu protocolo proprietário (NetBEUI) e hoje oferece suporte ao TCP/IP. Além da popularização da Internet, outro motivo que tornou o TCP/IP popular, foi o fato dele possuir arquitetura aberta possibilitando alterações conforme as necessidades e interesses de cada fabricante de sistemas operacionais, tornando-se um protocolo universal. A seguir será apresentada uma visão geral de suas camadas, e dos principais protocolos utilizados por estas camadas.

\subsubsection{Arquitetura TCP/IP}

O modelo de referência TCP/IP é organizado em quatro camadas, conforme mostra a figura 2.1. Cada camada tem o objetivo de oferecer serviços para a camada imediatamente acima. A camada de aplicação passa para a camada de transporte mensagens ou fluxos de bytes, que são encapsulados junto com o cabeçalho do protocolo utilizado pela camada de transportes (TCP ou UDP) em segmentos. Estes segmentos são passados para a camada de inter-rede, onde é adicionado o cabeçalho IP, passando a ser denominados datagramas. Os datagramas são passados para a camada de interface de rede, onde tornam-se quadros, que são transmitidos pela rede.

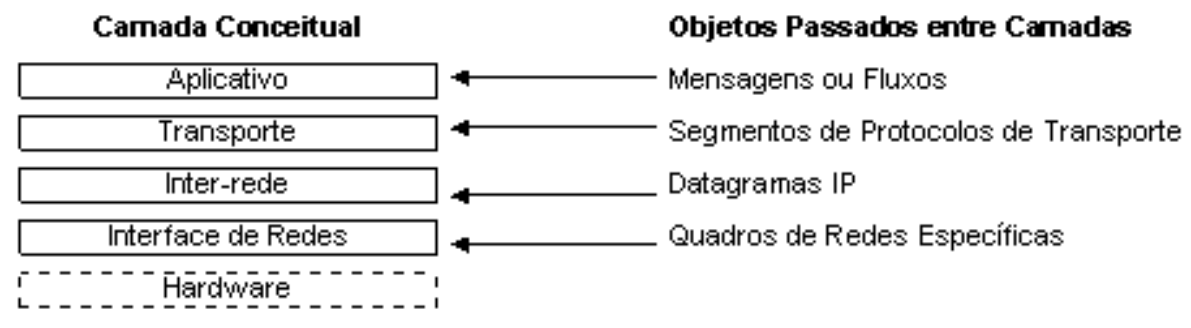

Figura 2.1: Arquitetura do TCP/IP.

\subsubsection{Descrição das Camadas e seus Protocolos}

\section{Camada de Aplicação}

É a camada de nível mais alto do modelo TCP/IP e seu objetivo é fazer a comunicação entre os aplicativos e o protocolo da camada de transporte. Para fazer essa comunicação é utilizado o conceito de portas, onde cada aplicativo executa em uma porta específica. Os principais protocolos que operam nesta camada são:

- HTTP (HiperText Transfer Protocol): Este protocolo é usado para a comunicação entre clientes e servidores na WWW (World Wide Web). Sua porta de comunicação padrão é a 80. Mais detalhes em (Fielding et al., 1999). 
- SMTP (Simple Mail Transfer Protocol): Este é o protocolo de correio eletrônico, usado quando se envia ou recebe e-mails. Sua porta de comunicação é a 25. Mais detalhes em (Klensin, 2001).

- FTP (File Transfer Protocol): Protocolo de transferência de arquivos, usado para enviar e receber arquivos pela rede. Sua porta de comunicação é a 20 para transmissão de dados e 21 para transmissão informações de controle. Mais detalhes em (Postel \& Reynolds, 1985).

- TELNET: Protocolo usado para efetuar o login remoto em máquinas na rede. Sua porta padrão de comunicação é a 23. Mais detalhes em (Postel \& Reynolds, 1983).

- DNS (Domain Name Server): Usado para mapear nome de hosts para seus respectivos endereços de redes. Sua porta padrão é a 53. Mais detalhes em (Mockapetris, 1987a) e (Mockapetris, 1987b).

\section{Camada de Transporte}

É responsável por receber os dados da camada de aplicação e somar a esses dados um cabeçalho de acordo com o protocolo utilizado, transformando-os em segmentos que são enviados à camada de inter-rede. Para tratar de várias aplicações enviando dados ao mesmo tempo, essa camada usa o conceito de multiplexação, onde recebe dados de vários canais (aplicações), mas entrega-os em um único canal para a camada de inter-rede. Os protocolos que atuam nesta camada são o TCP e o UDP.

- TCP (Transmission Control Protocol): Protocolo orientado à conexão, confiável, que garante a entrega dos dados ao destino sem erros. Além disso, faz o controle do fluxo das informações, evitando que um transmissor rápido sobrecarregue um receptor lento. Mais detalhes em (Postel, 1981c).

- UDP (User Datagram Protocol): Protocolo não orientado à conexão, não confiável, usado em aplicações onde à velocidade de transmissão é mais importante que a entrega precisa. Como exemplo pode-se citar a Transmissão de voz e vídeo. Mais detalhes em (Postel, 1980).

\section{Camada de Inter-rede}

Esta camada recebe um segmento da camada de transporte e o encapsula em um datagrama, preenche o cabeçalho do datagrama e o envia a camada de interface de rede. É também responsável pelo roteamento dos pacotes. Os principais protocolos que atuam nesta camada são: 
- IP (Internet Protocol): Esse protocolo define a unidade básica de transferência de dados utilizada através de uma interligação em redes TCP/IP. Desempenha a função de roteamento, definindo o caminho por onde os dados serão enviados e inclui um conjunto de informações que definem entre outras coisas como os hosts e os roteadores devem processar os pacotes. Mais detalhes em (Postel, 1981b).

- ICMP (Internet Control Message Protocol): Esse protocolo permite que os roteadores enviem mensagens de erro ou de controle para os outros roteadores ou para os hosts. Mais detalhes em (Postel, 1981a).

- ARP (Address Resolution Protocol): Uma máquina usa ARP para descobrir o endereço de hardware de outra máquina, difundindo uma solicitação ARP. A solicitação contém o endereço IP da máquina cujo endereço de hardware é requisitado. Todas as máquinas de um segmento recebem uma solicitação ARP. Se a solicitação combina com o endereço IP de alguma máquina, esta responde enviando o endereço de hardware solicitado. Mais detalhes em (Plummer, 1982).

- RARP (Reverse Address Resolution Protocol): Este protocolo destina-se à solução do problema inverso ao resolvido pelo ARP. O RARP identifica um host através de seu endereço físico, ou seja, permite, a partir de um endereço físico, obter um endereço IP correspondente. Mais detalhes em (Finlayson et al., 1984).

\section{Camada de Interface de Rede}

É a camada responsável por enviar o datagrama recebido pela camada de Inter-rede em forma de um quadro através da rede. O modelo TCP/IP não especifica nenhum protocolo para esta camada, apenas define que o host deve se conectar com a rede usando um protocolo, para que seja possível enviar pacotes IP (Tanenbaum, 2002). Como esse protocolo não é definido, ele varia de host para host e de rede para rede e é raramente descrito na literatura sobre o modelo TCP/IP.

\section{$2.3 \quad$ A World Wide Web}

A World Wide Web, $W W W$ ou simplesmente $W e b$, desde o seu surgimento, no início dos anos 90, tornou-se rapidamente o serviço mais utilizado da Internet, a ponto de muitos usuários mais leigos a confundirem com a própria Internet.

Do ponto de vista de sua arquitetura, a Web pode ser descrita como uma rede de computadores na Internet que fornece informação em forma de hipertexto. Para ver esta informação, pode-se usar um software chamado navegador (browser) para requisitar "documentos" ou "páginas" de servidores Web ("sites") e mostrá-los na tela do usuário. 
Em outras palavras, a Web emprega o paradigma cliente-servidor sobre a infra-estrutura da Internet.

A funcionalidade da Web é baseada em três padrões: a URL (Uniform Resource Locator), que especifica como cada página de informação recebe um "endereço" único onde pode ser encontrada; o protocolo HTTP, que especifica como o navegador e servidor enviam informações um ao outro; e a linguagem HTML, um método de codificar a informação de modo que possa ser exibida em uma grande quantidade de dispositivos. A organização responsável por desenvolver e manter os padrões utilizados pela Web é o World Wide Web Consortium (W3C) (Berners-Lee, 1994).

\subsubsection{Visão Geral do Protocolo HTTP}

O HyperText Transfer Protocol (HTTP) é um protocolo em nível de aplicação responsável pela transferência de dados e pela comunicação entre cliente e servidor na World Wide Web (WWW). A primeira versão do HTTP, denominado HTTP/0.9, era um protocolo simples para a transferência de dados no formato de texto ASCII, através de um único método de requisição, chamado GET. A versão HTTP/1.0 foi desenvolvida entre 1992 e 1996 para suprir a necessidade de transferir outros objetos que não fossem apenas texto (hipertexto, imagens, etc). Com essa versão, o protocolo passou a transferir mensagens do tipo MIME (Multipurpose Internet Mail Extension) e foram implementados novos métodos de requisição, chamados POST e HEAD. No HTTP/1.1, versão atual do protocolo descrito em (Fielding et al., 1999) foi desenvolvido um conjunto de implementações adicionais ao HTTP/1.0, como por exemplo o uso de conexões persistentes, o uso de servidores proxy que permite uma melhor organização da cache, novos métodos de requisições, entre outros.

Para que o protocolo HTTP possa transferir seus dados pela Web, é necessário que os protocolos TCP (Transmission Control Protocol) e IP (Internet Protocol) tornem possível a conectividade entre clientes e servidores através de sockets TCP/IP. Um programa requisitante (cliente) estabelece uma conexão com um outro programa receptor (servidor) e envia uma requisição para este. O servidor responde e, em seguida, encerra-se a conexão estabelecida. Mais detalhes sobre conexões HTTP podem ser encontrados na seção 2.3.3.

\subsubsection{Mensagens HTTP}

O protocolo HTTP faz a comunicação entre o cliente e o servidor através de mensagens. O cliente envia uma mensagem de requisição de um recurso para o servidor, que envia uma mensagem de resposta ao cliente com a solicitação.

\section{Mensagem de Requisição HTTP}


Uma mensagem de requisição é composta pelos seguintes campos: uma linha inicial (Request-Line); linhas de cabeçalhos (Request-header); uma linha em branco obrigatória; e um corpo de mensagem opcional. A linha inicial de uma requisição é composta por três partes separadas por espaços: o método (Method); a identificação da URI (Request-URI); e a versão do HTTP (HTTP-Version) utilizado. A figura 2.2 mostra um exemplo de requisição HTTP.

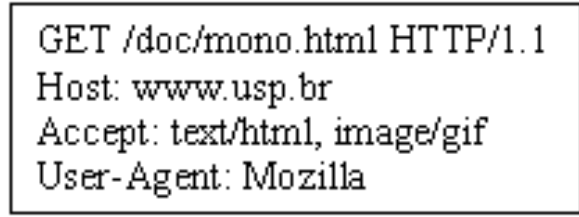

Figura 2.2: Exemplo de requisição HTTP.

O protocolo HTTP/1.1 possui um conjunto de métodos, definidos em (Fielding et al., 1999), que são utilizados na requisição de recursos, como os métodos GET, HEAD, POST, OPTIONS, PUT, DELETE, TRACE, CONNECT. O método determina o que o servidor deve fazer com a URL fornecida no momento da requisição de um recurso. A Tabela 2.1 apresenta uma breve descrição destes métodos.

\begin{tabular}{|c|c|}
\hline Método & Finalidade \\
\hline GET & $\begin{array}{l}\text { Solicita que seja retornado o recurso identifi- } \\
\text { cado pela URL }\end{array}$ \\
\hline HEAD & $\begin{array}{l}\text { Utilizado para obter informações de um re- } \\
\text { curso, sem retorná-lo ao cliente }\end{array}$ \\
\hline POST & $\begin{array}{l}\text { Envia informações adicionais do cliente para o } \\
\text { servidor no corpo da mensagem, por exemplo, } \\
\text { dados digitados em formulários HTML }\end{array}$ \\
\hline OPTIONS & $\begin{array}{l}\text { Usado para obter opções de comunicação dis- } \\
\text { ponível, sem necessariamente iniciar a recupe- } \\
\text { ração do recurso }\end{array}$ \\
\hline PUT & $\begin{array}{l}\text { Permite criar ou modificar um recurso no ser- } \\
\text { vidor Web }\end{array}$ \\
\hline DELETE & $\begin{array}{l}\text { Solicita que o recurso identificado pela URL } \\
\text { seja apagado do servidor Web }\end{array}$ \\
\hline TRACE & Envia mensagem de teste ao servidor \\
\hline CONNECT & $\begin{array}{l}\text { Reservado para comunicação com servidores } \\
\text { proxy }\end{array}$ \\
\hline
\end{tabular}

Tabela 2.1: Descrição dos métodos do protocolo HTTP 1.1.

\section{Mensagem de Resposta HTTP}

Uma mensagem de resposta do servidor é composta pelos seguintes campos: uma linha inicial (Status-Line); linhas de cabeçalhos (Response-header); uma linha em branco 
obrigatória; e um corpo de mensagem opcional. A linha inicial de uma resposta, chamada de linha de status, também possui três partes separadas por espaços: a versão do protocolo HTTP (HTTP-Version); um código de status (Status-Code) da resposta, que fornece o resultado da requisição; e uma frase (Reason-Phrase) de justificativa que descreve o código do status. A Figura 2.3 ilustra uma resposta HTTP.

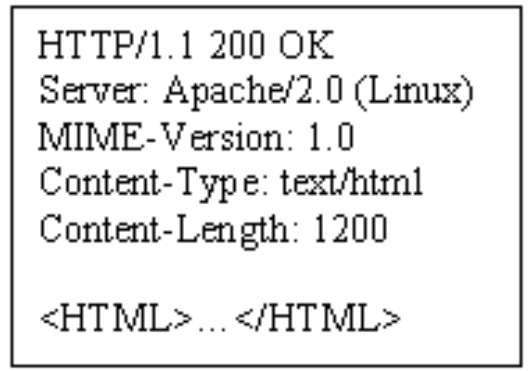

Figura 2.3: Exemplo de resposta HTTP.

O Status-Line de uma resposta HTTP indica ao cliente se sua requisição foi bem sucedida ou não. Essa situação é fornecida através de um código de retorno (StatusCode) e uma frase explicativa (Reason-Phrase). O código de status é formado por três dígitos e, o primeiro dígito representa a classe na qual este código pertence, classificada em cinco tipos, como mostrado na tabela 2.2.

\begin{tabular}{|c||l|}
\hline Classe & Descrição \\
\hline \hline $1 \times x$ & Informational (Informação) \\
\hline $2 x x$ & Succes (Sucesso) \\
\hline $3 x x$ & Redirection (Redirecionamento) \\
\hline $4 x x$ & Client Error (Erro no Cliente) \\
\hline $5 x x$ & Server Error (Erro no servidor) \\
\hline
\end{tabular}

Tabela 2.2: Descrição das classes de respostas do protocolo HTTP.

O protocolo HTTP define somente alguns códigos em cada classe, descritos em (Fielding et al., 1999), mas cada servidor pode criar seus próprios.

\subsubsection{Conexões HTTP}

O HTTP/1.0 é um protocolo stateless (Berners-Lee et al., 1996), significando que as conexões entre o cliente e o servidor são encerradas após o envio de cada requisição e resposta. Cada vez que uma conexão é estabelecida ou encerrada, é consumida uma grande quantidade de tempo da CPU, de capacidade de banda e de memória. Na maioria das vezes, para se obter o resultado esperado, é necessário realizar mais de uma solicitação de recursos, através de várias conexões. Por exemplo, no caso de uma página $W e b$, consistindo de diversos arquivos (html, gif, css, etc) são necessárias várias requisições para compor a página. O ideal seria que apenas uma conexão fosse utilizada para os pedidos e as 
respostas HTTP, diminuindo, assim, o overhead ocasionado pelas conexões. Este tipo de conexão é chamado de conexão persistente (Persistent Connection).

A conexão persistente, implementada como conexão padrão no protocolo $\operatorname{HTTP} / 1.1$, possibilitou uma conexão enviar várias requisições em seqüência, sem a necessidade de esperar por cada resposta, que serão recebidas na mesma ordem em que as solicitações foram enviadas. Este processo é chamado de pipelining (Fielding et al., 1999). Se uma requisição incluir o cabeçalho "Connection: close", a conexão será encerrada após o envio da resposta correspondente.

Utiliza-se esse cabeçalho quando não há suporte a conexões persistentes, quando for a última requisição a ser enviada na conexão, ou ainda, sempre que se quiser encerrar a conexão, antes mesmo de todas as requisições serem completadas. Além disso, o servidor pode fechar uma conexão se estiver ociosa por um determinado período de tempo. A Figura 2.4 ilustra como é realizada uma conexão TCP usando o protocolo HTTP 1.0 e o protocolo HTTP 1.1.

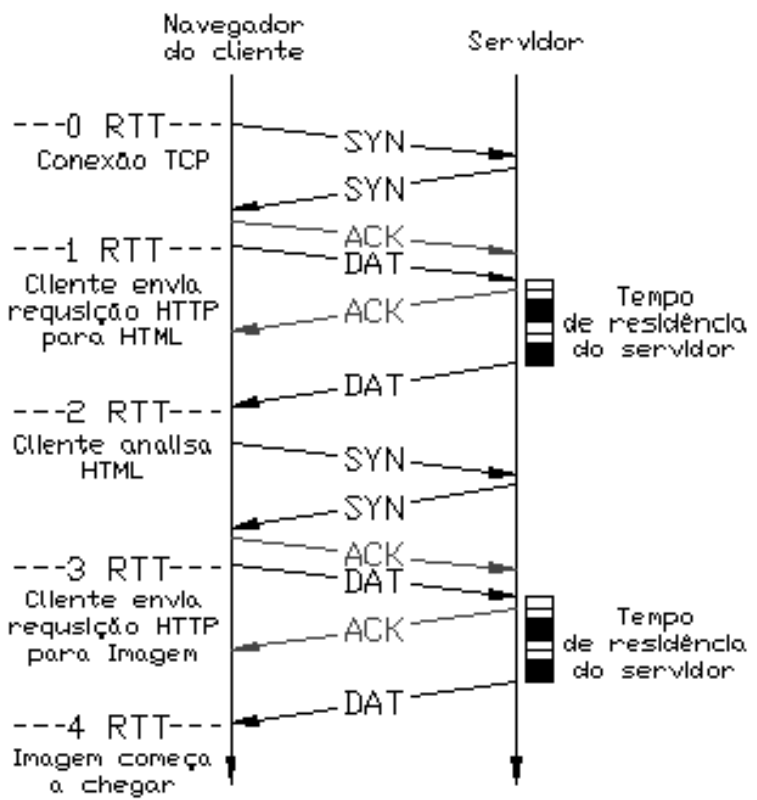

\a)

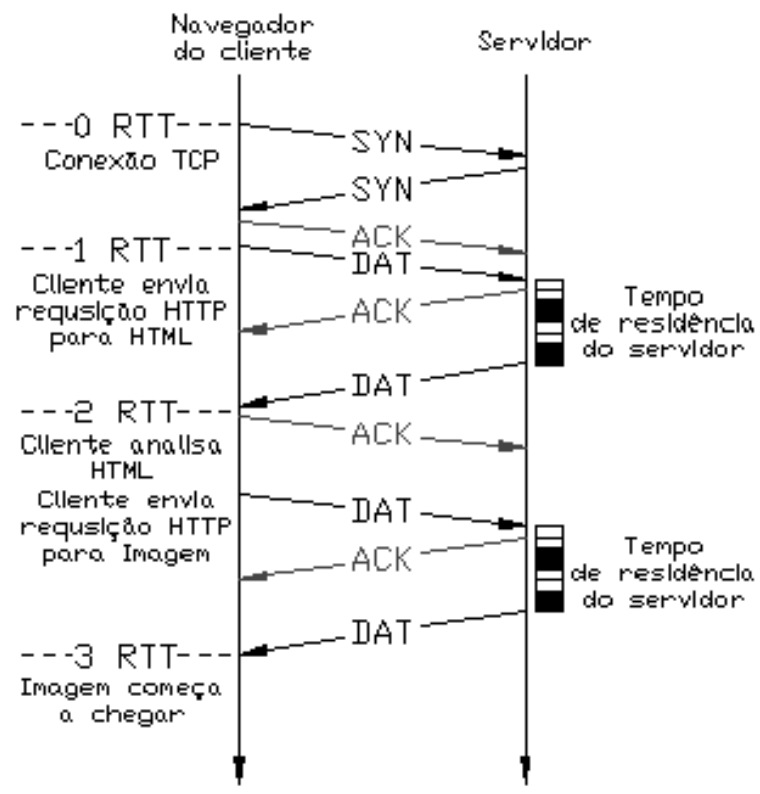

(b)

Figura 2.4: Conexões TCP usando o protocolo HTTP 1.0 (a) e 1.1 (b) (Menascé \& Almeida, 2003).

\subsection{Formas de Organização de servidores $W e b$}

Um servidor Web pode ser definido como um processo que se encontra em um laço infinito, permanentemente aguardando por requisições dos clientes (Orfali et al., 1999). Durante o atendimento das requisições, existem alguns atrasos que são inevitáveis, como a espera pela transmissão dos dados na rede, o acesso ao disco do servidor, o escalonamento dos processos pelo sistema operacional, entre outros. O servidor, portanto, deve 
ser projetado de modo a atender o maior número de requisições possível. Segundo Menascé (2003) a arquitetura de um servidor Web pode ser definida segundo o seu modelo de processamento e o comportamento do tamanho de seu pool. O modelo de processamento descreve se processos ou threads serão usados para atender as requisições e, o comportamento do tamanho do pool define como este varia de acordo com a carga presente no servidor. Segundo esses critérios, são apresentadas a seguir algumas formas de organização de servidores $W e b$, visando a atender um maior número de requisições possíveis, melhorando com isso o nível de concorrência.

\section{Servidor Iterativo}

Este seria o tipo de servidor mais simples, que apenas fica aguardando as requisições dos clientes e as trata uma por vez, na ordem em que chegaram, sem nenhum tipo de concorrência. Essa organização é muito ineficiente na prática, servindo apenas como um exemplo para fins didáticos.

\section{Processo por Requisição}

É uma das formas mais comuns para a construção de servidores concorrentes e, funciona da seguinte maneira: Um processo principal ("pai") do tipo dispatcher ${ }^{1}$ fica aguardando requisições em uma porta pré-definida. Ao chegar uma nova requisição, ele cria um novo processo ("filho") do tipo worker ${ }^{2}$ e passa a este a responsabilidade de atender a solicitação, retornando em seguida ao seu laço de espera. Assim que o processo worker termina de atender a requisição, ele deixa de existir.

O problema dessa abordagem, é que a criação de um novo processo é uma operação cara em termos computacionais. Mas, devido à simplicidade que essa solução apresenta, principalmente em ambientes UNIX, onde a criação de um novo processo é feita utilizando uma simples chamada ao comando fork (Stevens et al., 2003), ela é uma das mais utilizadas na construção de servidores dos mais diversos tipos.

\section{Poll de Processos}

A idéia de se usar um pool de processos é para tentar aproveitar a simplicidade da abordagem anterior, ao mesmo tempo em que se procura eliminar suas desvantagens. Para tanto, é criado no servidor um processo denominado dispatcher e um conjunto de processos denominados workers que constituem o process pool (Hu et al., 1997). O processo dispatcher fica permanentemente aguardando solicitações dos clientes e, ao receber uma requisição, escolhe algum dos processos workers ociosos para tratá-la, retornando ao seu laço de espera. Os processos workers, após atenderem a uma requisição, não encerram sua execução, continuam esperando até que sejam convocados para atuar novamente.

\footnotetext{
${ }^{1}$ Agente do servidor responsável pelo mapeamento de uma requisição para um determinado processo

${ }^{2}$ Agente do servidor responsável por atender uma determinada requisição
} 
O principal objetivo de utilizar um pool de processos é eliminar a sobrecarga da criação dos processos a cada nova requisição, porém surgem novos problemas, como por exemplo, o dispatcher se tornar o gargalo do servidor, além de um ponto único de falha do mesmo, pois todas as requisições têm que passar inicialmente por ele. E ainda, caso a carga no servidor seja muito alta e o número de processos no pool não tenha sido definido de maneira adequada, o servidor pode ser forçado a criar novos processos, recaindo-se no caso da abordagem anterior.

\section{Thread por Requisição}

Se ao invés de se criar processos para cada nova requisição que chega, fosse criada uma nova thread (linha de execução), o servidor diminuiria, consideravelmente, a sobrecarga causada pela criação de novos processos, pois uma thread consome muito menos recursos da máquina que um processo, além de diferentes threads poderem compartilhar o mesmo espaço de endereçamento, incluindo código e dados globais. E, ainda, como as threads se encontram dentro de um mesmo processo, a mudança de contexto entre elas também se dá de forma mais rápida (Menascé, 2003).

Outra vantagem do uso de threads em servidores $W e b$ é o fato que estes freqüentemente precisam esperar por E/S, pois é preciso aguardar pela leitura dos dados no disco e também pela recepção e envio dos pacotes pela rede. Enquanto uma thread espera por E/S, o controle é passado para outra thread, responsável por uma requisição diferente, o que acaba resultando numa utilização bem mais eficiente dos recursos da máquina.

De maneira geral, o uso de threads não só torna o servidor Web mais rápido, mas também permite que ele execute mais requisições concorrentemente, o que torna esta solução bastante atrativa para a construção dos servidores atuais. No entanto, esta abordagem é menos estável que as anteriores baseadas em processos (Menascé, 2003). Como as threads compartilham um mesmo endereço de memória, caso ocorra algum problema com uma determinanada thread, todas as outras podem ser afetadas, deixando o servidor inoperante.

\section{Pool de Threads}

Finalmente, outra alternativa possível é a utilização de um pool de threads, que são criadas quando o servidor Web é iniciado, com o objetivo de eliminar a sobrecarga de criação de uma nova thread para cada requisição que chega ao servidor, a exemplo do caso da utilização do pool de processos.

\subsection{Considerações Finais}

Neste capítulo, abordou-se a infra-estrutura da Internet e, conseqüentemente, da $W e b$, com destaque para a pilha de protocolos TCP/IP, que é a base de toda a estrutura 
de comunicação na rede e, para o protocolo HTTP, responsável pela comunicação entre clientes e servidores na Web. Também foram apresentadas algumas formas de organização de servidores $W e b$.

No próximo capítulo será discutido como a introdução de serviços diferenciados pode ajudar a resolver os problemas e limitações do modelo atual de serviços da Internet e como estender os conceitos de QoS para o nível de aplicação, especialmente na construção de servidores $W e b$. 


\section{Capítulo \\ 3 \\ Serviços Diferenciados}

\subsection{Considerações Iniciais}

O modelo atual de serviços da Internet começa a dar sinais de que pode estar atingindo o seu limite, pois quando se iniciaram as pesquisas sobre o mesmo, há mais de três décadas, não se imaginava que a Internet tivesse o grande volume de tráfego que tem hoje e nem a grande diversidade de aplicações que a usam como base atualmente. Por esse motivo é necessário repensar o modelo atual de serviços da Internet e, conseqüentemente, da Web, de modo a satisfazer as necessidades e expectativas dos usuários e dos diversos tipos de aplicações que funcionam sobre sua estrutura.

Como foi visto no capítulo anterior, a Internet é uma rede baseada na pilha de protocolos TCP/IP. Se por um lado o uso de protocolos abertos, flexíveis, que funcionam sobre uma gama de tecnologias diferentes, como o TCP/IP, foi um dos fatores que levaram a Internet a ter a popularidade que tem hoje, por outro, o fato do protocolo IP ser um protocolo não orientado à conexão, baseado no modelo de melhor esforço (Best Effort) (Networks, 2003), onde pacotes podem ser entregues através de caminhos diferentes, chegando fora de ordem, ou até mesmo serem perdidos, não proporciona a qualidade de serviço adequada para as novas aplicações que fazem uso da Internet atualmente, como aplicações multimídia e comércio eletrônico, por exemplo. Este capítulo aborda os problemas atuais da Internet e apresenta alguns conceitos sobre qualidade de serviço usados em nível de redes IP, procurando aproveitar esses conceitos para o uso também em nível de aplicação, especialmente em servidores Web. 


\subsection{Conceitos Básicos de QoS}

Qualidade de Serviço (QoS) em redes de computadores se refere à capacidade da rede em fornecer um serviço melhor para determinados tráfegos, de acordo com suas respectivas necessidades. O objetivo principal da QoS é fornecer prioridades, incluindo banda dedicada, controle de jitter (variação do atraso), latência e melhora na taxa de perda de dados (Zhao et al., 2000). No entanto, também é importante garantir que o fornecimento de prioridades a determinados fluxos não faça com que outros fluxos venham a falhar.

A QoS pode ser descrita de forma absoluta ou relativa. Na QoS absoluta são dadas garantias a cada fluxo individualmente, reservando recursos ao longo do caminho para que esse fluxo possa ter suas exigências de QoS atendidas. Caso a rede não seja capaz de garantir um serviço com essa característica, então a aplicação não terá acesso ao meio de comunicação. Esse tipo de QoS seria o ideal, mas a sua complexidade a torna às vezes inviável, especialmente em uma rede de grandes proporções como a Internet.

Na QoS relativa, a idéia é agrupar os fluxos em classes de serviço e dar a essas classes tratamento diferenciado de acordo com sua prioridade. Nesse caso, a rede garante que uma aplicação em uma classe de maior prioridade sempre terá um tratamento melhor que o de qualquer classe inferior. Entretanto não é dada nenhuma garantia as aplicações em termos de métricas, como no caso anterior, pois a QoS resultante dependerá da carga atual na rede, em cada classe (Vasiliou, 2000).

\subsubsection{Classificação de aplicações quanto ao tipo de tráfego}

Outro componente importante para a determinação do modelo de QoS a ser fornecido aos usuários diz respeito ao tipo de tráfego que as aplicações geram e qual o comportamento esperado da rede para que elas funcionem corretamente. Segundo Kamienski \& Sadok (2000), com relação ao tipo de tráfego as aplicações podem ser classificadas em:

- Aplicações não elásticas: São aplicações que possuem rígidas restrições temporais para que possam funcionar adequadamente. Essa classificação pode ainda ser dividida em duas categorias:

- Aplicações tolerantes: São aplicações mais flexíveis, onde alguns atrasos ou variações no atraso (jitter) são permitidos sem comprometer a qualidade.

- Aplicações intolerantes: Neste tipo de aplicação, atrasos são intoleráveis, sob pena de prejudicar o bom funcionamento da aplicação.

- Aplicações elásticas: Aplicações deste tipo não possuem restrições temporais e, admitem bem o serviço de melhor esforço. Para estas aplicações, a recepção correta dos dados é mais importante do que a sua apresentação em uma taxa constante. 


\subsection{Arquiteturas para QoS}

O objetivo da introdução de QoS na Internet atual é fornecer algum nível de previsibilidade e controle, além do serviço de melhor esforço das redes IP (Stardust, 1999a), pois, somente assim será possível atender às crescentes demandas das aplicações atuais e futuras. Qualidade de Serviço na Internet tem sido um assunto bastante pesquisado nos últimos anos, havendo propostas com várias abordagens procurando alcançar este objetivo (Wen \& Lu, 2002). Entre as abordagens, merecem destaque às arquiteturas de Serviços Integrados (IntServ) e Serviços Diferenciados (DiffServ) (Stardust, 1999a), (Zhao et al., 1999).

\subsubsection{Serviços Integrados}

A abordagem de Serviços Integrados foi a primeira das soluções propostas para dar suporte a QoS na Internet. Desenvolvida pela IETF e definida em (Braden et al., 1997), a arquitetura de serviços integrados (IntServ) utiliza a abordagem de reserva de recursos, que consiste em alocar previamente os recursos de rede necessários para as aplicações, garantindo as mesmas que seus pacotes chegaram ao destino em um tempo aceitável (áudio e vídeo, por exemplo).

Para reservar caminhos e recursos ao longo da rede, as aplicações fazem uso do protocolo RSVP (Resource Reservation Protocol), um protocolo de controle e sinalização que atua na camada de rede. O protocolo RSVP é considerado a solução mais elaborada e complexa para suporte a QoS e representa uma grande ruptura com o modelo tradicional de melhor esforço das redes IP (Stardust, 1999a), nas quais, não existe a preocupação de reservar recursos e nem mesmo de verificar se existe um caminho disponível antes de se enviar um pacote pela rede.

A abordagem de serviços integrados trabalha sobre fluxos individuais, reservando recursos aos mesmos nos roteadores da rede através do protocolo RSVP, com o objetivo de atender às demandas de QoS dos fluxos (Vasiliou, 2000). Além do modelo de melhor esforço encontrado nas redes IP, outras duas classes de serviço são definidas na arquitetura IntServ. São elas: Serviço Garantido e Serviço de Carga Controlada.

\section{Serviço Garantido}

Usado por aplicações intolerantes (aplicações de tempo real, por exemplo), fornecendo um limite máximo para o atraso fim a fim. Sua especificação pode ser encontrada em (Shenker et al., 1997).

\section{Serviço de Carga Controlada}


Recomendado para aplicações que toleram variações no atraso fim a fim, pois não fornece garantias de atraso máximo. Oferece um serviço equivalente ao modelo de melhor esforço, o qual é satisfatório para uma rede com pouco tráfego. Em situações de sobrecarga, a largura de banda será compartilhada entre múltiplos fluxos, garantindo um serviço melhor do que o normal. Esta classe de serviço está especificada em (Wroclawski, 1997).

\section{Protocolo RSVP (Resource Reservation Protocol)}

O RSVP é o protocolo usado para gerenciar recursos ao longo do caminho no qual deseja-se utilizar, para fluxos de aplicações que necessitem de QoS. Ele não realiza transporte de dados, é apenas um protocolo de sinalização que atua na camada de rede da pilha de protocolos TCP/IP. O processo de sinalização se dá antes da transmissão dos dados e é renovado sempre que necessário. Para haver a requisição dos recursos, o transmissor envia uma mensagem PATH ao receptor informando este sobre os recursos que necessita.

Após receber uma mensagem PATH, um receptor envia uma mensagem RESV de volta ao transmissor pelo caminho inverso da mensagem PATH, ou seja, ela passará primeiro pelo último roteador solicitando uma reserva de recursos de acordo com os parâmetros especificados em PATH. Em seguida essa mensagem é reencaminhada para todos os roteadores no caminho, até chegar no transmissor. Cada roteador pode aceitar ou rejeitar a reserva de recursos solicitada, de acordo com a quantidade de recursos disponíveis. Se a requisição é rejeitada, o roteador envia uma mensagem de erro para o receptor e a sinalização é encerrada. Caso contrário, são alocados os recursos necessários para o fluxo e, guardadas informações de estado relacionadas a este no roteador. A figura 3.1 ilustra esse processo.

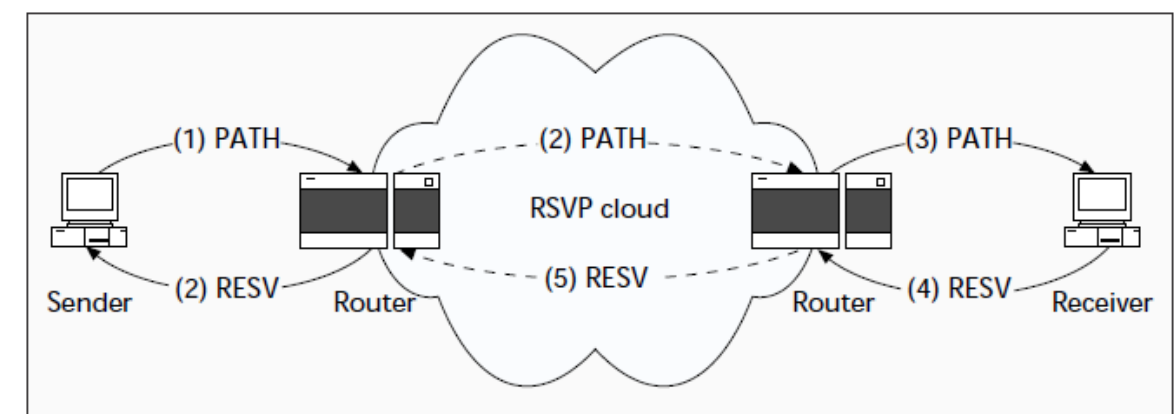

Figura 3.1: Funcionamento do protocolo RSVP (Zhao et al., 2000).

Outras Características do protocolo RSVP são:

- Reservas para aplicações podem ser feitas tanto para transmissão unicast como para multicast, se adaptando dinamicamente às alterações dos membros de um grupo ou de rotas.

- O RSVP apenas permite fazer reservas em um único sentido (unidirecional). Reservas em dois sentidos devem ser feitas separadamente em cada sentido. 
- As reservas para os fluxos são iniciadas pelo receptor dos dados.

- Toda reserva no RSVP tem um tempo máximo de validade, sendo necessário dar um refresh no estado das reservas de tempos em tempos. A responsabilidade por manter o estado das reservas é do receptor.

- O RSVP não é um protocolo de roteamento, não transporta dados, apenas informações de controle e sinalização referentes à reserva de recursos ao longo de um caminho. O RSVP usa as rotas escolhidas por qualquer protocolo de roteamento em uso atualmente ou que venha a ser utilizado no futuro.

- O RSVP oferece vários estilos de reservas, para se adaptar a uma grande variedade de aplicações e usos.

- Como as reservas feitas são independentes do protocolo de roteamento, o tráfego pode atravessar roteadores não habilitados para RSVP, que será encaminhado transparentemente.

- O RSVP suporta tanto o IPv4 quanto o IPv6.

\subsubsection{Serviços Diferenciados}

O IntServ seria a maneira ideal para prover qualidade de serviço na Internet, disponibilizando a cada fluxo a quantidade exata de recursos de que necessitam para cumprirem suas exigências de tempo e atraso. No entanto, a complexidade exigida para sua implementação, sendo necessário que os roteadores da rede guardem informações de estado para cada fluxo de maneira individual, torna inviável sua implantação em uma rede com as proporções da Internet.

Para contornar os problemas acima mencionados, surgiu a arquitetura de Serviços Diferenciados (DiffServ), no âmbito da IETF, conforme proposto em (Blake et al., 1998). A arquitetura DiffServ é baseada na idéia de classes de serviço (Magalhães \& Cardozo, 1999), nas quais os fluxos são agregados, tornando mais fácil o gerenciamento pelos roteadores, pois estes não precisam guardar o estado de cada fluxo individualmente como é o caso da arquitetura IntServ.

Para classificar os pacotes, de modo que estes possam ser tratados diferentemente, de acordo com suas prioridades, é usado o campo Type-of-Service do cabeçalho do protocolo IPv4 (ou o campo Traffic Class do IPv6), que passa a ser chamado de campo DS (Differentiated Services), conforme descrito em (Nichols et al., 1998). Atualmente, somente os seis primeiros bits do campo DS são usados, recebendo a denominação de campo DSCP (Differentiated Services CodePoint), como mostrado na figura 3.2. Seu objetivo é especificar o tratamento dado ao encaminhamento dos pacotes. 


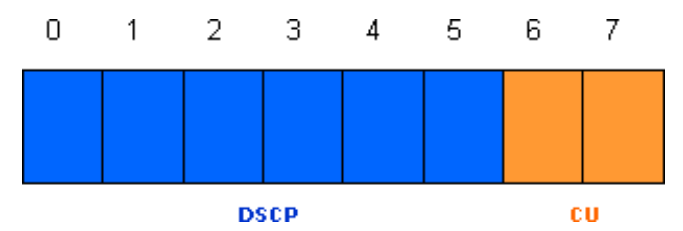

Figura 3.2: Campo DS (Oyama \& de Lucena, 2002).

A abordagem empregada pelo DiffServ baseia-se em um esquema de prioridades relativas, ou seja, ele não garante que o tráfego gerado por uma aplicação alcançará o seu destino dentro de um limite máximo de tempo, ou com uma variação máxima de atraso, mas sim que um tráfego com um certo nível de prioridade, receberá um tratamento melhor que qualquer outro que possua uma prioridade inferior (Xiao \& Ni, 1999).

Como o modelo DiffServ utiliza um campo do próprio datagrama IP, não é necessário utilizar um protocolo próprio (como o modelo IntServ, que utiliza o RSVP). Os pacotes são marcados nos pontos de ingresso na rede (hosts finais e roteadores de borda), mantendo assim, um dos princípios básicos do projeto da Internet, que é colocar a complexidade na fronteira da rede, ao contrário do modelo IntServ, que exige grande complexidade também dos roteadores internos à rede. No caso do modelo DiffServ, tudo que um roteador precisa fazer é examinar o campo DSCP de cada pacote para determinar qual o tratamento a ser dado ao mesmo. Esse tratamento específico de encaminhamento é chamado de PHB (PerHop Behavior). O modelo DiffServ define entre outras alternativas possíveis, duas classes de serviço principais: Encaminhamento Expresso e Encaminhamento Garantido.

\section{Encaminhamento Expresso}

O PHB EF (Expedited Forwarding), ou serviço de encaminhamento expresso define garantias mais rígidas de QoS para aplicações muito sensíveis a variações de características temporais da rede. Pode ser utilizado para implementar um serviço com pouco atraso, pouca variação do atraso (jitter) e largura de banda garantida, similar ao modelo IntServ, mas com a vantagem de ser mais simples, pois não é necessário manter o estado de fluxos individuais. Perda de pacotes, atrasos e variações de atraso ocorrem devido à existência de filas nos roteadores. Em geral, os pacotes pertencentes a esta classe são colocados em uma fila de maior prioridade que a do tráfego de melhor esforço e são os primeiros a serem encaminhados em qualquer situação e também serão os últimos a serem descartados em caso de congestionamento.

Algumas aplicações que podem fazer uso desse serviço são: Telefonia sobre IP, vídeoconferência e outras aplicações que necessitem criar linhas dedicadas em redes privadas virtuais (VPNs). Esta classe de serviço está definida em (Jacobson et al., 1999).

\section{Encaminhamento Garantido}

A classe de serviço Encaminhamento Garantido, ou PHB AF (Assured Forwarding), definida em (Heinanen et al., 1999), fornece entrega de pacotes IP em 4 classes onde, para 
cada uma, é alocada uma determinada quantia de recursos para o encaminhamento do tráfego (buffer e banda). Dentro de cada classe AF, um pacote IP pode ser associado a um dentre três níveis diferentes de precedência de descarte, como mostra a figura 3.3. É destinada a aplicações que demandem da rede um serviço mais confiável que aquele de melhor esforço, mas sem todas as garantias de QoS dadas pelo encaminhamento expresso.

\begin{tabular}{|c|c|c|c|c|}
\hline Default PHB Codepoint & \multicolumn{4}{|c|}{$000000(0)$} \\
\hline EF PHB & \multicolumn{4}{|c|}{$101110(46)$} \\
\hline \multirow{4}{*}{ AF PHB } & Classes & Low Drop Prec & Medium Drop Prec & High Drop Prec \\
\cline { 2 - 5 } & Class 1 & $001010(10)$ & $001100(12)$ & $001110(14)$ \\
\cline { 2 - 5 } & Class 2 & $010010(18)$ & $010100(20)$ & $010110(22)$ \\
\cline { 2 - 5 } & Class 3 & $011010(26)$ & $011100(28)$ & $011110(30)$ \\
\cline { 2 - 5 } & Class 4 & $100010(34)$ & $100100(36)$ & $100110(38)$ \\
\hline
\end{tabular}

Figura 3.3: Valores recomendados para identificar os PHBs (Oyama \& de Lucena, 2002).

Esse serviço não oferece limites superiores para o atraso e jitter, mas garante um tratamento preferencial ao tráfego que dele se utilize. É indicado quando se deseja obter da rede um serviço de entrega de pacotes mais consistente, por exemplo, uma empresa que realiza vendas na Internet e deseja que os pacotes de todos os usuários que a acessarem sejam encaminhados preferencialmente em relação ao tráfego de melhor esforço. Em situações de sobrecarga na rede, primeiro são descartados os pacotes pertencentes ao serviço de melhor esforço e em seguida os pacotes associados ao serviço de encaminhamento garantido segundo suas respectivas prioridades de descarte.

\section{Service Level Agreements (SLA)}

SLA (Service Level Agreements) pode ser definido como um acordo feito entre o transmissor e o receptor determinando os limites dos parâmetros utilizados na aplicação. Ele determina quais classes de serviço são suportadas e a quantidade de tráfego na banda entre os domínios. Um SLA é considerado estático se é negociado de forma regular, em bases mensais ou anuais e dinâmico quando é necessário o uso de um protocolo de sinalização e controle para o gerenciamento da banda, como o RSVP.

Como critério para a aplicação das políticas de QoS pode ser usada qualquer informação que possa ser extraída do conteúdo do tráfego, como data e hora, endereços de origem e destino, e outras, inclusive a contida nos cabeçalhos (Stardust, 1999b). Um SLA também pode especificar: procedimentos de tarifação e cobrança, serviços de criptografia e autenticação, procedimentos de renegociação dos parâmetros do SLA, ações a serem tomadas para o tráfego fora de perfil, entre outros (Vasiliou, 2000).

\section{Protocolo MPLS}

$\mathrm{Na}$ Internet, quando um roteador recebe um pacote, ele faz uma busca na sua tabela de roteamento e então, baseado no endereço IP do pacote, decide para onde enviá-lo (Tanenbaum, 2002). Essa busca pode levar bastante tempo, dependendo do tamanho da 
tabela de cada roteador. MPLS (Multiprotocol Label Switching) rompe com esse paradigma, usando um rótulo de tamanho fixo a partir do qual o roteador decide por onde enviar os pacotes.

O protocolo MPLS é uma abordagem alternativa a arquitetura DiffServ. Embora ambas as abordagens marquem os pacotes nos pontos de ingresso na rede e os desmarquem nos pontos de saída, no MPLS a marcação é utilizada para fazer o roteamento efetivamente, determinando qual o próximo hop a ser dado conforme o rótulo (label) colocado no pacote, e não apenas uma forma de atribuir prioridade aos pacotes dentro dos roteadores, como é o caso do DiffServ. O protocolo MPLS funciona integralmente nos roteadores, sem nenhum componente nos sistemas finais.

O rótulo de um pacote MPLS determina completamente qual caminho o mesmo deverá seguir pela rede, permitindo estabelecer canais (pipes) com largura de banda fixa nos moldes dos circuitos virtuais de uma rede ATM ou Frame Relay. Essa abordagem pode ser usada por empresas para a criação de redes privadas virtuais (VPNs), criando túneis seguros entre matrizes e filiais ou entre parceiros comerciais. Normalmente esse tipo de comunicação utiliza linhas privativas, porque a Internet é considerada insegura para transportar informações confidenciais. Mais detalhes sobre o protocolo MPLS (MultiProtocol Label Switching) encontra-se especificado em (Rosen et al., 2001).

\subsection{Serviços Diferenciados em Nível de Aplicação}

Nas seções anteriores, foram estudadas as formas de garantir QoS em nível de rede, particularmente as abordagens de serviços diferenciados e integrados. No entanto, com o crescente aumento da complexidade das aplicações que funcionam sobre a estrutura da Internet, qualquer esforço no sentido de fornecer QoS terá que ter a cooperação de todos os elementos do sistema, entre os quais, os servidores Web são essenciais, uma vez que são eles, em última análise, que vão atender os usuários.

O objetivo de discutir QoS em nível de rede nas seções anteriores foi fornecer e aproveitar parte do conhecimento já adquirido e testado na área, para a construção de servidores Web, pois, se estes não estiverem preparados para oferecer QoS, todo esforço realizado em nível de rede terá sido em vão, pois ele tratará todas as solicitações que receber por igual, ignorando a prioridade relativa das mesmas. A maior parte dos servidores atuais ainda trata todas as solicitações uniformemente, segundo a disciplina FCFS (First-Come First-Served), tornando-se assim, em casos de sobrecarga, o gargalo do sistema. Portanto, projetar servidores Web com capacidade de oferecer diferenciação de serviços é fundamental para a provisão de QoS na Web.

Nesta seção, serão examinados alguns trabalhos que se preocupam com o fornecimento de QoS em nível de aplicação, principalmente os que implementam servidores Web com características de diferenciação de serviços, assunto que é o objetivo do presente trabalho. 
A relevância desse tema se deve ao fato de cada vez mais a Internet estar se tornando um ambiente comercial (Andreolini et al., 2004) (Lee et al., 2004), onde empresas a utilizam para alavancar novos negócios e oferecer novos serviços. Para tanto, é fundamental que os servidores Web estejam preparados para tratar adequadamente as diferentes expectativas das empresas e usuários que utilizam a Web como plataforma.

\section{Serviços Diferenciados em Servidores $W e b$}

Atualmente, a maioria dos trabalhos na área de serviços diferenciados para a Web, focam sua abordagem no sentido de fornecer múltiplos níveis de serviço na rede e nos sistemas operacionais. Embora essas abordagens forneçam os resultados mais expressivos, implantá-las na prática torna-se inviável, devido ao fato da complexidade de se fazer a atualização dos roteadores e sistemas operacionais por toda a Internet.

Alguns trabalhos, no entanto, focam seus esforços no sentido de oferecer serviços diferenciados apenas no servidor e sem alterações no sistema operacional. É o caso do trabalho de Eggert \& Heidemann (1999), que consiste na idéia de dividir as solicitações que chegam ao servidor em foreground e background, onde as solicitações de background recebem um serviço de "menor esforço" (less effort), ou seja, elas só serão processadas e transmitidas aos clientes caso haja recursos ociosos disponíveis no servidor. Caso contrário, poderão ser postergadas indefinidamente ou até mesmo descartadas.

Para implementar os mecanismos de diferenciação de serviços foi utilizado o servidor Apache (APACHE SOFTWARE FOUNDATION, 2007), através de três abordagens diferentes: na primeira os autores limitam o número de processos que tratarão das requisições em background. Para tanto dois servidores Apache são colocados em uma mesma máquina, atendendo as requisições em portas diferentes; na segunda optou-se por diminuir a prioridade de processos em nível de sistema operacional, sem alterações no kernel, para as requisições background; e na terceira os autores limitam a taxa de transferência na rede para requisições background.

Para realizar os experimentos foram utilizados dois benchmarks WebStone (Trent \& Sake, 1995) sincronizados, um representando requisições do tipo foreground e outro do tipo background. Os resultados apresentados mostraram um melhor tratamento para as requisições do tipo foreground, em detrimento das requisições do tipo background, mostrando que é possível fornecer diferenciação de serviços utilizando para tanto somente mecanismos em nível de aplicação.

No trabalho de Almeida et al. (1998) são abordados mecanismos tanto em nível de usuário quanto em nível de kernel para prover diferenciação de serviços. O trabalho está inserido em um contexto onde um provedor de Internet possui vastos recursos e abriga sites de diferentes empresas, instituições e indivíduos, e precisa oferecer uma qualidade de serviço às requisições que chegam a cada site que ele hospeda, de acordo com a quantia paga por cada cliente pelo serviço de hospedagem. 
Foram consideradas duas classes de serviço: uma de alta prioridade para clientes que pagam pela hospedagem e outra de baixa prioridade para os não pagantes. Para implementar os mecanismos de diferenciação de serviços, foi alterado o código fonte do servidor Apache, para em um primeiro momento classificar as requisições em alta ou baixa prioridade. Depois um processo escalonador decide a ordem em que as requisições irão executar, além de limitar o tamanho da fila de cada classe de requisição, de acordo com suas prioridades. Também são feitas alterações no kernel do Linux para mapear as prioridades das requisições em prioridades dos processos que irão atendê-las.

Foram implementadas duas políticas de escalonamento: uma conservadora (workconserving), permitindo que processos de baixa prioridade executem como processos de alta prioridade, caso haja recursos disponíveis na categoria superior e uma não conservadora (non-work-conserving), não permitindo a migração de processos de uma categoria para outra. Nos experimentos, a política não conservadora apresentou os melhores resultados.

Em Andreolini et al. (2004) é implementado um protótipo de um Web cluster denominado Quality of Web-based Services (QoWS), com o objetivo de garantir QoS absoluta as classes de serviço, segundo seus respectivos SLAs. Esse protótipo consiste de um Web Switch responsável por classificar e controlar a aceitação de novas requisições, incorporando características de qualidade de serviços.

Para implementar o Web Switch foi utilizado um servidor Apache como proxy reverso, onde ele recebe as requisições que chegam ao sistema e as repassa a um dos nós do cluster de servidores Web, também compostos de servidores Apache. Após atenderem as requisições, os servidores respondem ao Web Switch, que repassa a resposta ao cliente que originou a requisição.

Foram consideradas quatro classes, duas de serviços (requisição dinâmica ou estática) e duas de clientes (normal ou top). Para fornecer qualidade de serviço foram considerados três algoritmos: um responsável apenas em controlar o número de requisições de cada classe no sistema, fornecendo um limiar para cada classe, onde acima deste nenhuma requisição da classe será aceita (quanto maior a importância da classe, maior é este limiar); um algoritmo que cria uma partição para cada classe no cluster de servidores de maneira estática; e um outro algoritmo que cria partições no cluster, de maneira dinâmica.

Para realizar os experimentos foi utilizado o benchmark Webstone para submeter carga sintética ao sistema. Os resultados mostraram que em caso de sobrecarga, esses mecanismos de QoS são eficientes, com destaque para a política de partição dinâmica do cluster.

Em Zhou et al. (2004), os autores propõem uma estratégia de alocação adaptativa de processos com o objetivo de se obter tempos de respostas diferenciados em Web Servers. A estratégia consiste em configurar o servidor Web Apache para atender em diferentes portas em uma mesma máquina, criando assim Virtual Servers, um para cada classe de requisição. Cada Virtual Server tem um pool de processos que irão atender as requisições. 
O tamanho que é definido para este pool de processos depende de quanto processamento se deseja disponibilizar para cada classe.

Um mecanismo de alocação de processos de forma adaptativa foi construído modificando o servidor Apache para que este incremente ou decremente o tamanho do pool de processos em cada Virtual Server de acordo com a utilização dos mesmos, ou seja, um pool com processos ociosos terá seu tamanho decrementado, enquanto um pool sobrecarregado terá seu tamanho incrementado.

A arquitetura do sistema consiste de um roteador responsável por classificar as requisições e enviá-las para a porta correspondente. O servidor Web, além de atender em diferentes portas, uma para cada classe de requisição, possui um módulo de alocação de processos, responsável por monitorar a utilização do pool de processos de cada Virtual Server e, aumentar ou diminuir o tamanho de cada pool de acordo com suas respectivas utilizações.

Experimentos foram realizados utilizando o Httperf (Mosberger \& Jin, 1998) para geração de carga, segundo uma distribuição de Poisson. Foram implementadas duas estratégias de alocação de processos, uma fixa e uma adaptativa. Os resultados mostraram que a estratégia de alocação adaptativa de processos pode alcançar diferenciação previsível e controlável no tempo de resposta das requisições, quando a carga no servidor se encontra em uma determinada faixa de valores.

No trabalho de Serra et al. (2005), são propostos mecanismos de controle de admissão e balanceamento de carga para prover qualidade de serviço. A arquitetura do sistema é composta por um Class Switch, que é responsável pela classificação e pelo controle de admissão das requisições. Ele recebe as requisições HTTP, classifica-as e envia as mesmas a um Cluster Gateway, que escolhe o servidor Web com menor carga de sua rede e repassa a requisição.

Cada nó do cluster de servidores Web possui um agente daemon que mede a carga do nó, baseada em uma técnica chamada de "Coefficient Reactivity" (Coeficiente de Reatividade)" (Serra et al., 2005) e a envia ao Cluster Gateway, que por sua vez passa as informações de carga de todos os servidores Web conectados a ele para o Class Switch. Dependendo do valor do "Coeficiente de Reatividade", um cluster de servidores Web que a princípio atende uma classe em modo de exclusividade, pode mudar para o modo compartilhado, passando a atender também requisições de outras classes, ou mudar para o modo saturado, onde não atende mais as requisições que chegam ao sistema.

Os experimentos mostraram que os mecanismos adotados no trabalho são capazes de compartilhar razoavelmente os recursos disponíveis em períodos de baixa carga no sistema e manter estáveis os acordos de QoS em períodos de alta carga.

Em (Shan \& Chuang Lin, 2005), é proposto um mecanismo de diferenciação de serviços mapeando a prioridade das requisições para prioridades de processos, mudando-as

\footnotetext{
${ }^{1}$ Parâmetro para medir QoS
} 
dependendo da importância da requisição. Para tanto foi utilizada uma máquina com a versão 1.3.33 do Web Server Apache, interligada a outras duas máquinas clientes, através de um hub. Uma máquina representa clientes com requisições de alta prioridade e a outra clientes com requisições de baixa prioridade. Para gerar a carga de trabalho foi utilizado o Httperf.

Foi construído um módulo para classificar as requisições no Apache através do endereço IP da máquina que gerou a requisição e, em seguida, mudar a prioridade do processo que a está atendendo, de acordo com a prioridade que lhe foi dada, usando para tanto o comando nice do Linux.

Os resultados mostraram que o mecanismo apresentado foi eficiente para prover diferenciação de serviços entre as classes consideradas. No entanto, nem sempre os resultados obtidos com a utilização do Apache com a inclusão desse mecanismo, foi melhor que com a utilização do Apache sem o mesmo.

Outro trabalho que propõe mecanismos de diferenciação de serviços em servidores $W e b$ é o caracterizado em Semprebom et al. (2006). Os autores fazem uso de escalonamento adaptativo por computação imprecisa e controle de admissão para obter diferenciação proporcional entre as classes. Computação imprecisa consiste em passar para o cliente uma versão parcial de um determinado objeto requisitado com o objetivo de diminuir o número de requisições na fila do servidor em momentos de sobrecarga, ao invés de simplesmente rejeitar a requisição. A escolha sobre qual requisição vai ficar com uma versão imprecisa de determinado objeto irá depender de sua prioridade.

Foram feitos experimentos utilizando tanto um simulador Java como um servidor Web Apache versão 2.2. Os resultados mostraram que o uso de versões imprecisas permite responder as requisições de usuários, mesmo com qualidade degradada e, evitar que estes tenham a sensação de negação de serviço. No entanto, em momentos de sobrecarga severa, as execuções imprecisas não conseguem mais reduzir a carga no sistema, sendo necessário descartar requisições através de mecanismos de controle de admissão.

Além dos trabalhos comentados nesta seção, foram estudados vários outros que implementam QoS em nível de aplicação, como os trabalhos de (Bhatti \& Friedrich, 1999), (Pandey et al., 1998), (Haddad \& Butler, 2004), (Luo, 2004), (Zhang et al., 2004) e (Sit et al., 2004).

\subsection{Considerações Finais}

Este capítulo apresentou uma visão geral da área de qualidade de serviço na Internet, destacando as arquiteturas de serviços integrados e diferenciados, com ênfase nesta última. Foi apresentada também uma revisão de alguns trabalhos na área de diferenciação de serviços em servidores Web. 
No próximo capítulo será apresentado o modelo de servidor Web com diferenciação de serviços (SWDS), proposto por Teixeira (2004), o qual é a base dos estudos deste trabalho, que tem como objetivo implementar um protótipo baseado neste modelo, e avaliar seu desempenho em ambiente real. 
Capítulo

4

\section{Servidor Web com Diferenciação de Serviços (SWDS)}

\subsection{Considerações Iniciais}

Como comentado nos capítulos anteriores, o modelo atual de serviços na Internet e, especialmente, na Web, trata todas as requisições de forma equivalente, sem nenhum tipo de diferenciação ou priorização. No entanto, verifica-se que nem todos os tipos de tráfego e transações são equivalentes ou têm a mesma prioridade para os usuários (Dovrolis \& Ramanathan, 1999). Assim, é essencial fornecer serviços com diferentes níveis de qualidade para diferentes tipos de requisições (Kant \& Mohapatra, 2000). Para a provisão de uma QoS abrangente, é necessário que se tenha um comprometimento fim a fim, com a colaboração de todos os elementos envolvidos no processo, em todos os níveis. Sendo assim, se faz necessário que os servidores $W e b$ sejam também capazes de reconhecer as diferentes demandas dos usuários e aplicações, de modo a estarem aptos a tratar de maneira diferenciada cada requisição, de acordo com a prioridade das mesmas.

Neste capítulo é apresentado o modelo de um Servidor Web com Diferenciação de Serviços proposto em (Teixeira, 2004), descrevendo seus principais componentes e também os algoritmos de controle de admissão e diferenciação de serviços propostos para o mesmo. Serão também discutidos alguns cenários de uso para serviços diferenciados. 


\subsection{Modelo de Servidor Web com Diferenciação de Ser- viços}

Esta seção descreve um modelo de Servidor Web com Diferenciação de Serviços (SWDS) (Teixeira, 2004). O objetivo deste modelo é definir uma arquitetura de servidor Web cuja finalidade é fornecer serviços diferenciados a seus clientes, de acordo com suas necessidades e segundo requisitos de QoS previamente acertados. O servidor SWDS é composto pelos seguintes módulos: um módulo classificador; um módulo de controle de admissão; e um cluster de processos ou servidores Web. A figura 4.1 ilustra a arquitetura do SWDS.

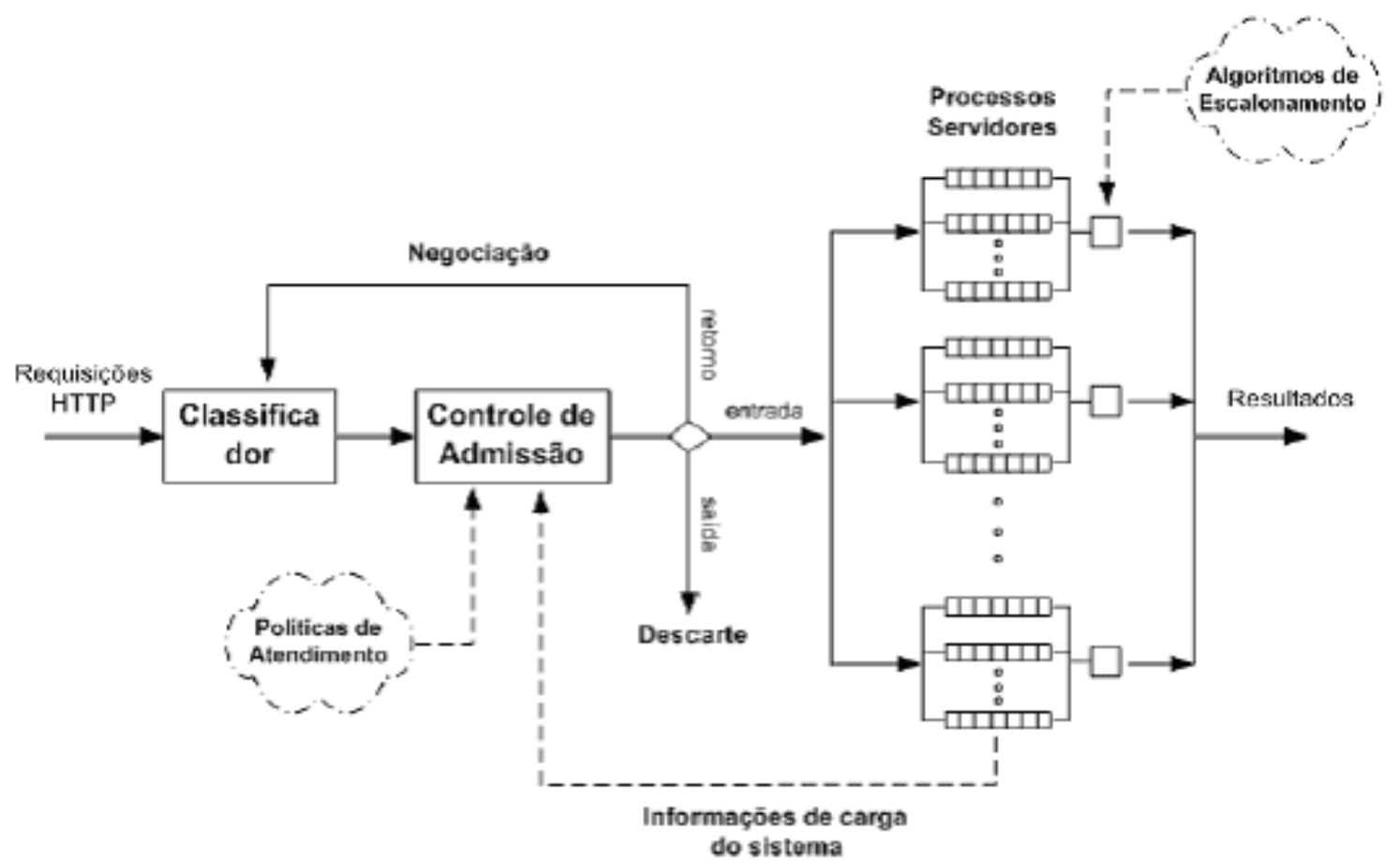

Figura 4.1: Arquitetura do SWDS (Teixeira, 2004).

\section{Classificador}

A população de clientes de um servidor $W e b$ é bastante variada, com diferentes necessidades e expectativas. Sendo assim, se faz necessário identificar as características das requisições HTTP que chegam ao servidor SWDS e subdividi-las em classes de serviço. Cada classe terá um tratamento de acordo com sua prioridade, podendo ser definida de forma explícita, ou seja, através de um contrato de serviço entre cliente e provedor, ou de forma implícita, deixando o próprio servidor decidir em que classe alocar as requisições recebidas, segundo suas características.

O classificador, então, é o elemento responsável por receber as requisições que chegam ao sistema e subdividi-las em classes de serviço, segundo critérios pré-estabelecidos. Para 
classificar as requisições em classes de serviço podem ser considerados, entre outros, os seguintes critérios:

- Urgência de atendimento: Neste caso, o tráfego emitido por um cliente (tráfego real), teria prioridade sobre o tráfego emitido de forma automática (tráfego especulativo), como um servidor proxy, por exemplo;

- Mecanismo de geração de conteúdo: As requisições HTTP podem ser divididas em estáticas ou dinâmicas, segundo a forma de geração do conteúdo retornado ao cliente. As requisições dinâmicas podem ainda envolver sessões convencionais ou seguras;

- Conteúdo solicitado: Outro critério que pode ser utilizado é o tipo de arquivo solicitado, por exemplo: texto, código HTML, imagens, applets, scripts, áudio/vídeo, dentre outros;

- Origem da requisição: As solicitações podem ser classificadas entre locais (pertencentes ao mesmo domínio do servidor $W e b$ ) ou remotas (provenientes de outros domínios);

- Políticas de atendimento diferenciadas: Neste caso os clientes são divididos em classes de serviço segundo políticas externas, por exemplo, o quanto cada um paga por um determinado serviço.

\section{Controle de Admissão}

Este módulo é responsável por receber as requisições já classificadas e gerenciar a sua aceitação pelo servidor, levando em conta as políticas de atendimento vigentes e as informações de carga no sistema. Caso o mesmo esteja sobrecarregado, uma requisição poderá ser rejeitada (descarte) ou ter suas exigências de qualidade de serviço relaxadas (negociação), a fim de que possa ser aceita em uma classe de prioridade inferior.

O Controle de Admissão é essencial para evitar a sobrecarga do sistema, o que comprometeria alcançar os níveis de QoS pretendidos. Sua arquitetura consiste de um módulo de coleta de informações de carga, uma área de variáveis globais, uma área de buffers e um módulo responsável pelos mecanismos de controle, o qual pode ser incrementado com novos algoritmos a qualquer tempo. A aplicação desses mecanismos se dá conforme políticas de atendimento, definidas pelo administrador do sistema. A figura 4.2 ilustra a arquitetura do módulo de controle de admissão do SWDS.

Em seguida são descritos os principais componentes da arquitetura do módulo de controle de admissão:

- Área de Variáveis Globais: Guarda informações referentes ao estado do sistema e às métricas relevantes para o Controle de Admissão, como o tamanho das filas do 


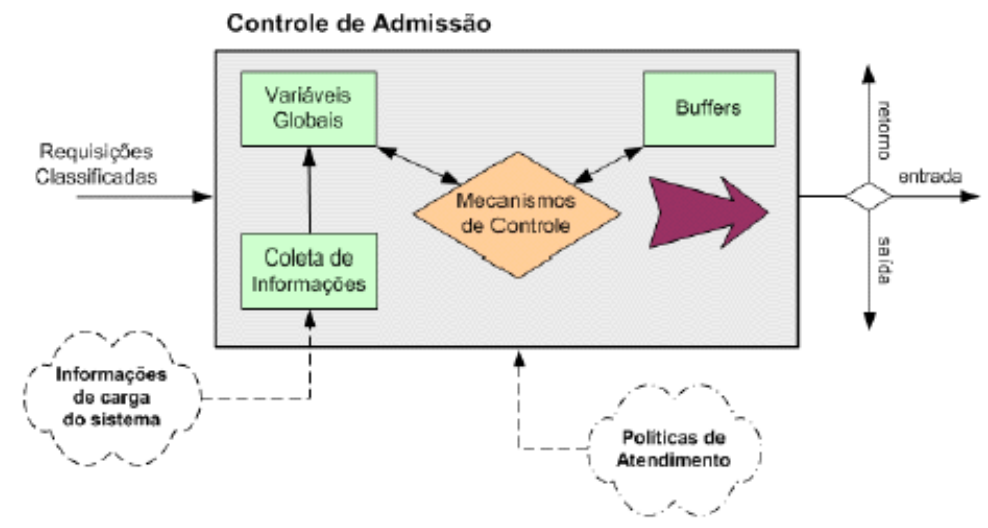

Figura 4.2: Controle de Admissão.

cluster, o tempo de resposta das requisições e a utilização do sistema. Esta área pode ser ampliada de acordo com a necessidade;

- Área de Buffers: Composta por buffers utilizados, por exemplo, para limitar o número de clientes de uma certa classe presentes no servidor, número de clientes em fila, etc;

- Coleta de Informações: Responsável por coletar informações atualizadas da carga do sistema, servindo como base para a tomada de decisões;

- Mecanismos de Controle: São os mecanismos de controle de admissão implementados no SWDS. Atualmente, estão implementados os seguintes mecanismos de controle:

- Tamanho das Filas: Define um limite para o tamanho das filas em cada nó do cluster, recusando novas requisições quando esse limite for atingido;

- Tempo de Resposta: Tenta manter o tempo de resposta abaixo de um certo limiar. Para tanto, são utilizados buffers independentes para cada classe de serviço, controlando o número de clientes presentes no servidor;

- Utilização do Sistema: Mede a utilização do cluster de servidores Web, empregando uma média exponencialmente ponderada, a qual pode ser ajustada para considerar valores atuais ou o histórico da carga do sistema. Se o sistema estiver sendo muito utilizado, a ponto de comprometer os níveis de QoS, novas requisições não serão aceitas.

\section{Cluster de Servidores Web}

O cluster de servidores Web é responsável por atender cada requisição conforme o algoritmo de escalonamento ou diferenciação de serviços vigente. Após a conclusão do processamento, os resultados são retornados ao cliente que originou a solicitação. Segundo Teixeira (2004), cada nó do cluster pode ser considerado um servidor Web convencional, 
composto de CPU, disco e interface de rede, ou até mesmo processos ou CPUs em um computador paralelo, pois o modelo não exige uma arquitetura formada necessariamente por máquinas dispostas em um sistema distribuído, assim como também não define nenhuma plataforma de hardware ou sistema operacional específico.

\subsection{Mecanismos de Diferenciação de Serviços}

Os mecanismos de diferenciação de serviços determinam como os clientes do servidor SWDS serão tratados de acordo com suas respectivas classes de serviço. Esses mecanismos tanto podem interferir diretamente na disciplina das filas do cluster (escalonando primeiro as classes de maior prioridade, por exemplo) quanto gerenciar a alocação dos nós às diferentes classes de serviço.

No modelo original, proposto por Teixeira (2004), foram implementados três algoritmos de diferenciação de serviços, os quais podem ser divididos em duas abordagens distintas: reserva de recursos e escalonamento baseado em prioridades.

\subsubsection{Reserva de Recursos}

Nessa abordagem, os algoritmos de diferenciação de serviços são aplicados ainda na fase de despacho das requisições HTTP, determinando a forma de distribuição das mesmas entre os nós do cluster. O módulo de controle de admissão atua como escalonador e atribui as requisições a grupos de processos servidores segundo a classe a que pertencem. Realizase, portanto, uma forma de enfileiramento baseado em classes (Class-Based Queueing CBQ), na qual é reservada parte da capacidade de processamento do servidor para cada classe de requisições.

No trabalho de Teixeira (2004), foi apresentado um algoritmo de diferenciação de serviços, elaborado segundo os princípios do CBQ ${ }^{1}$. Este algoritmo de diferenciação de serviço, chamado de algoritmo de reserva de recursos (RSV), faz a subdivisão do cluster de servidores Web em partições, associando essas partições às classes de serviço. Com isso, uma parcela da capacidade de processamento do servidor SWDS é reservada para cada classe de requisições, isolando assim o desempenho entre as classes e, evitando a interferência no comportamento entre elas.

Embora o algoritmo seja adequado em alguns casos, existem situações em que pode não ser eficiente (Teixeira et al., 2003). Isso se deve ao fato do particionamento do cluster ser feito de maneira estática, com a reserva de subconjuntos de servidores para determinadas classes de serviço. Esse tipo de particionamento é mais adequado em casos em que o padrão da carga de trabalho é razoavelmente conhecido e previsível, o que não é o caso da Web. Por ser um ambiente altamente dinâmico, a variação de carga na Web, pode

\footnotetext{
${ }^{1}$ Class-Based Queueing
} 
fazer com que alguns recursos destinados a uma classe de serviço fiquem sobrecarregados enquanto outros estão subtilizados. Uma possível solução para este problema seria a implementação de um algoritmo que realize o particionamento dinâmico do cluster. Este algoritmo já foi implementado em outro trabalho do grupo (Traldi et al., 2006) e será considerado na implementação do protótipo.

\subsubsection{Escalonamento Baseado em Prioridades}

A abordagem anterior estudou o uso de esquemas do tipo Class-Based Queueing para a diferenciação de serviços, mostrando algumas de suas limitações, principalmente quando se faz a alocação estática dos servidores (ou processos) às classes de usuários, o que pode não ser muito eficiente, devido ao fato da necessidade de se ter um conhecimento mais detalhado da carga que será imposta ao sistema, tornando-se inviável em um ambiente altamente dinâmico como a Web (Paxson \& Floyd, 2001).

Nessa abordagem, ao contrário do enfileiramento baseado em classes, o escalonamento buscando priorizar determinadas requisições é feito em cada nó do cluster, sendo escalonadas primeiro as requisições pertencentes às classes com maiores prioridades. A vantagem desta abordagem é que, havendo um balanceamento de carga eficiente, todos os recursos do sistema serão usados igualitariamente, pois não há reserva de recursos para determinadas classes. Além disso, a diferenciação de serviços é realizada de forma distribuída, ao contrário da abordagem anterior que depende de um componente central (Controle de Admissão) para esse fim. Desse modo, essa abordagem aumenta a confiabilidade e a escalabilidade do sistema, pois a responsabilidade associada à diferenciação de serviços é transferida para cada nó do cluster.

\section{Mecanismo de Prioridade Rigoroso}

Nesse algoritmo, as prioridades estabelecidas nas filas do cluster para as requisições são seguidas de maneira rígida, ou seja, primeiro serão atendidas todas as requisições de maior prioridade da fila, e somente depois as requisições de prioridade inferior serão atendidas. Em caso de duas requisições de mesma prioridade estarem na fila ao mesmo tempo, será atendida a qual tiver chegado primeiro (First Come First Served).

Os resultados apresentados em (Teixeira, 2004), demonstram que essa abordagem permite realizar a diferenciação de serviços de uma maneira mais simples e flexível do que a anterior (Reserva de Recursos). Entretanto, cuidados devem ser tomados na atribuição de prioridades aos clientes, caso contrário, uma determinada classe pode monopolizar todo o sistema. 
O mecanismo de prioridade adaptativo (PRIAdap), tem o objetivo de flexibilizar a prioridade das requisições, definindo uma constante K (valor de look-ahead) que, dependendo do seu valor, as requisições de alta prioridade terão mais ou menos importância. O algoritmo funciona da seguinte maneira: as requisições que chegam aos nós do cluster são enfileiradas por ordem de chegada. Quando o escalonador vai selecionar uma requisição para ser atendida, ele percorre até K posições na fila procurando por requisições da classe de maior prioridade. Caso não encontre, o escalonador volta no início da fila e passa a procurar por requisições da classe imediatamente inferior e, assim sucessivamente.

É fácil perceber, que quanto maior o valor de look-ahead $(\mathrm{K})$, mais as requisições de alta prioridade serão beneficiadas, enquanto que para um valor de $K=1$, a política utilizada será a FCFS (First Come First Served). Com ele, evitam-se os problemas de negação de serviço para classes de menor prioridade, como no caso do mecanismo de prioridades rigoroso, deixando o servidor SWDS mais flexível.

Desse modo, o servidor pode ser melhor ajustado para responder as variações de carga impostas ao sistema, característica extremamente importante em um ambiente altamente dinâmico como a Web.

\subsection{Cenários de Utilização}

A Web está se tornando cada vez mais uma mídia orientada a negócios e nesse contexto é normal que clientes ou empresas que pagam pela hospedagem de seus sites em provedores $W e b$, esperem um tratamento compatível com a quantia paga. Ou ainda, que aplicações sensíveis ao atraso no tempo de resposta sejam melhores atendidas que outras nas quais este atraso não é determinante para seu bom funcionamento. Para suprir essas necessidades é necessário utilizar mecanismos de diferenciação de serviços, pois, o modelo de melhor esforço, tornou-se inadequado e restritivo (Christin \& Liebeherr, 2003) (Roberts, 2004).

Os servidores Web não podem ser ignorados nesta questão de diferenciação de serviços, pois são eles que irão, em última análise, atender as requisições e, caso não estejam preparados para reconhecer diferentes classes de serviço, todo o esforço nesse sentido empregado em nível de rede poderá ser desconsiderado. Nesta seção, serão discutidos alguns possíveis cenários de uso de serviços diferenciados na Web, motivando sua aplicação.

Uma possibilidade seria em um cenário financeiro, onde em um banco pode-se encontrar diferentes tarefas, tais como: consulta de saldos, transferência de valores, pagamentos, entre outros. Com os serviços diferenciados é possível, por exemplo, dar prioridade às requisições de usuários que estejam fazendo uma transferência ou um pagamento, pois estas são transações mais complexas do que uma simples consulta, e requer mais cuidados.

Outro cenário propício para a utilização de servidores Web com diferenciação de serviços é em empresas Provedoras de Acesso à Internet, onde há um alto nível de concorrência 
entre os usuários. Nesse caso, é possível dividir os usuários em grupos, tais como pagantes e não pagantes, e os pagantes ainda poderiam ser divididos em mais grupos de acordo com a quantia que cada um paga, onde cada grupo, teria um tratamento diferenciado, segundo um contrato de serviço previamente acertado entre as partes.

O comércio eletrônico é também um ótimo cenário para a utilização de serviços diferenciados. Nesse caso, poderia ser dada preferência aos clientes em processo de conclusão de uma compra, ou para clientes com um bom histórico de compras na loja, em lugar daqueles que estejam simplesmente navegando pelo site. Mais é importante ressaltar que neste caso deve se ter cuidado com o serviço fornecido para as classes com menor prioridade, pois usuários ocasionais podem também se tornar clientes, o que não ocorrerá caso o seu atendimento tenha sido muito abaixo de suas expectativas.

Os exemplos citados acima são apenas alguns entre muitos para a aplicação de serviços diferenciados, tais como sites de empresas, serviços de download, sites de conteúdo multimídia, etc. Em todos os casos, é preciso ter cuidado para propiciar um atendimento justo às diversas classes de usuários, evitando que uma classe seja demasiadamente prejudicada em benefício de outra com maior prioridade.

\subsection{Considerações Finais}

Este capítulo apresentou a arquitetura de um Servidor Web com Diferenciação de Serviços (SWDS), proposto por Teixeira (2004), cujo objetivo é atender seus clientes de acordo com suas expectativas e prioridades. Foi apresentado também o módulo de controle de admissão, responsável por aceitar ou rejeitar novas requisições de acordo com a carga de trabalho atual do sistema.

Finalmente, foram comentados alguns cenários de aplicação de serviços diferenciados em servidores $W e b$, que se mostram como uma motivação para a implementação de um protótipo do SWDS, proposta deste trabalho.

No próximo capítulo será apresentada uma arquitetura para um protótipo baseado no SWDS. Serão apresentados os principais mecanismos utilizados para a implementação do protótipo e também a arquitetura de testes, além da carga de trabalho considerada e as ferramentas utilizadas para a realização dos experimentos com o protótipo. 


\section{Capítulo \\ 5 \\ Implementação de um protótipo do SWDS}

\subsection{Considerações Iniciais}

No capítulo anterior foi apresentado o modelo de servidor Web com diferenciação de serviços (SWDS) proposto por Teixeira (2004), detalhando seus componentes e os algoritmos propostos para o modelo.

Neste capítulo será apresentada, a arquitetura de um protótipo baseado nesse modelo, utilizando para tanto um cluster de servidores Web Apache (APACHE SOFTWARE FOUNDATION, 2007) localmente distribuídos. Será abordada a implementação do classificador e do controle de admissão por meio da utilização de um Web Switch construído utilizando o Apache configurado para atuar como proxy reverso (ver mecanismos de proxy na seção 5.2).

Também serão apresentados os algoritmos de diferenciação de serviços utilizados pelo protótipo e como os mesmos foram implementados. No final é apresentada a arquitetura utilizada para a realização dos experimentos, composta por um conjunto de máquinas utilizando o gerador de carga sintética Httperf (Mosberger \& Jin, 1998) simulando os clientes Web.

\subsection{Arquitetura do Protótipo}

Para mapear o modelo e implementar os algoritmos propostos, foi considerada uma arquitetura de cluster de servidores Web (Web Cluster). Um Web Cluster é composto 
por uma arquitetura distribuída de servidores $W e b$, que pode ser organizada de várias maneiras (Cardellinni \& Casalicchio, 2002).

Para a finalidade desta implementação, foi delegada a uma máquina a responsabilidade de receber as requisições dos clientes (Front-End) e repassá-las a um servidor que será responsável por atendê-las (Back-End). O Front-End e os Back-Ends são conectados por meio de uma rede local de alta velocidade. Após atender as requisições o Back-End envia a resposta de volta ao Front-End que a repassa ao cliente. O servidor que recebe as requisições (Front-End) em uma arquitetura de cluster de servidores Web é comumente chamado na literatura de Web Switch (Cardellinni \& Casalicchio, 2002).

O Web Switch pode operar na camada 4 (camada de transporte) ou na camada 7 (camada de aplicação), tomando como base de referência a pilha de protocolos do modelo OSI. Um Web Switch que opera na camada 4 (layer 4) é considerado não ciente de conteúdo, pois estabelece a conexão com o servidor Back-End assim que recebe o primeiro sinal $S Y N$ do protocolo TCP, isto é, ainda na camada de transporte e, portanto, antes de receber a requisição HTTP, não podendo tomar ciência de seu conteúdo.

No caso de um switch layer 7, primeiro é estabelecida uma conexão TCP completa com o cliente antes de selecionar o servidor que irá processar a requisição, assim, ele tem "consciência" do conteúdo de uma requisição HTTP para poder tomar possíveis decisões. Portanto, é considerado um switch ciente de conteúdo. Entretanto, um switch layer 7 tem a desvantagem de ser mais lento comparado a um switch layer 4, pois este último não precisa criar uma conexão TCP completa com o cliente antes de se conectar com o servidor Back-End. Por outro lado, um switch layer 7 tem a vantagem de poder analisar o conteúdo de uma requisição antes de tomar decisões de escalonamento.

Neste trabalho foi utilizado um Web Switch layer 7 pelo fato do mesmo ser ciente de conteúdo e possibilitar, assim, a análise da requisição HTTP antes de escaloná-la. A figura 5.1 ilustra as interações entre cliente, Web Switch e Web Server (Back-End) tanto para um Web Switch layer 4 (esquerda) como para um layer 7 (direita).
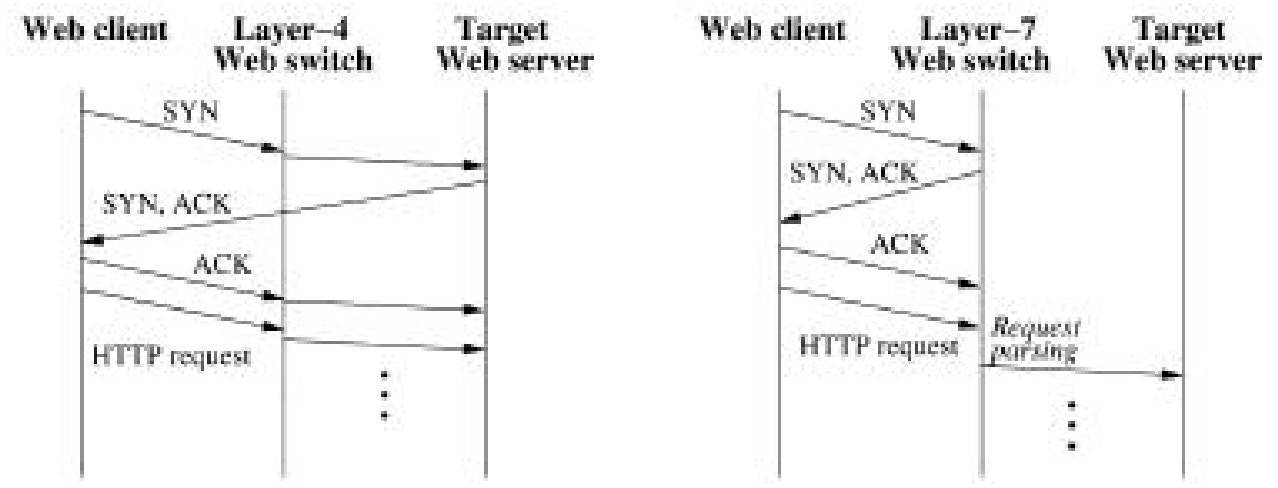

Figura 5.1: Operações de um Web Switch layer 4 (Esquerda) e layer 7 (Direita) (Cardellinni \& Casalicchio, 2002). 
Um Web Switch também pode ser classificado como one-way ou two-way. Em um switch one-way, quando chega uma requisição, esta é repassada ao servidor Back-End juntamente com o ponto final da conexão TCP correspondente, ficando assim o servidor Back-End responsável por responder diretamente ao cliente. No caso de um switch twoway, após este receber uma requisição, a repassa ao servidor Back-End que irá atendê-la e, espera a resposta para repassá-la ao cliente.

Arquiteturas one-way são mais eficientes que as two-way, mas são também menos portáveis e mais difíceis de implementar, pois exigem mudanças no kernel do sistema operacional tanto no Web Switch (Front-End), quanto nos Web Servers (Back-Ends). Neste trabalho foi utilizada uma arquitetura de Web Switch two-way, pelo fato da mesma ser mais portável, bem como de mais fácil implementação, pois, não se exige alterações no kernel do sistema operacional, o que foge do escopo deste trabalho, que busca implementar soluções apenas em nível de usuário.

Informações adicionais sobre organização de cluster de servidores Web estão disponíveis em (Cardellinni \& Casalicchio, 2002). A figura 5.2 mostra uma visão geral da arquitetura do protótipo proposto neste trabalho.

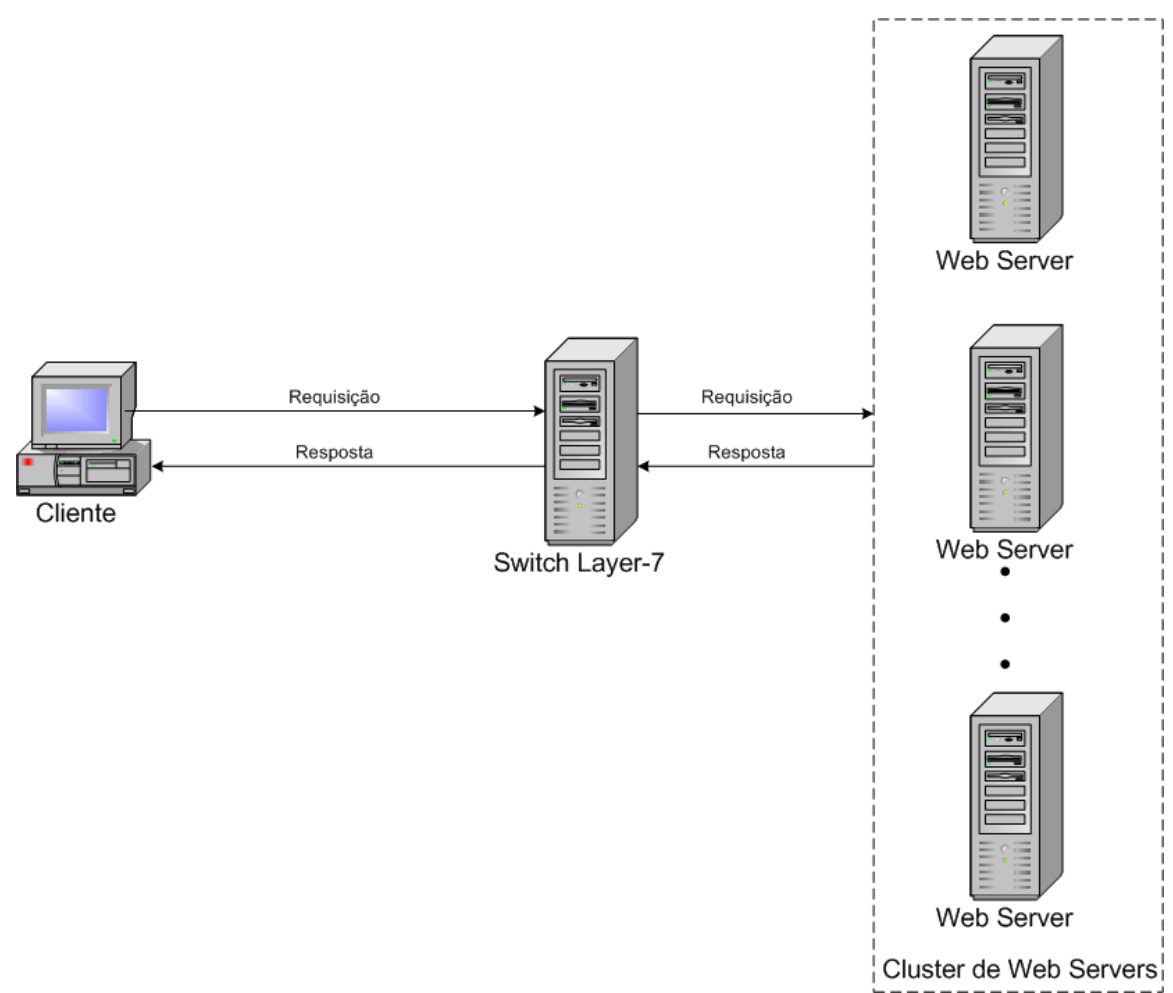

Figura 5.2: Visão geral da arquitetura do protótipo do SWDS.

Para implementar o Web Switch foi utilizado o Web Server Apache configurado como proxy reverso (Engelschall, 1998). Para tanto foram utilizados os módulos mod_proxy e mod_rewrite (APACHE SOFTWARE FOUNDATION, 2007) para trabalharem em conjunto com o Apache. 
O mod_rewrite faz o papel de classificador no sistema. Quando recebe uma requisição, este a classifica para alguma classe de prioridade, utilizando as informações extraídas do cabeçalho HTTP da mesma. Em seguida, a classificação da requisição é passada para um programa desenvolvido em linguagem C (adm_control), que faz o papel de controle de admissão no sistema implementado. Esse programa é responsável pelas políticas de escalonamento e de QoS utilizadas no sistema.

A comunicação entre o classificador (mod_rewrite) e o Controle de Admissão (adm_control) é feita através dos manipuladores de arquivos stdin/stdout. Para tomar decisões de escalonamento e controle de admissão o $a d m_{-}$control recebe as informações de carga dos servidores através de mensagens UDP enviadas periodicamente pelos mesmos. Essas informações são o número de conexões ativas e a média de carga em cada um deles. Tais informações são obtidas através do comando netstat e do arquivo / proc/loadavg do Linux. Após receber do mod_rewrite a classificação da requisição, o Controle de Admissão retorna qual servidor deverá atender a requisição de acordo com a política de escalonamento ou de QoS utilizada, fazendo assim o seu papel de escalonador no sistema.

Após tomada a decisão sobre qual servidor deverá atender a requisição, esta retorna para o mod_rewrite que reescreve a URL de acordo com o servidor que irá atendê-la. Em seguida, a URL modificada é passada ao mod_proxy que encaminha a requisição para o servidor correspondente.

Os nós do cluster são compostos por servidores Web Apache padrão e programas responsáveis pelo monitoramento de carga e envio dessas informações para o Web Switch. A figura 5.3 ilustra a arquitetura do sistema proposto e as interações entre os componentes.

\section{Classificador (mod_rewrite)}

O mod_rewrite reescreve URLs baseado em regras (baseado em um parser de expressão regular). Este módulo dá suporte a um número ilimitado de regras e um número ilimitado de condições de regras fixas para cada regra, provendo assim um mecanismo de manipulação de $U R L$ realmente flexível e poderoso.

As manipulações de URLs podem depender de vários testes, de variáveis do servidor, variáveis de ambiente e informações extraídas de cabeçalhos HTTP, podendo até mesmo utilizar programas externos, em vários formatos, para obter reescritas de URLs ainda mais flexíveis. O resultado da reescrita pode ser usado por um sub-processo interno, para redirecionamento externo ou para redirecionamento interno (na mesma rede local) através de um proxy.

Foram exploradas todas essas características do mod_rewrite para implementar o classificador do sistema. A seguir são descritas algumas diretivas no mod_rewrite utilizadas para a implementação do classificador:

- RewriteEngine: Habilita ou não a função de reescrita no mod_rewrite. 


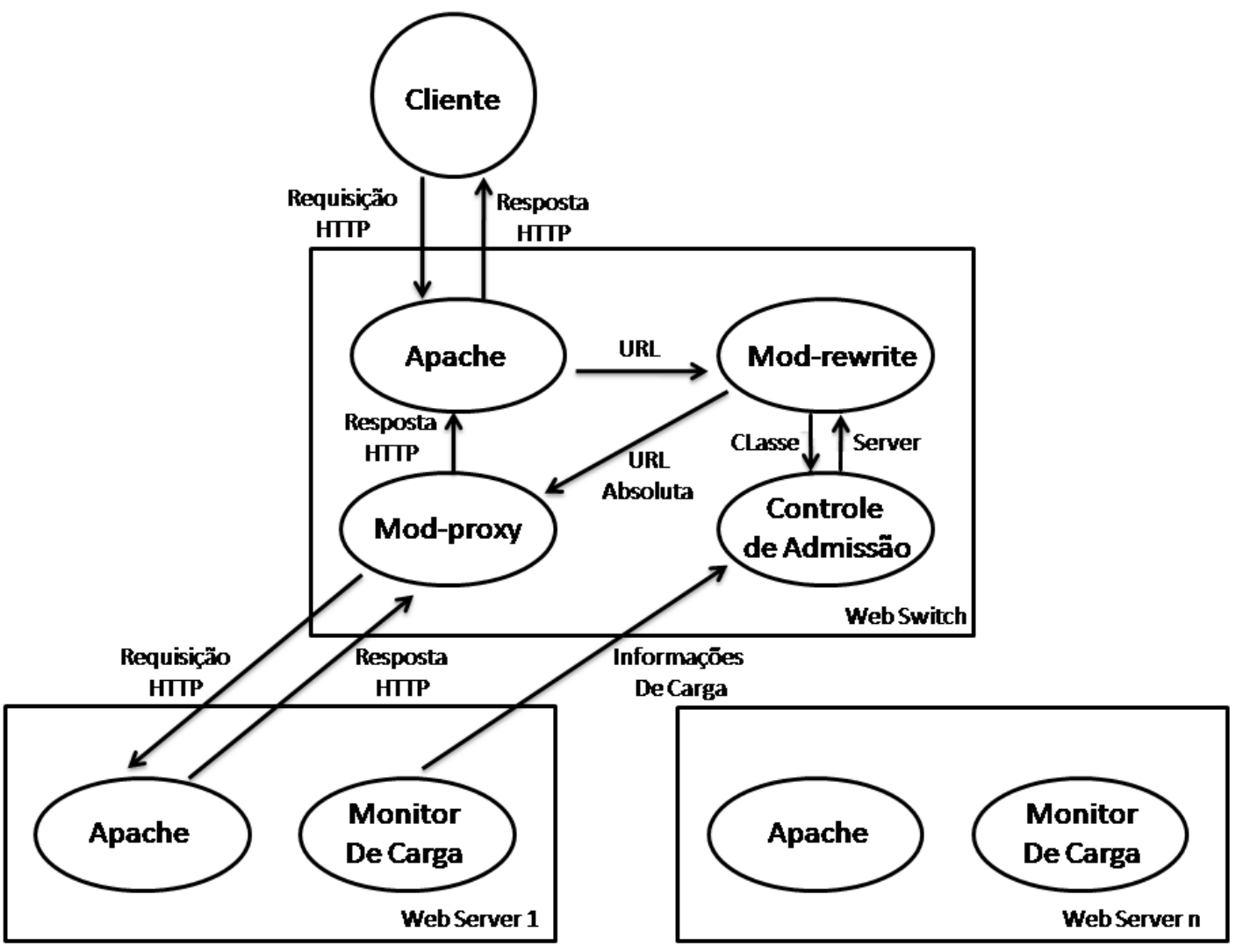

Figura 5.3: Arquitetura do Web Switch e interações com o cliente e o Web Server.

- RewriteRule: Define regras para a reescrita de URLs.

- RewriteCond: Define Condições para se aplicar determinada regra de reescrita de URLs. Os testes para verificação de determinada condição podem envolver variáveis de servidor, variáveis de ambiente e cabeçalhos HTTP.

- RewriteMap: Define uma função de mapeamento do tipo chave-valor que pode ser utilizada pela diretiva RewriteRule. Essa função pode ser estática (um arquivo texto contendo pares de chaves-valores, por exemplo) ou dinâmica (programas externos que lêem uma chave do RewriteRule através do manipulador de arquivo stdin e devolvem um valor correspondente a esta chave escrevendo o mesmo em stdout).

- RewriteLock: Define o nome de um arquivo (lockfile) para prover sincronização no RewriteMap.

A figura 5.4 ilustra um exemplo de como essas diretivas foram utilizadas no arquivo httpd.conf do apache configurado como proxy reverso no Web Switch.

No exemplo apresentado na figura 5.4, após ser habilitada a reescrita de URLs pelo mod_rewrite, é definido um programa (adm_control) que servirá como um mapa para reescrita de URLs dinamicamente (servermap). Esse programa é o Controle de Admissão do protótipo. Em seguida é definido um arquivo para prover sincronização no acesso 


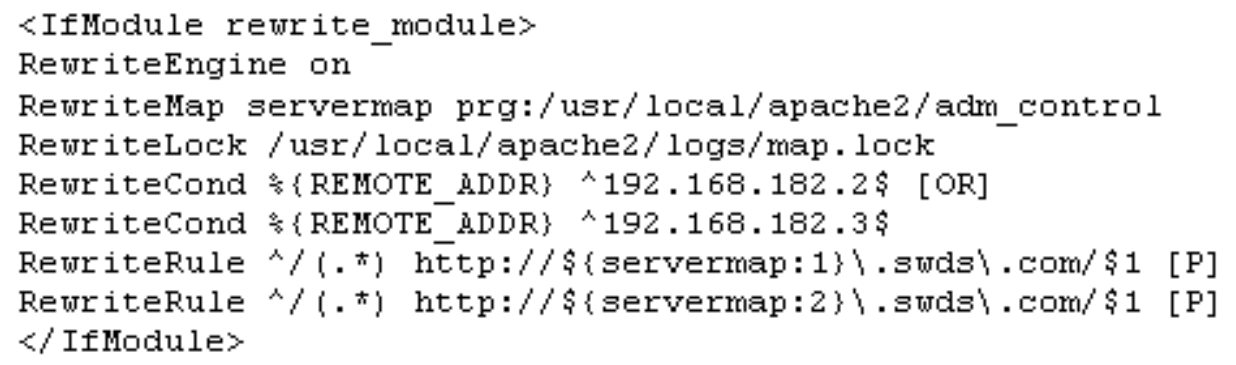

Figura 5.4: Exemplo de utilização do mod_rewrite.

ao programa (map.lock). Em seguida, é definida a condição para a primeira regra ser aplicada, isto é, se o endereço IP do cliente que faz a requisição for 192.168.182.2 ou 192.168.182.3, a requisição será classificada como sendo da classe 1. Esta informação é então passada para o Controle de Admissão ( $\$$ servermap: 1$\}$ ), que irá tomar a decisão para qual servidor a requisição deverá ser encaminhada, ou se a mesma deverá ser descartada. Caso a condição não seja satisfeita, a primeira regra não será aplicada e sim a segunda, sendo então a requisição classificada como pertencente à classe 2 ( $\$$ \{servermap: 2$\})$.

A diretiva $[\mathrm{P}]$, presente no final das duas regras, significa que se trata de um redirecionamento interno através de um proxy. Mais informações sobre o mod_rewrite podem ser obtidas em (APACHE SOFTWARE FOUNDATION, 2007).

\section{Controle de admissão}

O Controle de admissão do protótipo é um programa multi-thread, implementado em linguagem C. A figura 5.5 ilustra a arquitetura do controle de admissão.

Na figura 5.5 pode-se observar que o programa é composto por três threads: Uma thread é responsável por receber a classificação da requisição do classificador (mod_rewrite) e decidir o destino da requisição, de acordo com a política de QoS vigente; outra responsável pela coleta das informações vindas dos servidores; e a terceira thread é responsável por monitorar e alterar os parâmetros do Controle de Admissão, no caso de políticas adaptativas. Todas as threads se comunicam através da escrita e leitura em uma área de variáveis globais. A seguir são descritos com mais detalhes os componentes do controle de admissão:

- Área de variáveis globais: Guarda informações relevantes sobre o estado do sistema e sobre as métricas de QoS utilizadas, tais como número de conexões ativas em cada servidor, utilização do sistema, tabela de servidores disponíveis para cada classe, etc. Pode ser ampliada de acordo com a necessidade.

- Escalonador: Thread responsável por receber a classificação da requisição e definir o que deve ser feito com esta, enviando-a para algum servidor disponível ou rejeitando-a em caso de sobrecarga. 


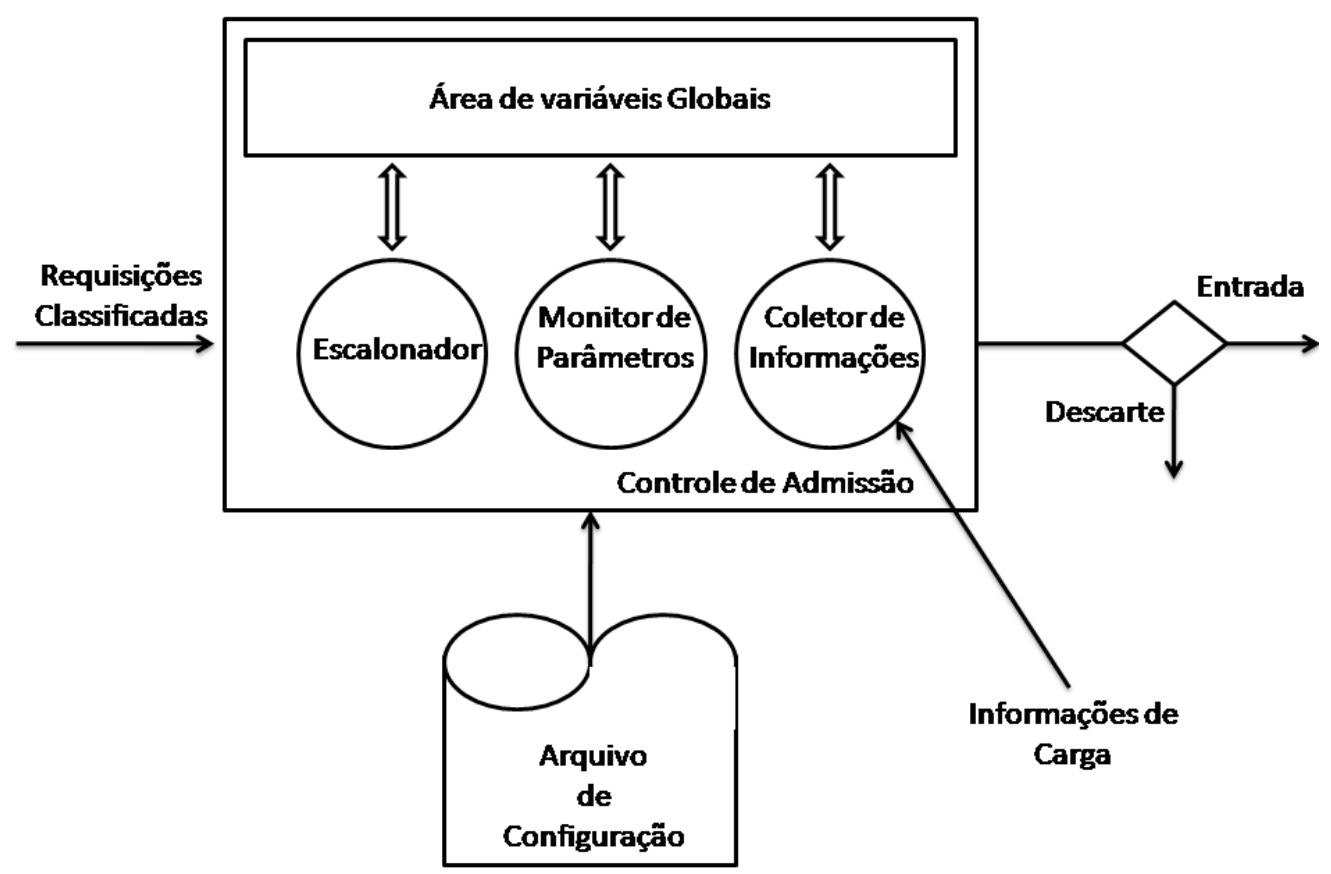

Figura 5.5: Arquitetura do controle de admissão.

- Monitor de parâmetros: Thread responsável por monitorar os dados da área de variáveis globais e alterar os parâmetros de QoS, se necessário, sendo muito útil no caso de políticas adaptativas.

- Coletor de informações: Responsável por coletar as informações de carga vindas dos servidores ativos, tais como o número de conexões ativas e a carga média do sistema em cada um deles. A comunicação é feita através de mensagens, usando-se o protocolo UDP.

Quando iniciado, o servidor Apache lê o arquivo de configuração httpd.conf e no momento em que encontra a linha RewriteMap (ver figura 5.4), inicia o controle de admissão (adm_control). A partir desse ponto o controle de admissão lê um arquivo de configuração denominado swds. conf, que contém parâmetros tais como, a política de escalonamento que deve ser usada. Em seguida são inicializadas as variáveis globais referentes aos parâmetros utilizados pelo sistema e em seqüência as threads responsáveis pelo escalonamento, monitoramento e coleta de dados.

\section{Mecanismos de Proxy (mod_proxy)}

Este módulo implementa um proxy/gateway para o Apache. Ele implementa mecanismos de proxy para AJP13 (Apache JServe Protocol versão 1.3), FTP, CONNECT (para SSL), HTTP/0.9, HTTP/1.0 e HTTP/1.1. O módulo pode ser configurado para se conectar a outros módulos de proxy, para estes e outros protocolos. 
As características de proxy do Apache são divididas em vários módulos além do mod_proxy: mod_proxy_http, mod_proxy_ftp, mod_proxy_ajp, mod_proxy_balancer, e mod_proxy_connect. O Apache pode ser configurado como um proxy ou como um proxy reverso.

Um proxy é um servidor intermediário que fica entre o cliente e o servidor de origem. Para alcançar algum conteúdo no servidor de origem, o cliente envia uma requisição ao proxy, solicitando acesso ao servidor de origem e o proxy, então, faz a requisição ao servidor de origem, recebe a resposta e a repassa ao cliente.

Um uso típico de um proxy é permitir acesso à internet para clientes internos à uma rede local que, caso contrário, são restringidos por um firewall. Um proxy também pode servir como cache (através do módulo mod_cache no Apache, por exemplo) para reduzir o uso da rede. O Apache pode ser configurado como proxy através da ativação da diretiva ProxyRequests. É necessário que o cliente seja adequadamente configurado para que possa solicitar os serviços do proxy.

Um proxy reverso, ao contrário, aparece para o cliente apenas como um servidor Web comum. Nenhuma configuração especial no cliente é necessária. O cliente faz seus pedidos normalmente ao proxy reverso e este decide para onde enviar esses pedidos, repassando o conteúdo ao cliente de forma transparente, como se ele mesmo tivesse processado a requisição.

Um uso típico de um proxy reverso é permitir que os usuários da internet tenham acesso a um servidor que está atrás de um firewall em uma rede interna. Também pode ser usado para balancear a carga entre alguns servidores back-ends em um cluster de servidores por exemplo (Engelschall, 1998), ou para prover mecanismos de cache para um servidor back-end mais lento.

O Apache pode ser configurado como proxy reverso através da diretiva ProxyPass ou através da flag $[\mathrm{P}]$ na diretiva RewriteRule. Mais detalhes sobre mecanismos de proxy no Apache podem ser obtidos em (APACHE SOFTWARE FOUNDATION, 2007).

\subsection{Algoritmos de Diferenciação de Serviços}

Os algoritmos para prover diferenciação de serviços implementados no protótipo estão divididos em três grupos: algoritmos de reserva de recursos; escalonamento baseado em prioridades; e mecanismos de controle de admissão. A seguir serão descritos os algoritmos implementados no protótipo em cada um dos três grupos citados.

\subsubsection{Algoritmos de Reserva de Recursos}

\section{RSV}


Como abordado no capítulo 4, em (Teixeira, 2004) foi proposto um tipo de algoritmo denominado RSV que tem como objetivo subdividir o cluster de servidores em partições e associar cada partição a uma classe de serviço ou a um conjunto de classes de serviço, de maneira estática. Dessa forma, é feita uma reserva efetiva de uma parcela da capacidade de processamento do servidor implementado, para cada categoria de requisições.

A implementação desse algoritmo foi feita da seguinte maneira: após a requisição chegar ao sistema e ser classificada, ela é passada para o Controle de Admissão, especificamente para a thread responsável pelo escalonamento das requisições, que consulta a área de variáveis globais para verificar os nós alocados para classe à qual a requisição pertence. Se existir mais de um nó alocado para a classe da requisição, será feito o escalonamento da requisição para algum desses nós por meio do algoritmo round robin. Se houver apenas um nó alocado para a classe da requisição, esta será então escalonada para esse nó.

\section{RSVadap}

O algoritmo RSV tem uma séria limitação. Pelo fato da alocação de nós em cada classe ser feita de maneira estática, ele não é sensível à variação da carga de trabalho, ou seja, caso determinada classe precise de mais recursos para atender à sua demanda, isso não será possível com o algoritmo RSV.

Para suprir essa necessidade foi proposto por (Traldi et al., 2006) uma variação do RSV que fosse capaz de se adaptar dinamicamente à variação da carga de trabalho, surgindo assim o RSVadap (Reserva Adaptativa de Recursos). Seu objetivo é fazer a alocação dos recursos do sistema para as classes dos usuários sob demanda, segundo a carga de trabalho vigente. Em um Web Server distribuído, esses recursos podem ser os nós do cluster. O algoritmo se baseia no número de requisições de cada classe presente no sistema no momento da análise e no nível de diferenciação pretendido para a alocação dos recursos.

Adotam-se $\mathrm{nr}_{X}$ como sendo o número de requisições da classe $\mathrm{X}$ no sistema e $\mathrm{nn}_{X}$ como o número de nós do cluster reservados para a mesma classe em um determinado momento. Considerando duas classes de requisições, $\mathrm{X}$ e Y, com X possuindo prioridade sobre Y, o algoritmo decide pela alocação de mais um nó na classe X, caso $\frac{n r_{X}}{n n_{X}}>(1$ nd) $\cdot \frac{n r_{Y}}{n n_{Y}}$, onde nd é um valor entre 0 e 1 e representa o nível de diferenciação esperado entre as classes. Caso $\frac{n r_{X} \cdot n n_{X}}{n n_{X}-1}<(1-\mathrm{nd}) \cdot \frac{n r_{Y} \cdot n n_{Y}}{n n_{Y}+1}$, o algoritmo desaloca um nó da classe $\mathrm{X}$ e o aloca na classe $\mathrm{Y}$, pois considera que a classe de maior prioridade, mesmo com um nó a menos, continuará recebendo serviço preferencial em relação à outra classe. A descrição completa desse algoritmo pode ser encontrada em (Traldi et al., 2006).

A implementação do algoritmo RSVadap é semelhante à do RSV, com a diferença de que o número de nós alocados para cada classe é alterado dinamicamente. Para tanto, a thread responsável por monitorar os parâmetros do sistema monitora continuamente o número de requisições de cada classe presente no sistema e o número de nós do cluster 
disponíveis para cada classe. A partir dessas informações é verificado se devem ser alteradas as variáveis que definem o número de nós alocados para cada classe, segundo os critérios estabelecidos pelo algoritmo.

\subsubsection{Escalonamento Baseado em Prioridades}

A diferença dessa abordagem para a anterior é que nesse caso é alterada a ordem na qual as requisições são atendidas pelos nós do cluster. São criados mecanismos de escalonamento nos nós dos servidores que irão atender as requisições, de maneira que se possa priorizar alguma dessas classes. Como apresentado no capítulo 4, em (Teixeira, 2004) são propostos dois tipos de algoritmos de escalonamento baseados em prioridades: Prioridade Rigoroso (Strict Priority Queueing) e Prioridade Adaptativa (PRIadap).

No entanto, da maneira como os algoritmos foram propostos, há a necessidade de mudanças em nível de kernel para que possam ser implementados, pois exigem mudanças na disciplina da fila de conexões que o servidor irá atender. Assim, para os propósitos deste trabalho, foi proposto um novo algoritmo, denominado por PriProcess (Prioridade de Processos), que pudesse ser implementado em nível de usuário.

O algoritmo PriProcess considera duas filas de requisições que serão atendidas por cada nó servidor, uma de baixa prioridade e outra de alta prioridade. Para tanto foram utilizados dois Web Servers Apache executando em cada nó do cluster. Um na porta 80 e outro na porta 8080, e foi aumentada a prioridade dos processos do servidor Apache que irá atender requisições de alta prioridade com o comando nice do Linux. Quando a requisição chega ao Web Switch, ela é classificada e escalonada para um nó por meio do algoritmo round robin, mas a porta para qual deverá seguir depende da sua prioridade.

O Apache, quando iniciado em sua forma de organização padrão para Linux (preforking) (APACHE SOFTWARE FOUNDATION, 2007), cria um conjunto de processos, os quais ficam esperando as requisições para atendê-las. Cada processo atende a uma única requisição de cada vez. Após terminar de atender determinada requisição, o processo retorna ao estado ocioso e fica no aguardo de uma nova requisição. A figura 5.6 ilustra o modelo preforking de atendimento de requisições no Apache.

Quando a requisição chega ao servidor ela fica em uma fila em camadas mais baixas que a camada de aplicação. Essas camadas (rede, transporte, etc) são gerenciadas pelo sistema operacional e, sendo assim, para alterar a ordem do atendimento das requisições são necessárias mudanças no kernel do sistema operacional. A maneira encontrada para prover diferenciação de serviços, sem ter que alterar o kernel do sistema operacional, foi alterar a prioridade dos processos que atendem as requisições. Ou seja, como cada requisição é mapeada para um processo no Apache, se esse processo tiver mais prioridade que outros, a requisição que ele atende também terá. 


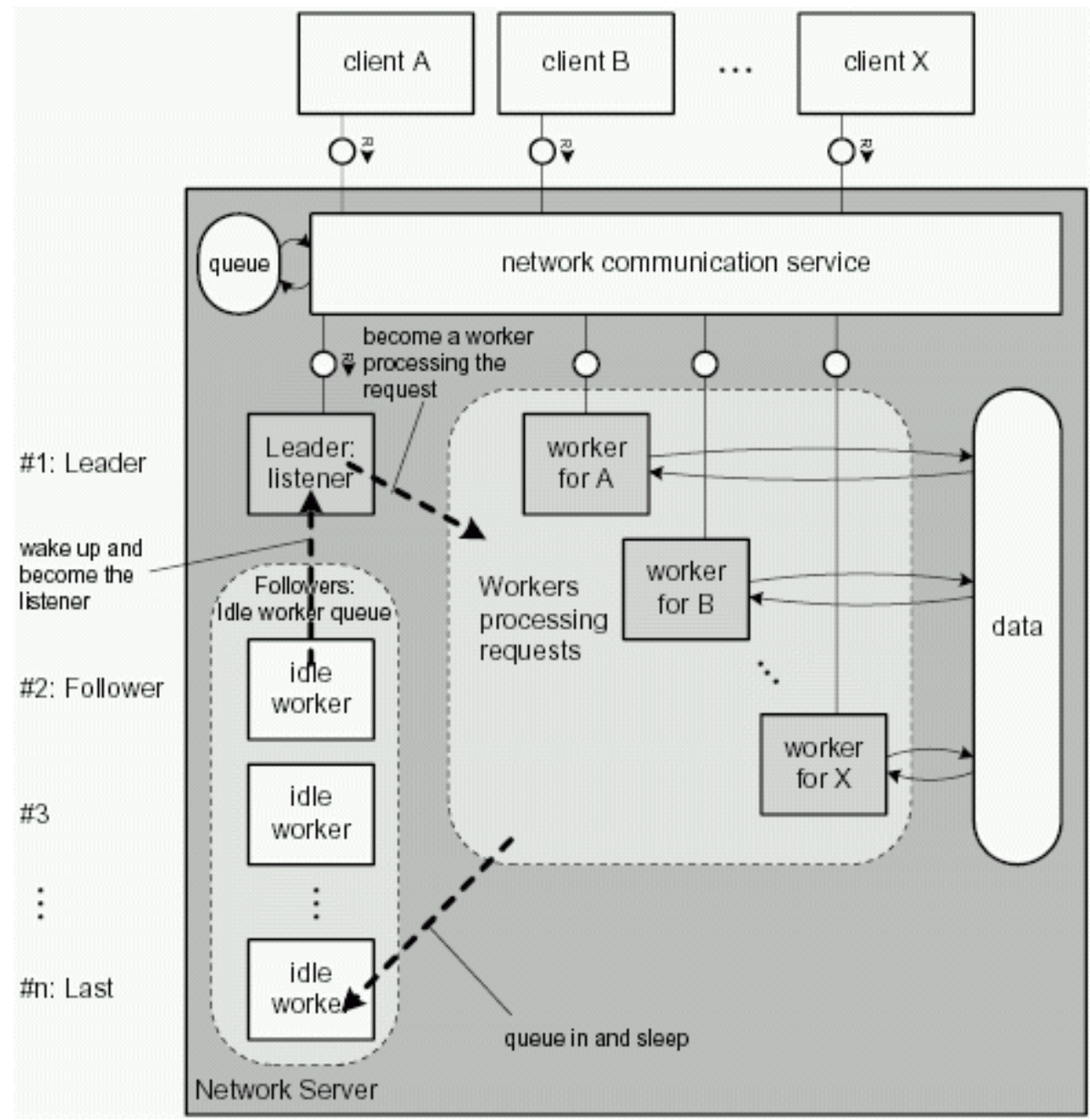

Figura 5.6: Modelo preforking de atendimento de requisições (Gröne et al., 2004).

Portanto, não foi alterada a ordem na qual as requisições são atendidas pelos processos, mas sim a ordem na qual os processos são escalonados para o processador. Isso foi feito de maneira simples e sem alterações no kernel do sistema operacional. Para tanto foram usados dois Apaches executando em cada nó do cluster: um esperando requisições na porta 80 e outro na porta 8080.

A prioridade dos processos do Apache que espera requisições na porta 8080 foi aumentada com o comando nice do Linux, e as requisições de alta prioridade foram escalonadas para essa porta independente de qual nó fosse atendê-las. Sendo assim, espera-se que a fila de requisições de alta prioridade (porta 8080) tenha atendimento melhor que a fila das requisições de baixa prioridade (porta 80). A figura 5.7 ilustra esse processo.

\subsubsection{Mecanismos de Controle de Admissão}

No capítulo 4 foram apresentados três mecanismos de controle de admissão propostos em (Teixeira, 2004). Um mecanismo é baseado no tamanho das filas, outro, por sua vez, 


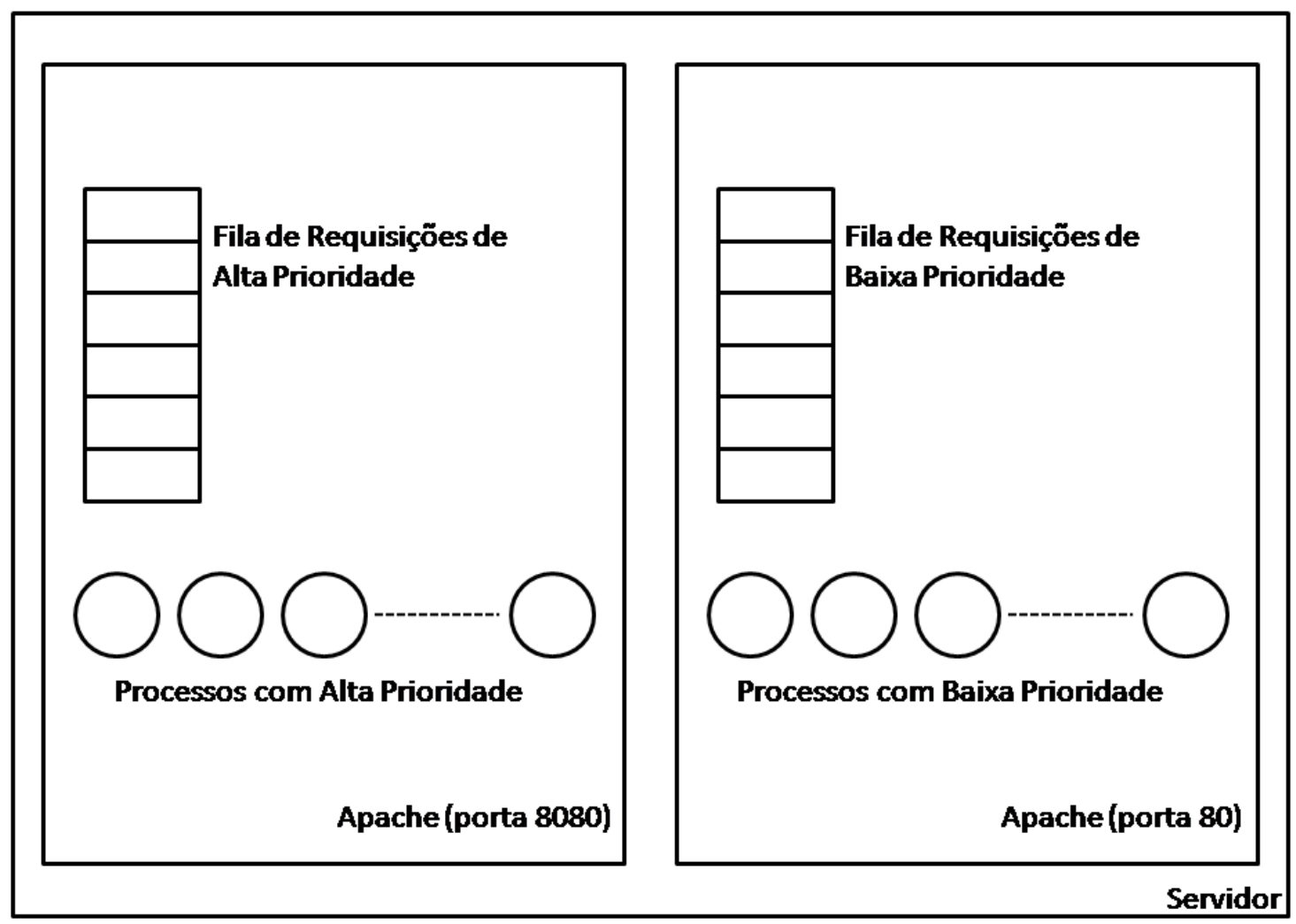

Figura 5.7: Filas de prioridades para o atendimento das requisições.

baseado no tempo de respostas das requisições e, finalmente, um algoritmo baseado na média de utilização do sistema.

Para a implementação no protótipo foi utilizada uma variação da terceira abordagem. Foi considerada a média de utilização do sistema através de dados coletados no arquivo /proc/loadavg do Linux. Esse arquivo contém três valores que indicam, respectivamente, a carga média do sistema no(s) último(s) 1, 5 e 15 minutos. O primeiro valor foi utilizado como referência, ou seja, a carga média do sistema no último minuto. Dois thresholds foram definidos: um para requisições de alta prioridade e outro para requisições de baixa prioridade.

Quando uma requisição chega ao sistema, ela é classificada e escalonada para algum nó do cluster para ser atendida. Caso a carga média no último minuto, do nó para o qual a requisição foi escalonada, não tenha ultrapassado o threshold definido para a classe à qual ela pertence, ela é atendida, caso contrário é descartada.

\subsection{Arquitetura de Testes}

Para realização dos experimentos visando a avaliação do protótipo proposto e implementado, foi utilizado um conjunto de 10 máquinas para simular os clientes, interconectadas ao Web Cluster através de um switch 100 Mbps Fast-Ethernet. O Web Cluster é 
composto por 6 máquinas, das quais 2 são utilizadas para implementar o Web Switch de maneira distribuída, diminuindo assim as chances deste se tornar um gargalo do sistema e 4 Web Servers para atender as requisições. Todas as máquinas que formam o Web Cluster utilizam a versão 2.2.4 do Web Server Apache (APACHE SOFTWARE FOUNDATION, 2007).

Cada máquina possui a seguinte configuração: Processador Pentium 4 HT de 3, 4 Ghz, 1 GB de memória, interface de rede 3Com 3C905C-TX-M 10/100 PCI e um disco rígido SAMSUNG SATA 7200 RPM com 120GB de capacidade. Todas as máquinas utilizam a distribuição $K U B U N T U$ do sistema operacional Linux com kernel 2.6.17. A figura 5.8 mostra a arquitetura utilizada nos testes.

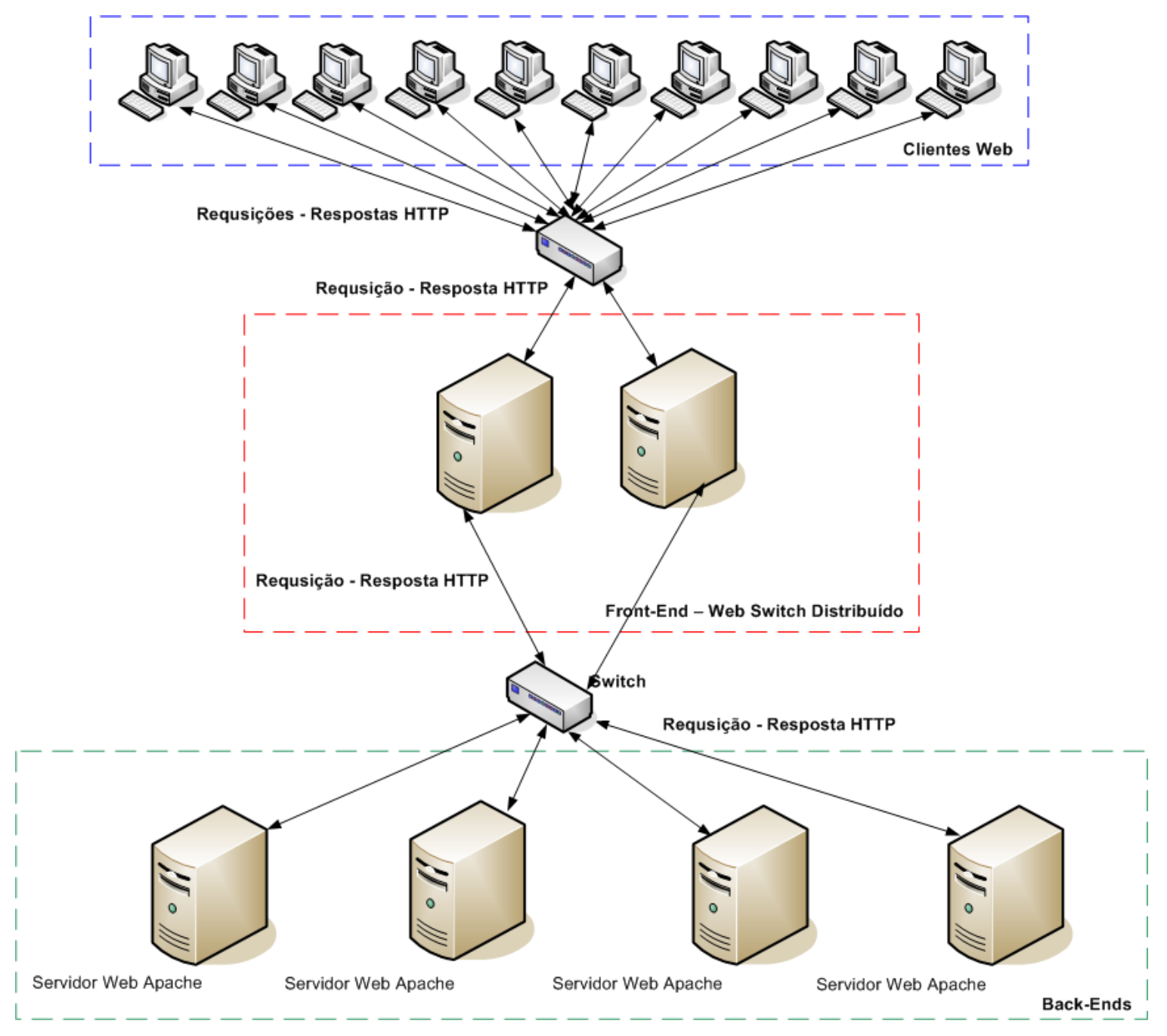

Figura 5.8: Arquitetura de Testes

Como gerador de carga sintética foi utilizada a versão 0.8 do Httperf (Mosberger \& Jin, 1998), em uma versão modificada para que pudesse gerar as requisições para um Web Switch distribuído.

Foram considerados dois tipos de carga de trabalho. Uma carga de trabalho sintética, composta por arquivos que seguem o modelo descrito pelo SURGE (Barford \& Crovella, 
1998), como mostra a tabela 5.1, acrescida de $15 \%$ de requisicões dinâmicas do tipo CGI, das quais $10 \%$ são $C P U$-Bound e $5 \%$ são Disk-Bound. Os valores considerados para a porcentagem de requisições dinâmicas e, para distribuição destas entre $C P U$-Bound e Disk-Bound, foram baseados nos trabalhos de Castilho (2006) e de Sabo (2006). E um segundo tipo, que é uma carga sintética, hipotética, composta 100\% por requisições dinâmicas com alto consumo de CPU.

\begin{tabular}{|c|c|c|c|}
\hline \hline Componente & Modelo & Função Densidade Probabilidade & Parâmetros \\
\hline \hline Tamanho de Arquivos - Corpo & Lognormal & $p(x)=\frac{1}{x \sigma \sqrt{2 \pi}} e^{-(\ln (x)-\mu)^{2} / 2 \sigma^{2}}$ & $\mu=9.357 ; \sigma=1.318$ \\
\hline \hline Tamanho de Arquivos - Cauda & Pareto & $p(x)=\alpha K^{\alpha} x^{-\alpha+1}$ & $k=133 K ; \sigma=1.1$ \\
\hline \hline Popularidade & Zipf & & \\
\hline \hline Localidade Temporal & Lognormal & $p(x)=\frac{1}{x \sigma \sqrt{2 \pi}} e^{-(\ln (x)-\mu)^{2} / 2 \sigma^{2}}$ & $\mu=1.5 ; \sigma=0.80$ \\
\hline
\end{tabular}

Tabela 5.1: Modelo de carga utilizado no SURGE

\subsection{Considerações Finais}

Neste capítulo foi apresentada a arquitetura e as decisões de implementação do protótipo do SWDS, mostrando como foi feito o mapeamento do modelo e dos algoritmos propostos em (Teixeira, 2004) para um ambiente real e, como o Web Server Apache foi utilizado para implementar um cluster de servidores $W e b$, dando suporte aos algoritmos de diferenciação de serviços propostos.

Foi abordado como foram utilizados os módulos mod_proxy e mod_rewite para implementar um proxy reverso utilizando o Apache. Também foram apresentadas as vantagens e desvantagens da utilização de um Web Switch layer 7 two-way, utilizado nesta implementação.

Por fim, foi apresentada a arquitetura de testes do sistema com a configuração das máquinas utilizadas, arquitetura de rede, além da especificação da carga de trabalho utilizada para os experimentos.

No próximo capítulo serão apresentados os resultados obtidos com os experimentos realizados e uma discussão sobre os mesmos, com uma comparação entre os algoritmos implementados. 


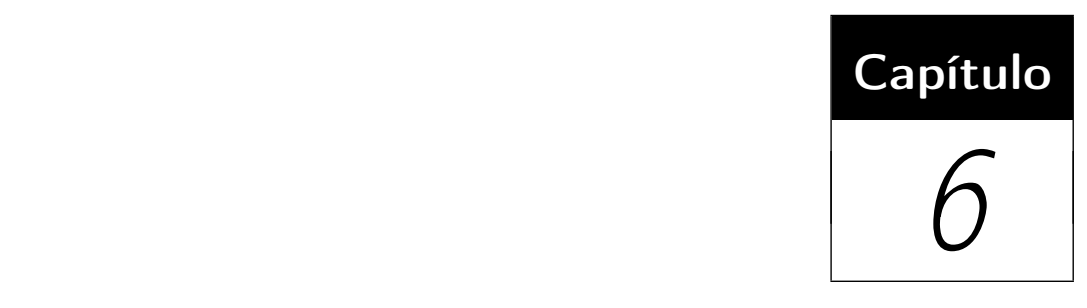

Resultados Experimentais

\subsection{Considerações Iniciais}

No capítulo anterior foi apresentada a arquitetura proposta e implementada para o protótipo de um servidor web com diferenciação de serviços, baseado no SWDS, abordando os seus principais componentes, tais como o Classificador, o Controle de Admissão e o cluster de servidores Web, além da implementação dos algoritmos propostos.

Neste capítulo serão apresentados os resultados obtidos através dos experimentos realizados com o sistema. Primeiro serão apresentados os resultados referentes aos algoritmos baseados em reserva de recursos, o RSV e o RSVadap. Em seguida serão apresentados os resultados para o algoritmo que utiliza a abordagem de escalonamento baseado em prioridades, o PriProcess e, finalmente, os resultados da utilização do PriProcess somado a mecanismos de controle de admissão.

Os resultados dos experimentos visam a verificar se os algoritmos propostos e implementados no protótipo conseguem fornecer QoS relativa entre as classes consideradas e se fazem isso de maneira eficiente, ou seja, se os resultados obtidos com os algoritmos são melhores do que os resultados obtidos sem os mesmos.

Como métrica para comparação está sendo considerada a média dos tempos de respostas fim a fim, medidos nos clientes, isto é, considerando o tempo de resposta da rede e do servidor. 


\subsection{Algoritmos de Reserva de Recursos}

\subsubsection{Introdução}

Nesta seção serão analisados os resultados obtidos com a utilização dos algoritmos de reserva de recursos, RSV e RSVadap. Primeiro serão considerados os resultados no caso onde o sistema é submetido a uma carga de trabalho sintética, composta majoritariamente por requisições estáticas, descrita no capítulo 5 e depois com a utilização de uma carga sintética hipotética, composta $100 \%$ por requisições dinâmicas que exigem maior processamento por parte do servidor.

\subsubsection{Planejamento dos Experimentos}

Com o protótipo implementado (seção 5.2) e a arquitetura de testes definida (seção 5.4), seguiu-se para o planejamento e execução dos experimentos. Para avaliar os algoritmos baseados em reserva de recursos aqui propostos, foram considerados dois tipos de carga de trabalho como descrito na seção 5.4, uma composta majoritariamente por requisições estáticas, com parâmetros que se assemelham a uma carga padrão da Web e outra hipotética composta somente por requisições dinâmicas com alto consumo de CPU.

Nos experimentos, o cluster de servidores Web é dividido de acordo com a quantidade de classes consideradas. As requisições que chegam ao sistema são classificadas em duas classes, de alta e baixa prioridade, pelo módulo Classificador do protótipo, sendo atribuídas aos nós do cluster alocados para a classe à qual elas pertencem, segundo um esquema de rodízio (ver descrição dos algoritmos na seção 5.3.2). A taxa de chegada das requisições varia de 100 em 100 requisições por segundo, iniciando com 500 requisições por segundo e indo até o servidor ou a rede ficarem sobrecarregados.

Os experimentos foram executados 3 vezes, com duração de 15 minutos cada, para cada valor obtido no caso do segundo tipo de carga de trabalho (dinâmica) e 6 vezes, com duração de 15 minutos cada, para cada valor obtido no caso do primeiro tipo de carga de trabalho (estática), pelo fato desta última ter mais parâmetros a serem considerados. As métricas de desempenho utilizadas são a média dos tempos de respostas para o atendimento das requisições e o percentual de requisições completadas com sucesso, para ambas as classes consideradas.

Para analisar sob quais fatores os algoritmos baseados em reserva de recursos implementados no protótipo são adequados, foram definidos alguns cenários através da variação de alguns parâmetros. Um deles é a carga de trabalho, como descrito anteriormente. A princípio seria usado apenas o primeiro tipo de carga, composta majoritariamente por requisições estáticas, mas como não foi possível sobrecarregar o servidor com essa carga, 
decidiu-se usar também um segundo tipo de carga, composta somente por requisições dinâmicas com alto consumo de CPU.

Outro parâmetro é a porcentagem de requisições da classe de alta prioridade presente no sistema. Por meio desse parâmetro especificaram-se situações onde essa classe tinha recursos suficientes para ter privilégios em seu atendimento e outras onde esses recursos não eram suficientes para isso. Foram considerados dois algoritmos de diferenciação de serviços baseados em reserva de recursos, um que divide o cluster de maneira estática e outro que divide dinâmicamente, podendo se adaptar à variação de carga. O número de nós alocados para cada classe inicialmente, não variou. Também foi considerado um algoritmo de balanceamento de carga (round-robin), afim de compará-lo com os algoritmos de diferenciação de serviços.

Para a avaliação dos algoritmos baseados em reserva de recursos, o módulo de Controle de Admissão foi utilizado apenas para o escalonamento das requisições, não provendo nenhum mecanismo para controlar a carga no sistema. Os resultados apresentados estão dentro de um intervalo de confiança de $95 \%$.

\subsubsection{Carga de trabalho sintética, composta majoritariamente por requisições estáticas}

Os resultados apresentados nesta subseção foram alcançados através da submissão do sistema a uma carga de trabalho sintética composta majoritariamente por requisições estáticas, ou seja, que se assemelham à carga de trabalho padrão existente na $W e b$, baseada nos estudos apresentados em (Barford \& Crovella, 1998) e (Castilho, 2006). A seguir serão apresentados os resultados para os dois algoritmos baseados em reserva de recursos considerados neste trabalho, o RSV e o RSVadap.

\section{RSV}

Inicialmente serão apresentados os resultados obtidos com a utilização do algoritmo RSV considerando $20 \%$ de requisições da classe 1 (alta prioridade) e $80 \%$ de requisições da classe 2 (baixa prioridade). Foi reservado 1 nó do cluster para as requisições da classe 1 e 3 nós para as requisições da classe 2. Os resultados obtidos podem ser vistos nas figuras 6.1 e 6.2 .

Pelo gráfico apresentado na figura 6.1 não é possível perceber diferença no atendimento entre as classes, ficando suas curvas praticamente sobrepostas. Pode ser observado ainda que quando a taxa de chegada das requisições chega a 1500 requisições por segundo, há um grande aumento na média dos tempos de respostas, passando de menos de 200 milisegundos para mais de 3,5 segundos. A figura 6.2 mostra que nesse ponto requisições começam a não ser completadas, por exceder o tempo máximo de espera do cliente por uma resposta do servidor (timeout), que nesse caso é de 30 segundos. 


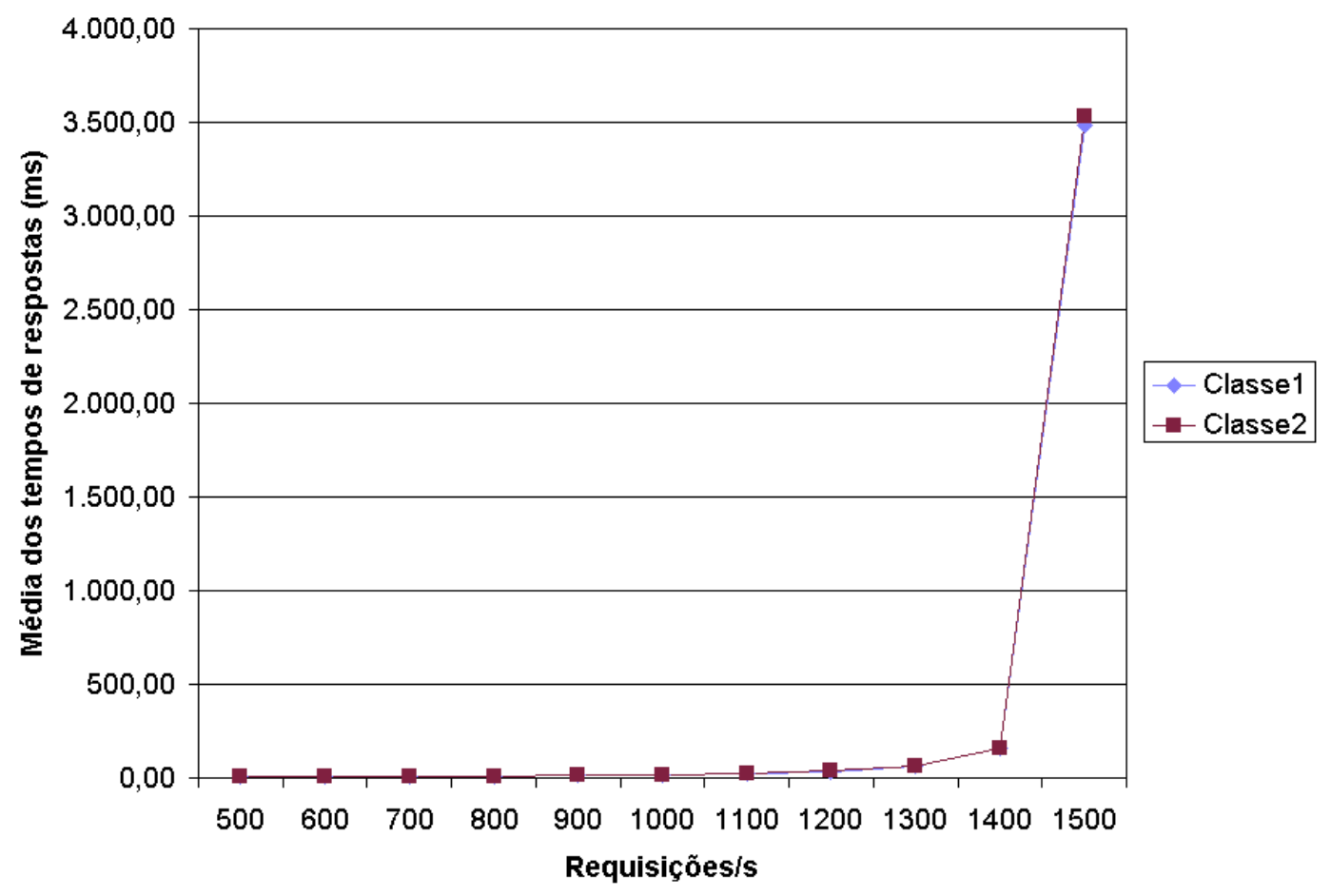

Figura 6.1: Médias dos tempos de respostas para o algoritmo RSV.

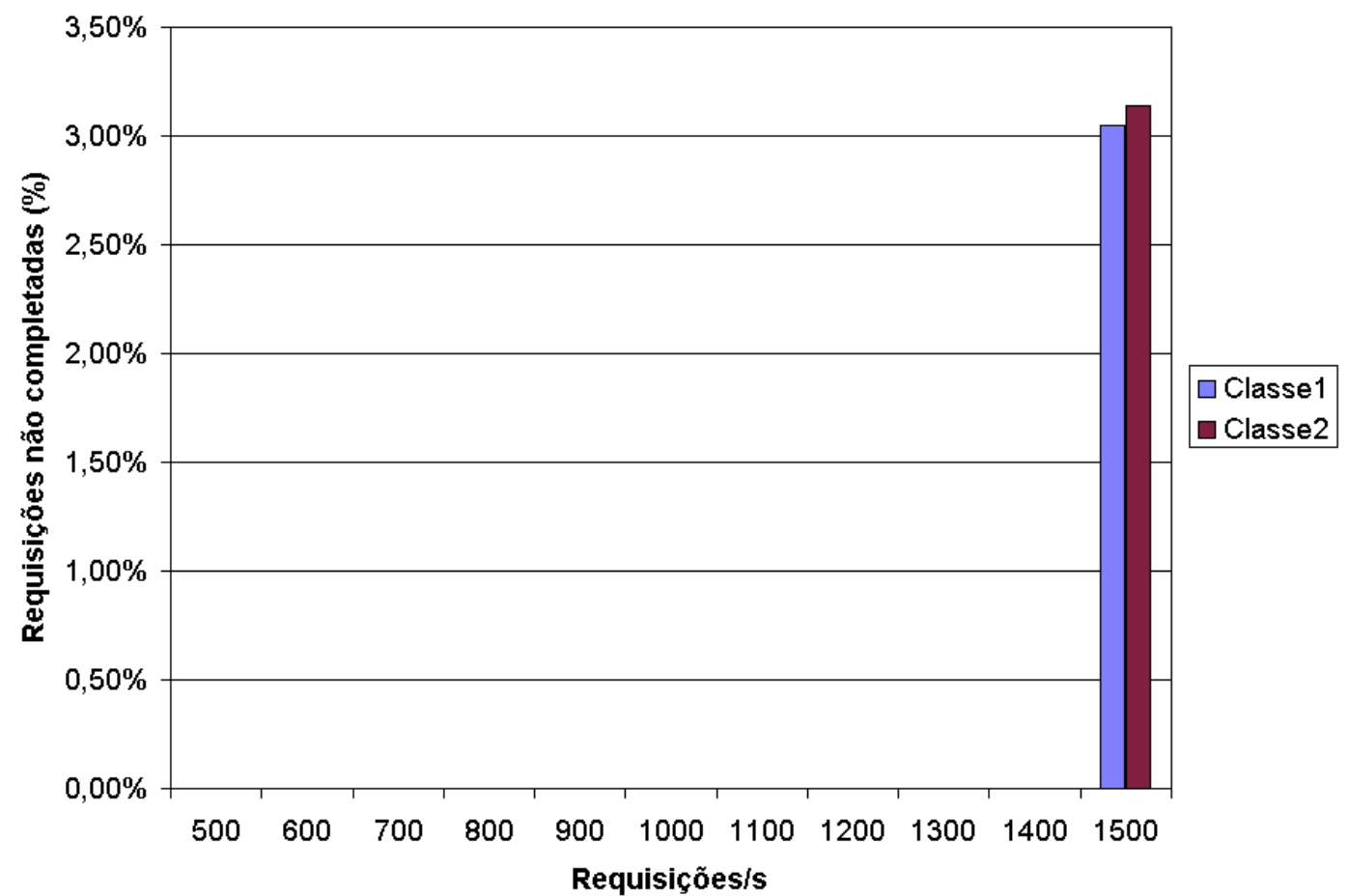

Figura 6.2: Porcentagem de requisições não completadas por ultrapassarem o tempo máximo de espera no cliente (timeout) com a utilização do algoritmo RSV.

A explicação para esse fato é que, quando a taxa de chegada das requisições atinge 1500 requisições por segundo, há uma saturação da rede no ponto de saída das requisições, isto é, no Web Switch. Como mostra a tabela 6.1, cada cliente nesse ponto está consumindo 
16,7 Mbps da rede, totalizando um consumo de $167 \mathrm{Mbps}$ para 10 clientes. Todos os dados partem de um ponto comum, o Web Switch. Como este é composto por duas máquinas distribuídas, cada máquina fica com uma carga total de 167 Mbps dividido por 2, isto é, 83,5 Mbps. Como foi utilizada uma rede Ethernet de $100 \mathrm{Mbps}$, está sendo consumido mais de $80 \%$ da rede no ponto de saída do Web Switch, o que causa saturação (Masterson, 2000).

\begin{tabular}{|l|c|c|c|c|c|c|c|c|c|c|c|}
\hline \hline \multicolumn{10}{|c|}{ Web Switch } \\
\hline \hline $\begin{array}{l}\text { Recurso/Taxa de } \\
\text { Chegada (reqs/s) }\end{array}$ & 500 & 600 & 700 & 800 & 900 & 1000 & 1100 & 1200 & 1300 & 1400 & 1500 \\
\hline CPU & $10 \%$ & $10 \%$ & $15 \%$ & $20 \%$ & $20 \%$ & $25 \%$ & $25 \%$ & $25 \%$ & $30 \%$ & $40 \%$ & $50 \%$ \\
\hline Memória & $20 \%$ & $40 \%$ & $55 \%$ & $70 \%$ & $90 \%$ & $100 \%$ & $100 \%$ & $100 \%$ & $100 \%$ & $100 \%$ & $100 \%$ \\
\hline \hline \multicolumn{8}{|c|}{ Web Server } \\
\hline \hline $\begin{array}{l}\text { Recurso/Taxa de } \\
\text { Chegada (reqs/s) }\end{array}$ & 500 & 600 & 700 & 800 & 900 & 1000 & 1100 & 1200 & 1300 & 1400 & 1500 \\
\hline CPU & $10 \%$ & $10 \%$ & $10 \%$ & $15 \%$ & $15 \%$ & $15 \%$ & $20 \%$ & $20 \%$ & $20 \%$ & $20 \%$ & $20 \%$ \\
\hline Memória & $60 \%$ & $60 \%$ & $60 \%$ & $60 \%$ & $60 \%$ & $65 \%$ & $70 \%$ & $80 \%$ & $90 \%$ & $95 \%$ & $100 \%$ \\
\hline \hline
\end{tabular}

Tabela 6.1: Utilização dos recursos do sistema quando submetido a uma carga de trabalho real

Percebe-se também pela tabela 6.1 que o consumo de CPU nesse instante nos servidores é de apenas 20\%, o que não é suficiente para sobrecarregá-los e ser possível, assim, perceber algum tipo de diferenciação, já que esta só é percebida quando o servidor começa a ser sobrecarregado.

\section{RSVadap}

Foi feito um novo experimento, utilizando-se desta vez o algoritmo RSVadap. Foram consideradas 50\% das requisições da classe 1 e $50 \%$ das requisições da classe 2. Os experimentos foram iniciados com 1 nó alocado para classe 1 e 3 nós alocados para a classe 2. O nível de diferenciação utilizado foi de 0.5. As figuras 6.3 e 6.4 mostram os resultados obtidos.

Percebe-se pela figura 6.3, que ocorre o mesmo comportamento observado no caso do algoritmo RSV, pelos mesmos motivos já citados anteriormente, ou seja, praticamente não houve diferenciação porque a rede atingiu seu ponto de saturação antes que os servidores começassem a ficar sobrecarregados.

\subsubsection{Carga de trabalho sintética, hipotética, composta $100 \%$ por requisições com alto consumo de $\mathrm{CPU}$}

O objetivo de utilizar uma carga sintética, hipotética, foi forçar o servidor a atingir seu ponto de sobrecarga antes da rede, para que fosse possível observar como os algoritmos propostos se comportam nesse caso. 


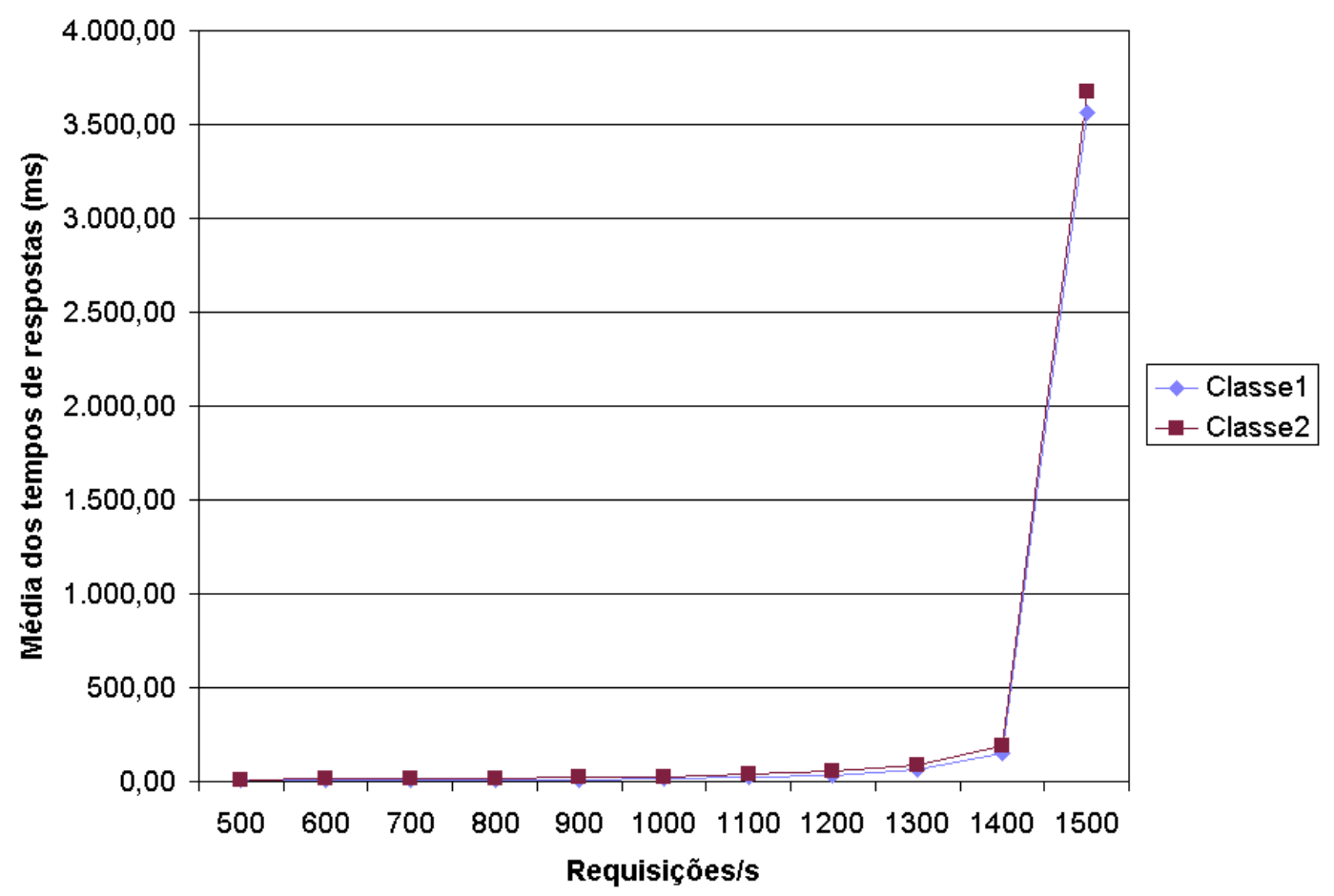

Figura 6.3: Médias dos tempos de respostas para o algoritmo RSVadap.

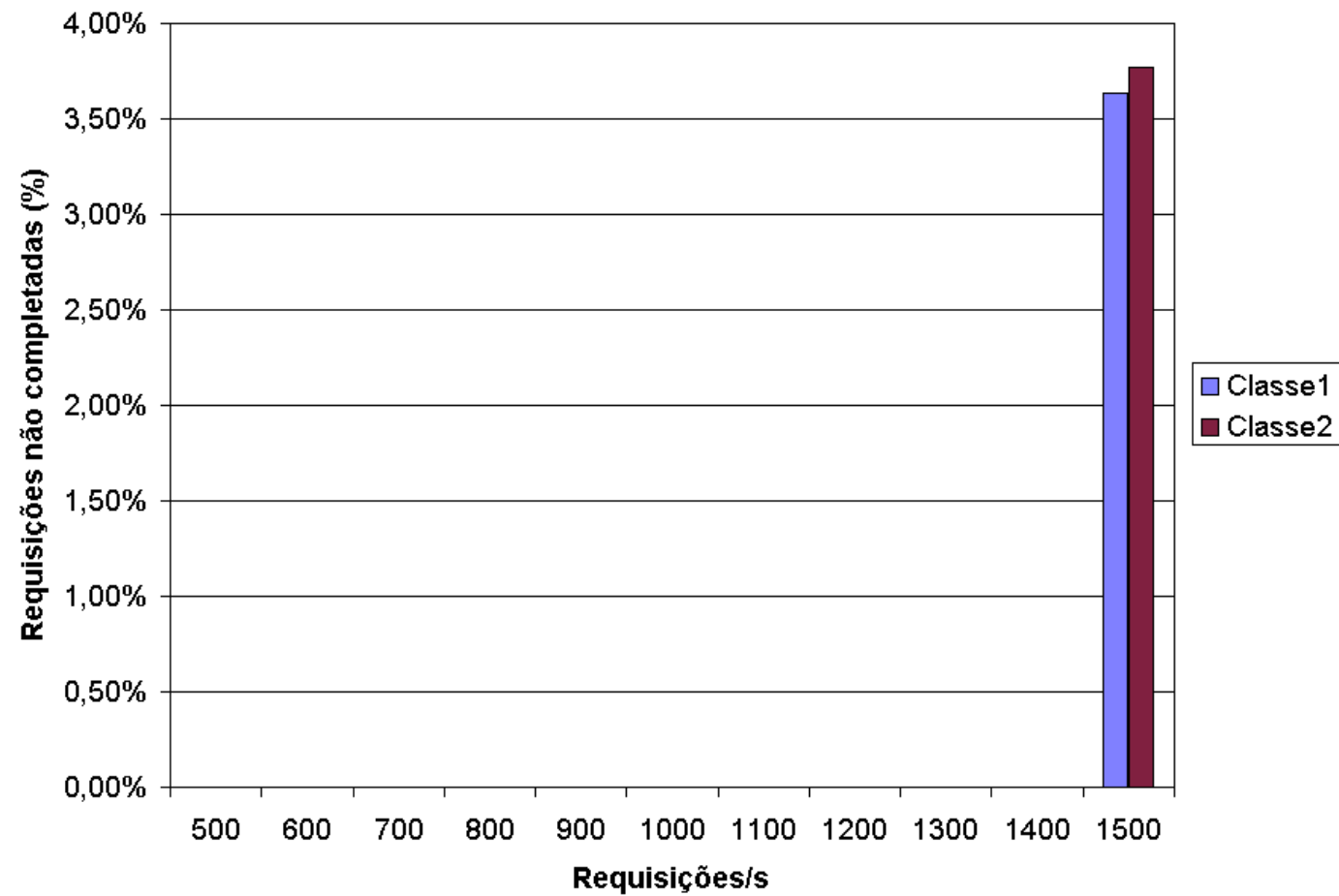

Figura 6.4: Porcentagem de requisições não completadas por ultrapassarem o tempo máximo de espera no cliente (timeout) com a utilização do algoritmo RSVadap.

Primeiro foi feito um experimento com a carga considerada, utilizando o algoritmo Round-Robin, a fim de estabelecer uma base para a comparação dos resultados obtidos com os algoritmos de diferenciação de serviços propostos. Também foi verificado o consumo 
de CPU, memória e rede no sistema, submetido a esse novo tipo de carga de trabalho. A tabela 6.2 mostra os resultados.

\begin{tabular}{|c|c|c|c|c|c|c|c|c|c|c|c|c|c|}
\hline \multicolumn{14}{|c|}{ Web Switch } \\
\hline $\begin{array}{l}\text { Recurso/Taxa de } \\
\text { chegada (reqs/s) }\end{array}$ & 500 & 600 & 700 & 800 & 900 & 1000 & 1100 & 1200 & 1300 & 1400 & 1500 & 1600 & 1700 \\
\hline $\mathrm{CPU}$ & $10 \%$ & $10 \%$ & $10 \%$ & $10 \%$ & $10 \%$ & $15 \%$ & $15 \%$ & $15 \%$ & $15 \%$ & $15 \%$ & $15 \%$ & $20 \%$ & $20 \%$ \\
\hline Memória & $20 \%$ & $40 \%$ & $60 \%$ & $80 \%$ & $90 \%$ & $90 \%$ & $100 \%$ & $100 \%$ & $100 \%$ & $100 \%$ & $100 \%$ & $100 \%$ & $100 \%$ \\
\hline \multicolumn{14}{|c|}{ Web Server } \\
\hline $\begin{array}{l}\text { Recurso/Taxa de } \\
\text { chegada (reqs/s) }\end{array}$ & 500 & 600 & 700 & 800 & 900 & 1000 & 1100 & 1200 & 1300 & 1400 & 1500 & 1600 & 1700 \\
\hline CPU & $25 \%$ & $25 \%$ & $30 \%$ & $35 \%$ & $40 \%$ & $45 \%$ & $50 \%$ & $55 \%$ & $60 \%$ & $70 \%$ & $80 \%$ & $90 \%$ & $100 \%$ \\
\hline Memória & $10 \%$ & $15 \%$ & $20 \%$ & $25 \%$ & $25 \%$ & $25 \%$ & $30 \%$ & $30 \%$ & $35 \%$ & $40 \%$ & $40 \%$ & $45 \%$ & $50 \%$ \\
\hline \multicolumn{14}{|c|}{ Cliente } \\
\hline $\begin{array}{l}\text { Recurso/Taxa de } \\
\text { chegada (reqs/s) }\end{array}$ & 500 & 600 & 700 & 800 & 900 & 1000 & 1100 & 1200 & 1300 & 1400 & 1500 & 1600 & 1700 \\
\hline Rede (Mbps) & 0,5 & 0,6 & 0,7 & 0,8 & 0,9 & 1 & 1,1 & 1,2 & 1,3 & 1,4 & 1,4 & 1,5 & 1,4 \\
\hline
\end{tabular}

Tabela 6.2: Utilização dos recursos do sistema quando submetido a uma carga de trabalho hipotética composta $100 \%$ por requisições com alto consumo de CPU

A tabela 6.2 mostra que durante os experimentos o consumo da rede continuou baixo e foi atingido $100 \%$ de utilização de CPU nos servidores, alcançando assim o objetivo pretendido de sobrecarregar o servidor sem sobrecarregar a rede.

\section{RSV}

Foi utilizado novamente o algoritmo RSV, considerando $20 \%$ de requisições da classe 1 e $80 \%$ de requisições da classe 2 . Foi reservado 1 nó do cluster para as requisições da classe 1 e 3 nós para as requisições da classe 2. As figuras 6.5 e 6.6 mostram os resultados obtidos e uma comparação com o round robin.

Pode-se observar nas figuras 6.5 e 6.6 que o algoritmo RSV foi eficiente para prover diferenciação de serviços entre as classes, privilegiando as requisições de alta prioridade (classe 1) em relação as de baixa prioridade (classe 2), tanto nas médias dos tempos de respostas como na porcentagem de requisições completadas.

Os experimentos mostraram o RSV com desempenho inferior ao Round Robin, até mesmo no atendimento das requisições de alta prioridade. Isto se deve ao fato do Web Switch usar uma arquitetura two-way (já discutida no capítulo 5). Com isso, quando se sobrecarrega algum nó do cluster de servidores, o Web Switch também sente o efeito, pois tem que esperar o processamento das requisições para repassar a resposta ao cliente. Como toda requisição independente de sua classe precisa passar pelo Web Switch, se este for sobrecarregado, todas as requisições ficam prejudicadas.

Por exemplo, nesse caso, considerando-se $20 \%$ de requisições de alta prioridade (classe 1) com $25 \%$ dos recursos (servidores) e, $80 \%$ de requisições de baixa prioridade (classe 2) com $75 \%$ dos recursos, é fácil perceber que $80 \%$ das requisições estão sendo mais prejudicadas que no caso da utilização do algoritmo round robin. Isto gera também uma 


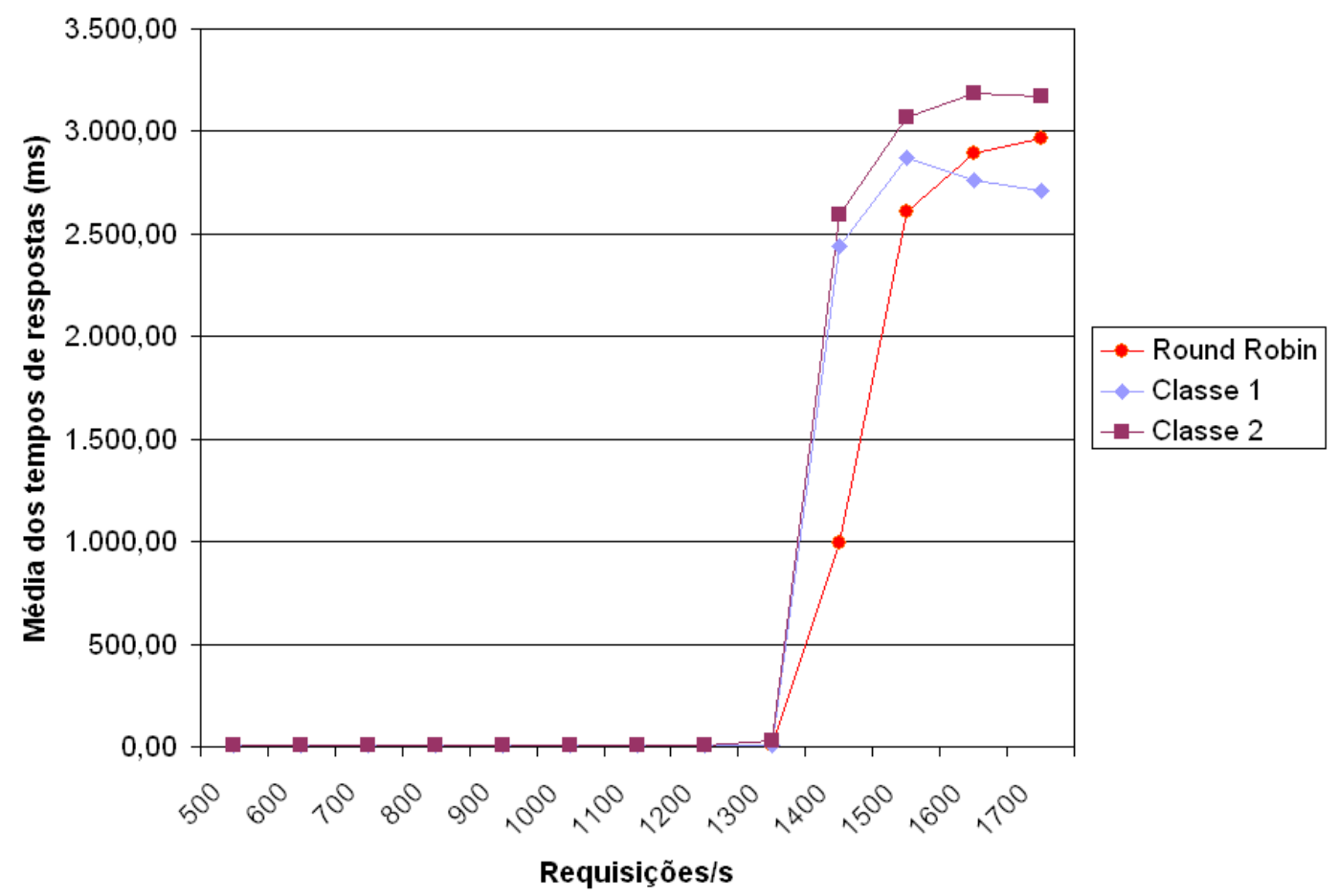

Figura 6.5: Médias dos tempos de respostas para o algoritmo RSV com $20 \%$ de requisições de alta prioridade (carga hipotética).

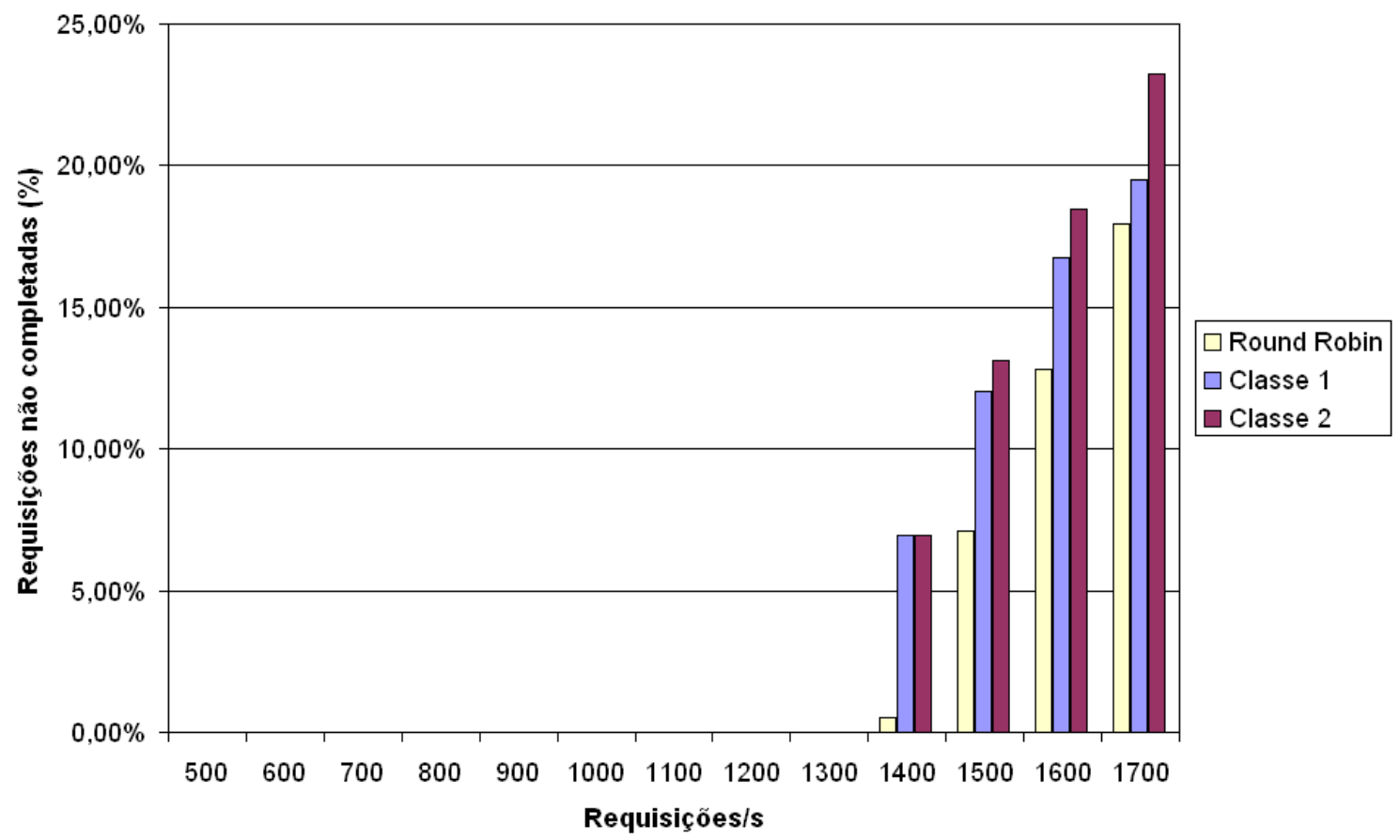

Figura 6.6: Porcentagem de requisições não completadas por ultrapassarem o tempo máximo de espera no cliente (timeout) com a utilização do algoritmo RSV com $20 \%$ de requisições de alta prioridade (carga hipotética).

sobrecarga maior no Web Switch, já que este precisa aguardar a resposta dessas requisições para repassá-la ao cliente. 
Sendo assim, com o Web Switch sobrecarregado, este demora mais para atender as requisições que estão querendo entrar no sistema para serem classificadas e escalonadas, independente da classe a qual pertençam, pois, mesmo que haja recursos ociosos para determinada classe, estes não poderão ser utilizados antes que a requisição seja classificada e escalonada, o que é feito pelo Web Switch, que atende a todas as requisições utilizando-se a política FCFS (First Come First Served).

Portanto, com $80 \%$ das requisições com menos recursos que no caso do algoritmo round robin, sendo assim prejudicadas em seus atendimentos, houve prejuízo também para as $20 \%$ de requisições que ficaram com mais recursos que no caso do algoritmo round robin, pelo fato destas últimas ficarem esperando mais tempo para serem atendidas pelo Web Switch.

A solução para esse problema seria implementar um Web Switch one-way, perdendo assim portabilidade como já discutido no capítulo 5. Alternativamente, pode-se fazer o redirecionamento externo onde, ao invés do Web Switch ter que esperar pela resposta do servidor, ele simplesmente manda uma mensagem de redirecionamento (HTTP 302) que diz ao cliente para se conectar diretamente com o servidor que irá atendê-lo. Entretanto, essa última abordagem leva à perda da transparência e da visão única do sistema, pois o cliente saberia qual servidor que o está atendendo.

Foram feitos novos experimentos com o algoritmo RSV, considerando desta vez $30 \%$ de requisições da classe 1 e $70 \%$ de requisições da classe 2. Assim como anteriormente, foi reservado 1 nó do sistema para as requisições de classe 1 e 3 nós para as requisições da classe 2. O objetivo foi verificar como o algoritmo RSV se comporta com a variação da carga. As figuras 6.7 e 6.8 ilustram os resultados obtidos.

Pode-se observar pelas figuras 6.7 e 6.8 que a variação da porcentagem de requisições de alta prioridade de $20 \%$ para $30 \%$ fez com que se invertesse o resultado esperado de privilegiar esta classe de requisições.

Nota-se também que, diferentemente do caso anterior, neste caso, ambas as classes tiveram melhor desempenho do que quando utilizado o algoritmo round robin, tanto nas médias dos tempos de respostas, quanto na porcentagem de requisições atendidas. Isto se deve ao fato de que neste caso, $70 \%$ das requisições possuem mais recursos disponíveis que no caso do round robin, ou seja, $70 \%$ das requisições possuem $75 \%$ dos recursos.

Com isso, essas requisições passam a ser melhor atendidas e apresentam tempos de respostas menores, aliviando assim a sobrecarga no Web Switch, o que melhora também o desempenho dos outros $30 \%$ de requisições que possuem menos recursos, pois o Web Switch estando menos sobrecarregado, passa a atender de maneira mais rápida também a essas requisições.

\section{RSVadap}




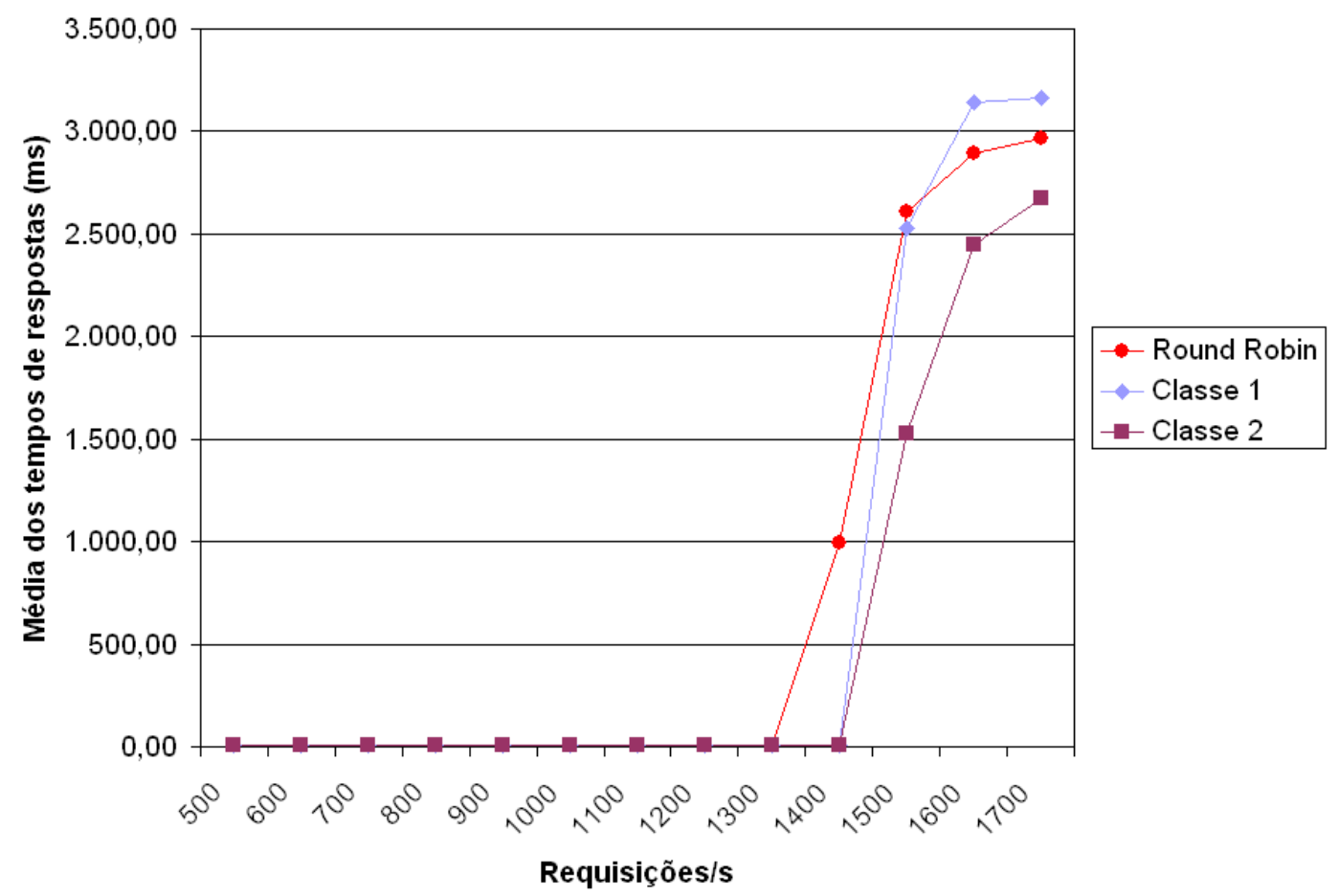

Figura 6.7: Médias dos tempos de respostas para o algoritmo RSV com 30\% de requisições de alta prioridade (carga hipotética).

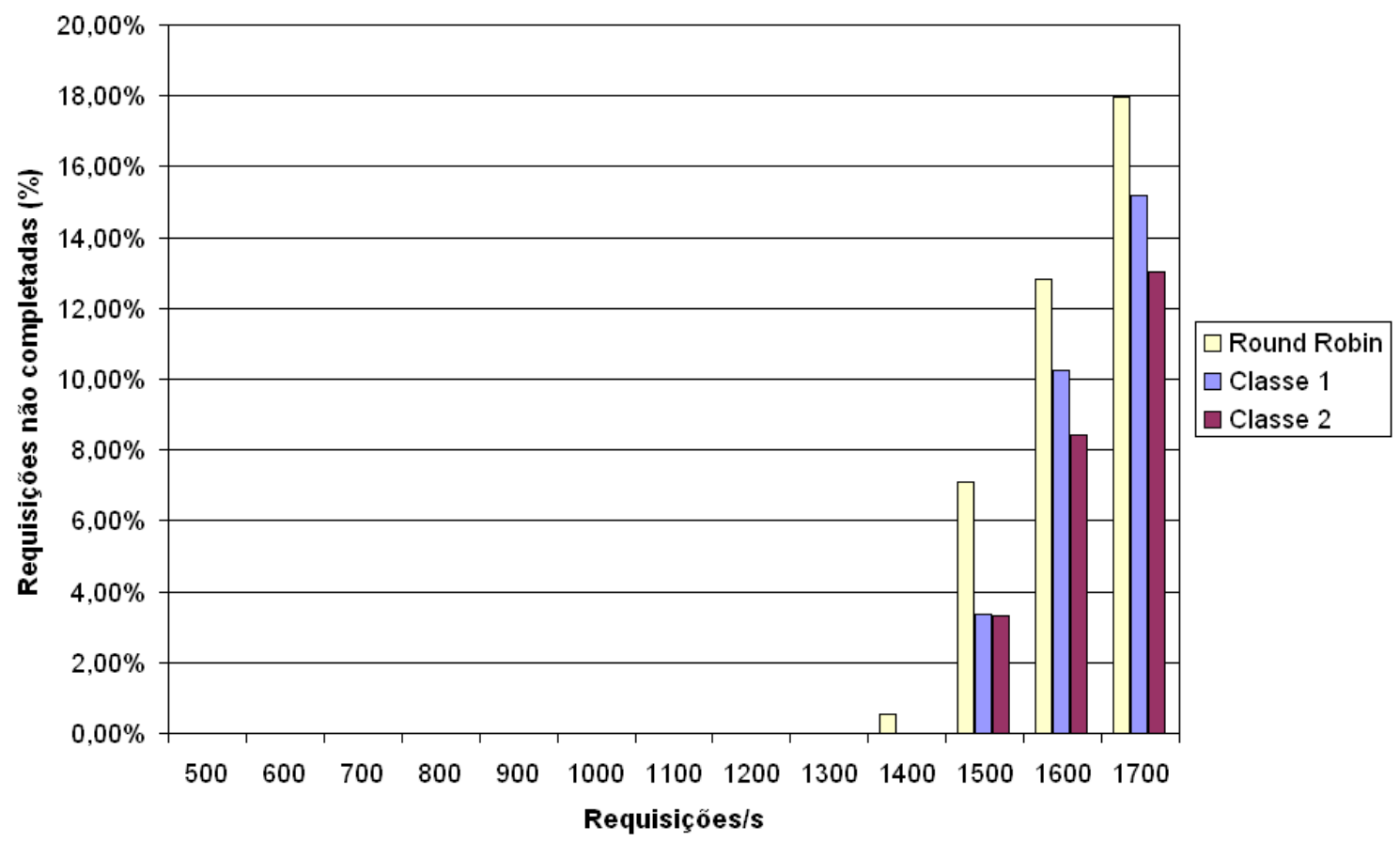

Figura 6.8: Porcentagem de requisições não completadas por ultrapassarem o tempo máximo de espera no cliente (timeout) com a utilização do algoritmo RSV com $30 \%$ de requisições de alta prioridade (carga hipotética).

Foi feito então um novo experimento utilizando o algoritmo RSVadap, considerandose $50 \%$ das requisições da classe 1 e $50 \%$ das requisições da classe 2 . Os experimentos 
foram iniciados com 1 nó servidor alocado para classe 1 e 3 nós servidores alocados para a classe 2 e o nível de diferenciação utilizado foi de 0.5. As figuras 6.9 e 6.10 mostram os resultados obtidos.

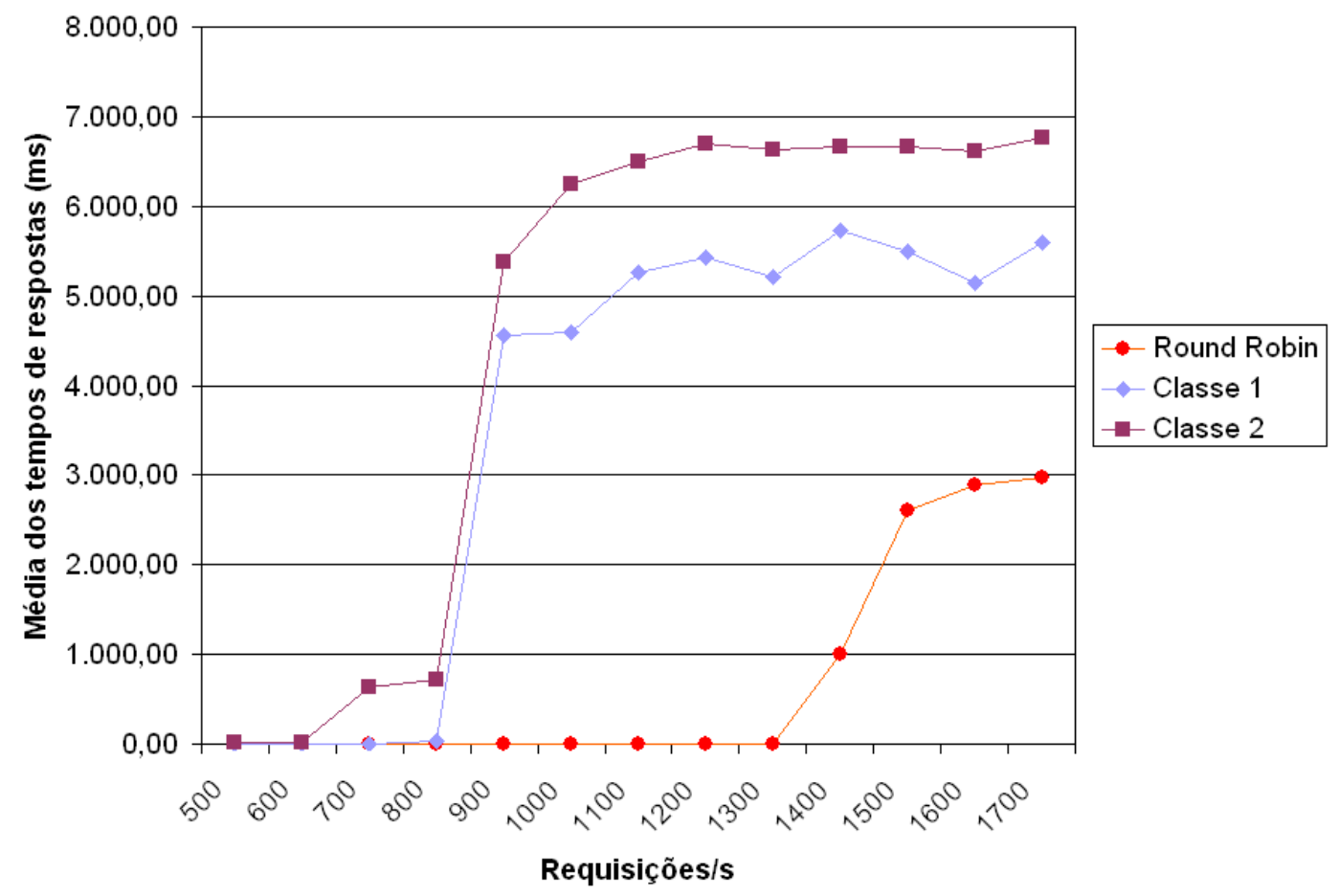

Figura 6.9: Médias dos tempos de respostas para o algoritmo RSVadap com $50 \%$ de requisições de alta prioridade e nível de diferenciação 0.5 (carga hipotética).

Pode-se observar nas figuras 6.9 e 6.10 que o sistema foi capaz de se adaptar à variação da carga de trabalho e o objetivo de privilegiar a classe de alta prioridade foi atingido. No entanto, os tempos de respostas obtidos para essa classe foram bem superiores aos obtidos com o algoritmo round robin. Percebe-se também que as requisições começam a não ser completadas muito prematuramente, em comparação ao round robin, isto é, com 800 requisições por segundo já começa a haver requisições não completadas. Isto se deve ao mesmo motivo já explicado anteriormente no caso do algoritmo RSV e nesse caso se agravou ainda mais, porque quando o atendimento de uma determinada classe fica muito prejudicado, como conseqüência, o de todas as outras também ficam, porque o Web Switch tem que esperar as respostas das requisições para repassá-las aos clientes e não consegue atender as requisições que chegam ao sistema.

Nesse caso, após iniciar os experimentos, o algoritmo ajustou os nós reservados para cada classe, alocando 3 nós para a classe de maior prioridade e 1 nó para a classe de menor prioridade (ver descrição do algoritmo RSVadap no capítulo 5). Como ambas têm a mesma quantidade de requisições, as requisições da classe de menor prioridade ficaram muito prejudicadas. 


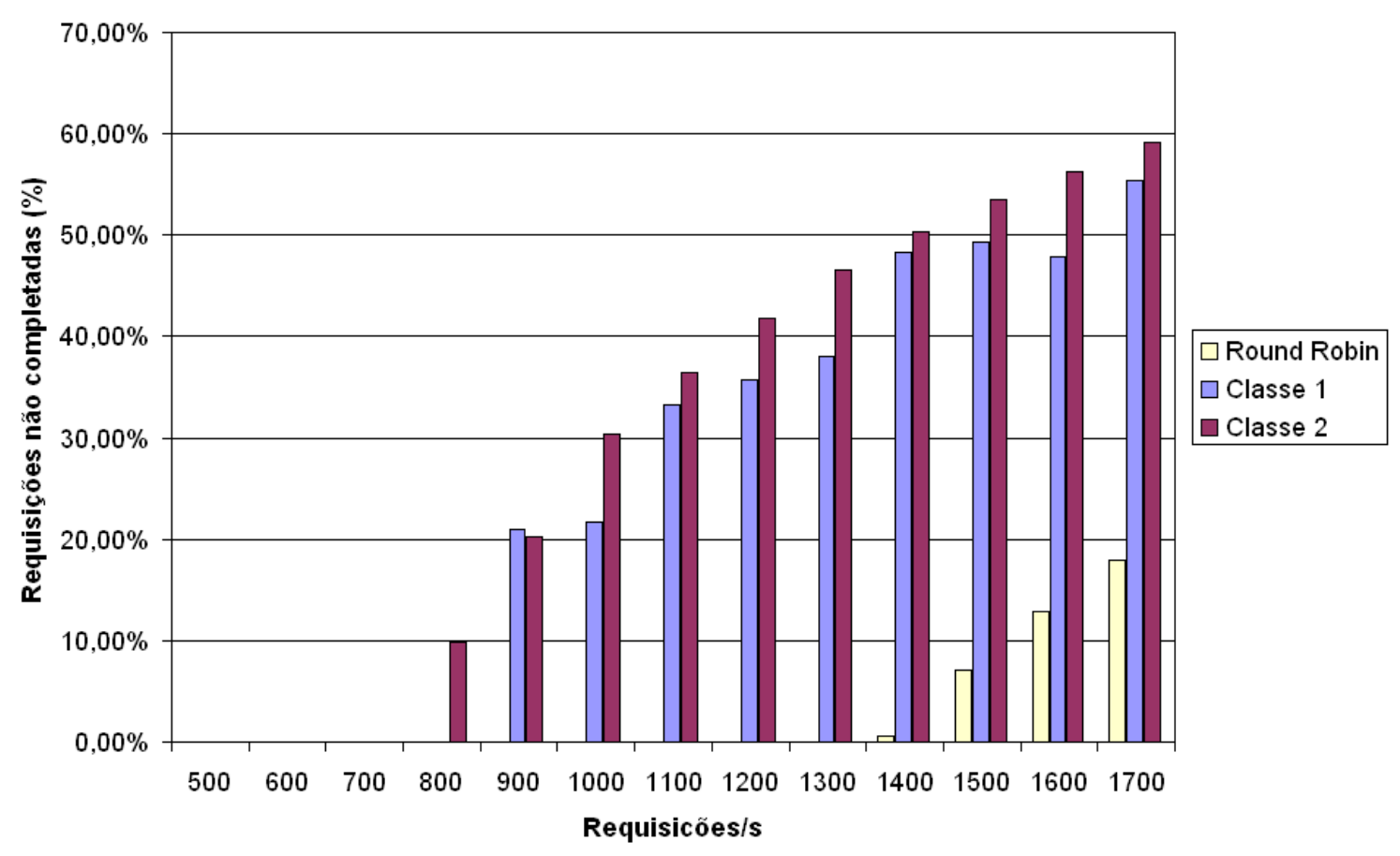

Figura 6.10: Porcentagem de requisições não completadas para o algoritmo RSVadap com $50 \%$ de requisições de alta prioridade e nível de diferenciação 0.5 (carga hipotética).

Sendo assim, se as requisições da classe de baixa prioridade demoram muito para ser atendidas no servidor, o Web Switch vai ficando sobrecarregado, o que prejudica o atendimento das requisições da classe de alta prioridade também.

\subsubsection{Considerações sobre os algoritmos baseados em reserva de recursos}

Os algoritmos de reserva de recursos se mostraram eficientes no sentido de prover diferenciação de serviços entre as classes consideradas. Como já discutido em (Teixeira, 2004) e comprovado agora, através de experimentos com o protótipo, o algoritmo RSV é eficiente apenas em situações onde a carga de trabalho é bem definida e pouco variável, pois o mesmo não é sensível à variação da carga.

Por outro lado, o algoritmo RSVadap, como discutido em (Traldi et al., 2006) se mostrou capaz de se adaptar à variação da carga de trabalho e manter a diferenciação desejada, o que pode ser observado através dos experimentos realizados.

Porém, ambos algoritmos se mostraram ineficientes quando comparados com o algoritmo round robin. Isto se deve ao fato da arquitetura do Web Switch ser uma arquitetura two-way, como já discutido anteriormente, o que não possibilita um isolamento total dos recursos disponíveis para cada classe, já que o Web Switch é compartilhado por ambas.

Para melhorar o desempenho dos algoritmos, seria necessária a implementação dos mesmos em um Web Switch one-way, que é mais eficiente que um Web Switch two-way 
(Cardellinni \& Casalicchio, 2002), mas são menos portáveis e mais difíceis de implementar, exigindo mudanças no kernel do sistema operacional tanto das máquinas que farão o papel do Web Switch como das máquinas que serão os servidores Web, o que foge do escopo deste trabalho que visa implementar mecanismos apenas em nível de usuário.

\subsection{Escalonamento Baseado em Prioridades}

\subsubsection{Introdução}

Serão apresentados agora os resultados dos experimentos realizados com a utilização do algoritmo de escalonamento baseado em prioridades proposto no capítulo 5, o PriProcess. A diferença desse algoritmo para os outros baseados em reserva de recursos é que, nesse caso, todas as requisições compartilham todos os recursos do sistema. O escalonamento das requisições buscando priorizar determinada classe é feito nos nós dos servidores que irão atendê-las. O Web Switch, nesse caso, faz apenas o escalonamento de acordo com uma dada política (neste caso o round robin) para escolher qual nó deverá atender determinada requisição, mas sem o objetivo de priorizar qualquer uma destas. Como na seção anterior, foram considerados os dois tipos de carga de trabalho já descritos no capítulo 5 .

\subsubsection{Planejamento dos Experimentos}

Para avaliar o algoritmo de escalonamento baseado em prioridades aqui proposto (PriProcess), assim como na seção 6.2, foram considerados dois tipos de carga de trabalho como descrito na seção 5.4, uma composta majoritariamente por requisições estáticas e outra composta somente por requisições dinâmicas com alto consumo de CPU.

Nos experimentos, as requisições que chegam ao sistema são divididas em duas classes, de alta e baixa prioridade, pelo módulo Classificador do protótipo, sendo atribuídas aos nós do cluster segundo um esquema de rodízio (round robin). A ordem em que serão atendidas em cada nó do cluster depende de suas respectivas prioridades (ver descrição do algoritmo na seção 5.3.2). A taxa de chegada das requisições varia de 100 em 100 requisições por segundo, iniciando com 500 requisições por segundo e indo até o servidor ou a rede ficarem sobrecarregados.

Assim como na seção 6.2, os experimentos foram executados 3 vezes, com duração de 15 minutos cada, para cada valor obtido no caso do segundo tipo de carga de trabalho (dinâmica) e 6 vezes, com duração de 15 minutos cada, para cada valor obtido no caso do primeiro tipo de carga de trabalho (estática). As métricas de desempenho utilizadas são a média dos tempos de respostas para o atendimento das requisições e o percentual de requisições completadas com sucesso, para ambas as classes consideradas. 
Para analisar sob quais fatores o PriProcess é adequado, foram definidos alguns cenários através da variação de alguns parâmetros. Assim como na seção 6.2, um dos parâmetros é a carga de trabalho, como descrito anteriormente. Outro parâmetro é a porcentagem de requisições da classe de alta prioridade presentes no sistema. Por meio desse parâmetro especificaram-se várias situações, variando a porcentagem de requisições de alta prioridade presentes no sistema em 10\%, 30\%, 50\%, 70\% e 90\%. O objetivo da variação desse parâmetro foi verificar como o sistema se comporta em situações extremas, como, por exemplo, quando sobrecarregado por requisições de alta prioridade(90\% classe 1 e $10 \%$ classe 2 ) ou quando sobrecarregado por requisições de baixa prioridade( $10 \%$ classe 1 e $90 \%$ classe 2) e, também em situações onde há um equilíbrio entre as classes $(50 \%$ classe 1 e $50 \%$ classe 2). Também foi considerado o algoritmo round-robin, com o objetivo de compará-lo com o algoritmo aqui proposto.

Assim como na seção 6.2, o módulo de Controle de Admissão foi utilizado apenas para o escalonamento das requisições, não provendo nenhum mecanismo para controlar a carga no sistema. Os resultados apresentados estão dentro de um intervalo de confiança de $95 \%$.

\subsubsection{Carga de trabalho sintética, composta majoritariamente por requisições estáticas}

Inicialmente serão apresentados os resultados obtidos com a utilização do algoritmo PriProcess considerando $50 \%$ de requisições da classe 1 (alta prioridade) e $50 \%$ de requisições da classe 2 (baixa prioridade). Os resultados obtidos podem ser observados nas figuras 6.11 e 6.12 .

Como nos experimentos anteriores, com os algoritmos baseados em reserva de recursos usando essa mesma carga de trabalho, não foi possível notar diferença entre o atendimento das requisições com a utilização do PriProcess. O gráfico apresentado pela figura 6.11 mostra que praticamente não houve diferença no atendimento entre as classes, ficando suas curvas sobrepostas. Os motivos são os mesmos já discutidos anteriormente, ou seja, não foi possível sobrecarregar os servidores com a carga de trabalho considerada.

\subsubsection{Carga de trabalho sintética, hipotética, composta $100 \%$ por requisições dinâmicas com alto consumo de CPU}

Foram repetidos os experimentos, utilizando-se novamente o PriProcess com os mesmos parâmetros citados anteriormente, isto é, considerando $50 \%$ de requisições da classe 1 (alta prioridade) e $50 \%$ de requisições da classe 2 (baixa prioridade). Os resultados obtidos podem ser vistos nas figuras 6.13 e 6.14, comparados com o algoritmo round robin.

Pelos gráficos apresentados nas figuras 6.13 e 6.14 pode-se perceber que o algoritmo PriProcess foi eficiente no sentido de fornecer diferenciação de serviços entre as classes. 


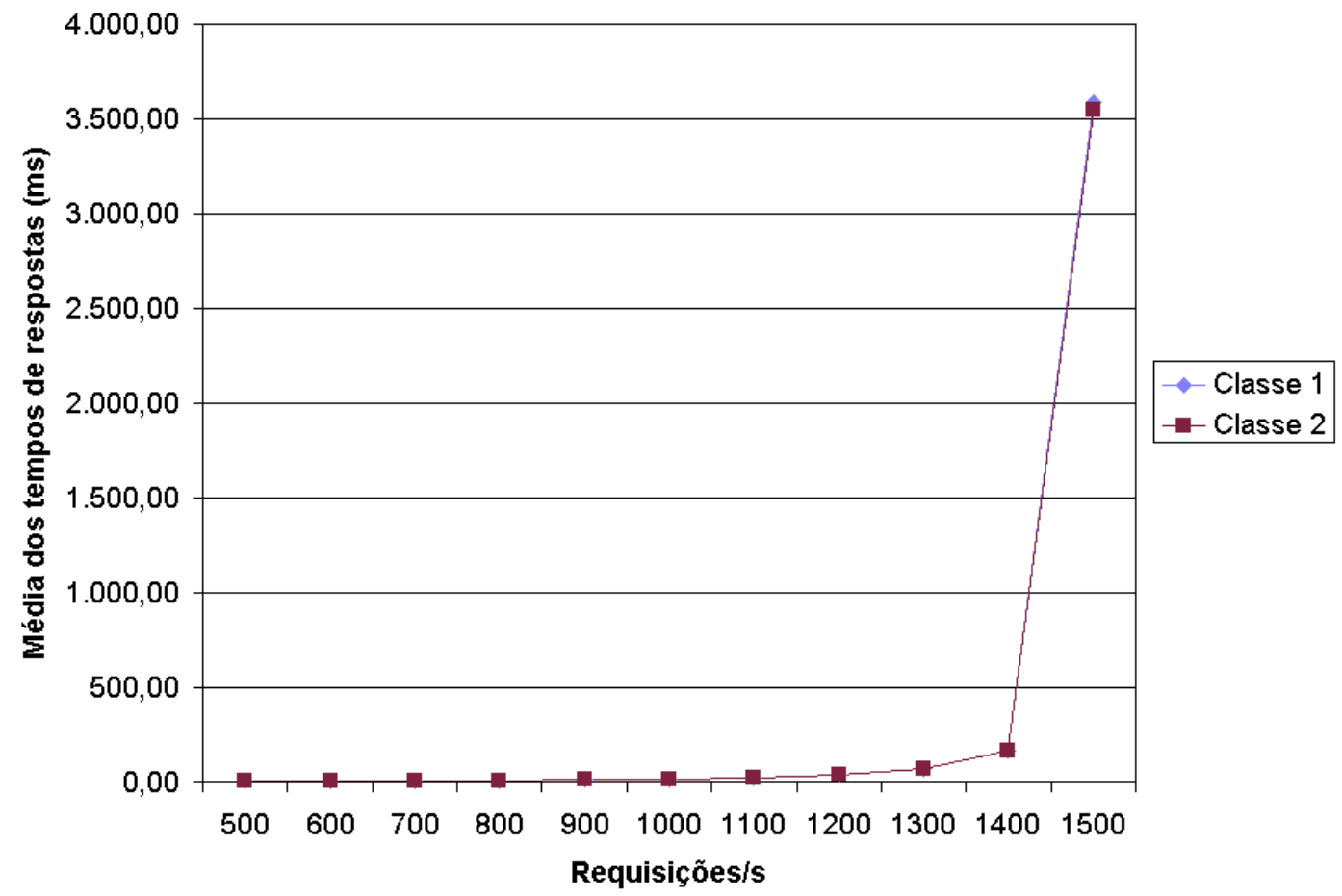

Figura 6.11: Médias dos tempos de respostas para o algoritmo PriProcess com $50 \%$ de requisições de alta prioridade.

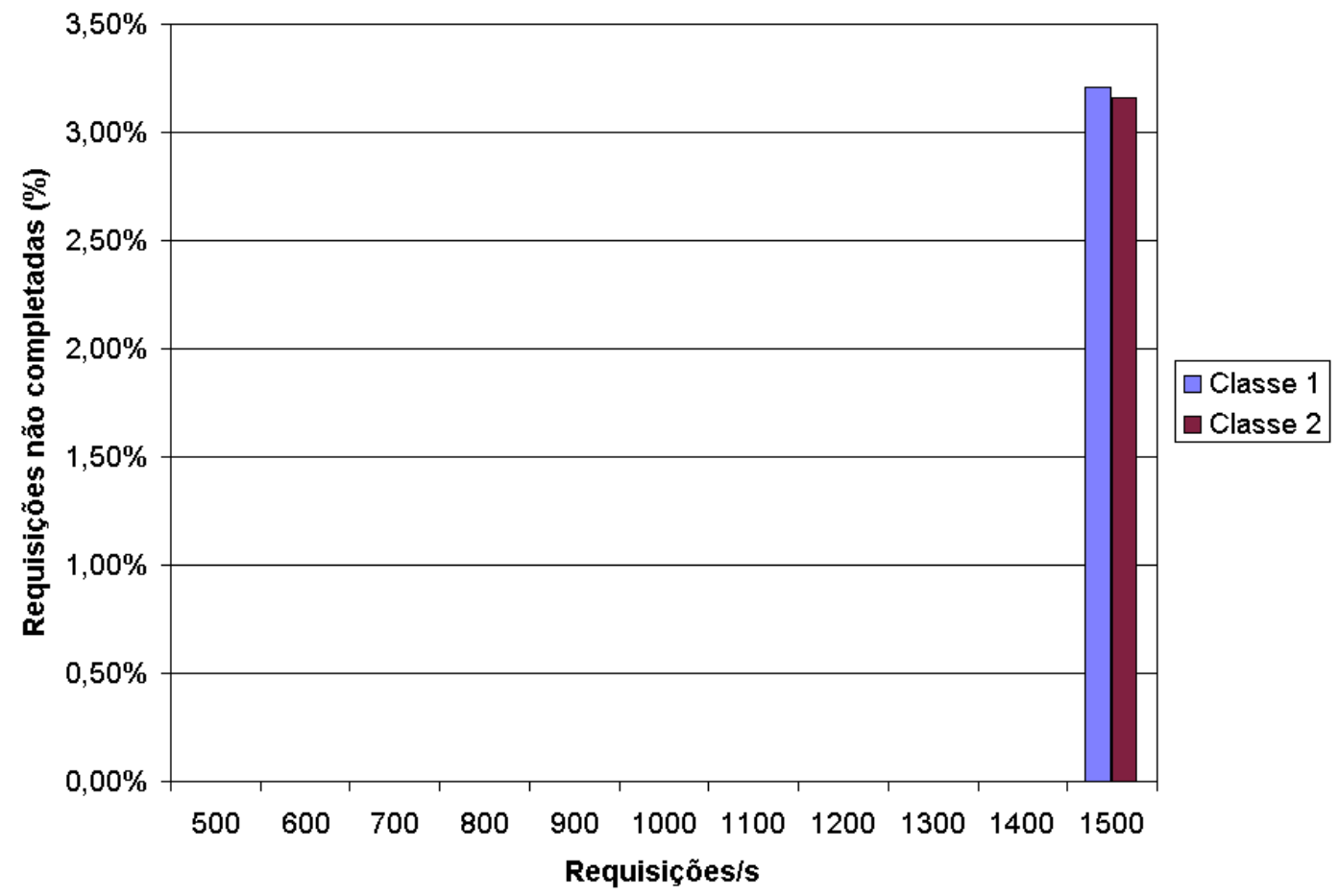

Figura 6.12: Porcentagem de requisições não completadas para o algoritmo PriProcess com $50 \%$ de requisições de alta prioridade.

Tanto a média dos tempos de respostas como a porcentagem de requisições completadas para a classe de alta prioridade, foram melhores que para a classe de baixa prioridade e, 


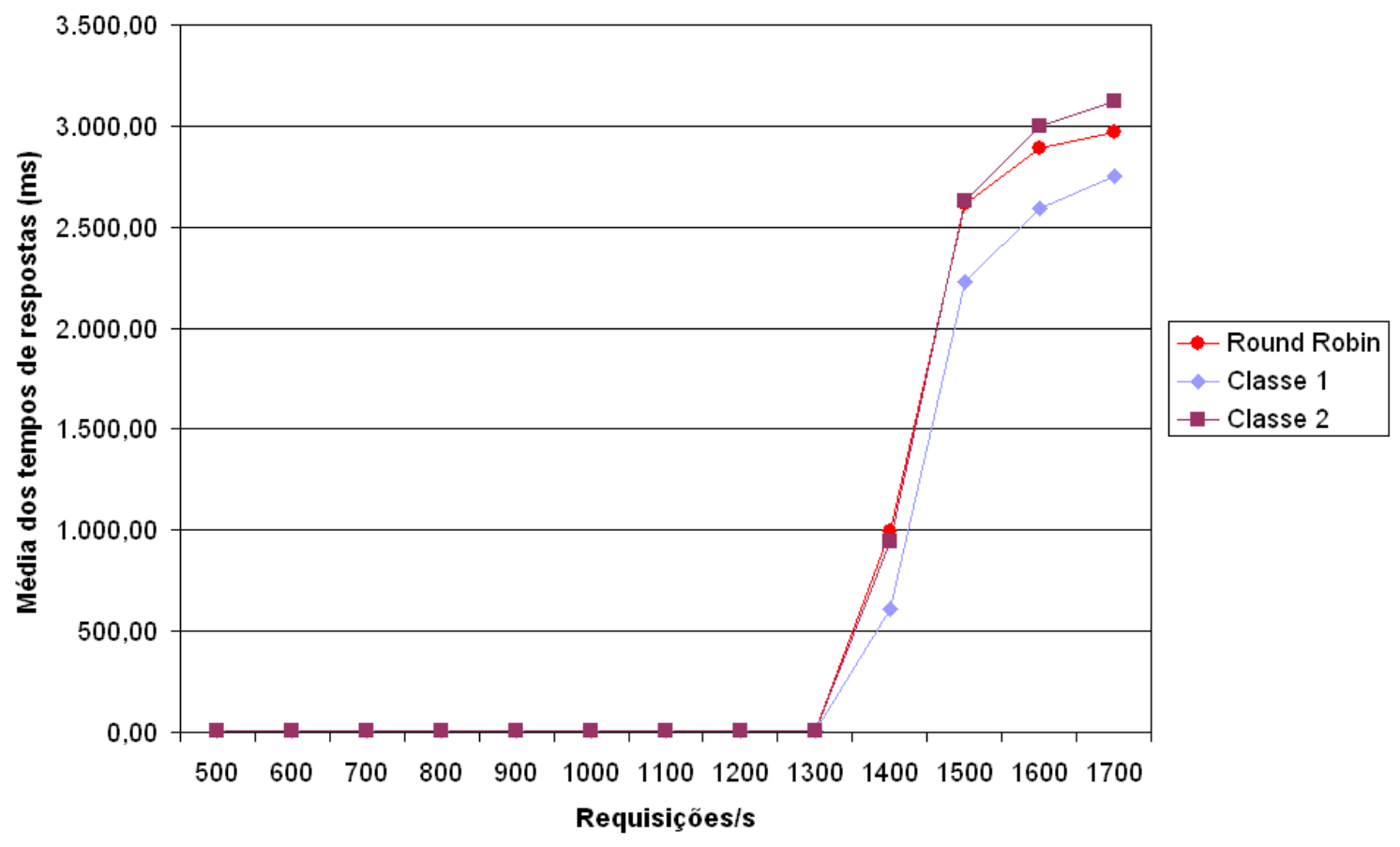

Figura 6.13: Médias dos tempos de respostas para o algoritmo PriProcess com 50\% de requisições de alta prioridade (carga hipotética).

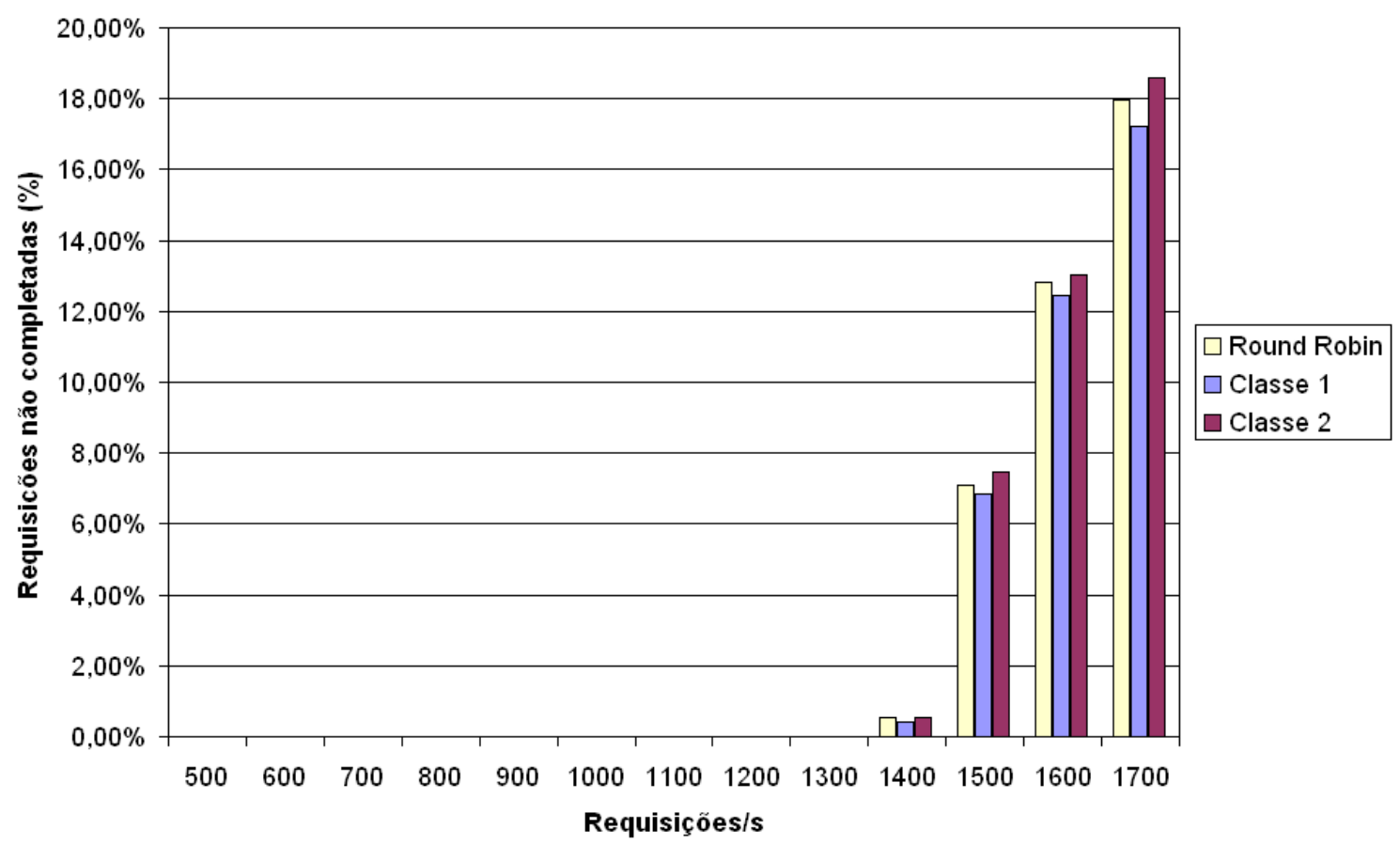

Figura 6.14: Porcentagem de requisições não completadas para o algoritmo PriProcess com $50 \%$ de requisições de alta prioridade (carga hipotética).

também melhores que os resultados obtidos com a utilização do round robin, alcançando assim os seus objetivos. 
A fim de comparar como o algoritmo PriProcess se comporta variando a porcentagem de requisições de cada classe, foram feitos novos experimentos, considerando 10\%, 30\% $70 \%$ e $90 \%$ de requisições de alta prioridade. Foram escolhidas duas taxas de chegada de requisições para ilustrar os resultados, 1500 requisições por segundo, que é o momento onde o servidor começa a ficar sobrecarregado e 1700 requisições por segundo, que é quando o servidor já está bem sobrecarregado. As tabelas 6.3 e 6.4 ilustram os resultados. Os gráficos correspondentes são apresentados no apêndice A.

\begin{tabular}{|c|c|c|c|c|}
\hline Classe/Taxa de chegada & \multicolumn{2}{|c|}{$1500 \mathrm{reqs} / \mathrm{s}$} & \multicolumn{2}{|c|}{$1700 \mathrm{reqs} / \mathrm{s}$} \\
\hline \hline Classe 1/Classe 2 & Classe 1 & Classe 2 & Classe 1 & Classe 2 \\
\hline \hline $10 \% / 90 \%$ & $2,01 \mathrm{~s}$ & $2,59 \mathrm{~s}$ & $2,62 \mathrm{~s}$ & $3,06 \mathrm{~s}$ \\
\hline $30 \% / 70 \%$ & $2,19 \mathrm{~s}$ & $2,62 \mathrm{~s}$ & $2,64 \mathrm{~s}$ & $3,07 \mathrm{~s}$ \\
\hline $50 \% / 50 \%$ & $2,23 \mathrm{~s}$ & $2,63 \mathrm{~s}$ & $2,64 \mathrm{~s}$ & $3,12 \mathrm{~s}$ \\
\hline $70 \% / 30 \%$ & $2,31 \mathrm{~s}$ & $2,81 \mathrm{~s}$ & $2,72 \mathrm{~s}$ & $3,28 \mathrm{~s}$ \\
\hline $90 \% / 10 \%$ & $2,44 \mathrm{~s}$ & $3,11 \mathrm{~s}$ & $2,75 \mathrm{~s}$ & $3,54 \mathrm{~s}$ \\
\hline
\end{tabular}

Tabela 6.3: Comparação das médias dos tempos de respostas (segundos) utilizando o algoritmo PriPocess submetido a diferentes cargas de trabalho

\begin{tabular}{|c|c|c|c|c|}
\hline Classe/Taxa de chegada & \multicolumn{2}{|c|}{1500 reqs $/ \mathrm{s}$} & \multicolumn{2}{|c|}{1700 reqs $/ \mathrm{s}$} \\
\hline \hline Classe 1/Classe 2 & Classe 1 & Classe 2 & Classe 1 & Classe 2 \\
\hline \hline $10 \% / 90 \%$ & $6,5 \%$ & $7,1 \%$ & $15,9 \%$ & $17,1 \%$ \\
\hline $30 \% / 70 \%$ & $6,9 \%$ & $7,1 \%$ & $16,2 \%$ & $18,2 \%$ \\
\hline $50 \% / 50 \%$ & $7,2 \%$ & $7,5 \%$ & $16,7 \%$ & $18,2 \%$ \\
\hline $70 \% / 30 \%$ & $7,5 \%$ & $7,7 \%$ & $17,2 \%$ & $18,6 \%$ \\
\hline $90 \% / 10 \%$ & $8,2 \%$ & $8,5 \%$ & $17,4 \%$ & $18,7 \%$ \\
\hline
\end{tabular}

Tabela 6.4: Comparação da porcentagem de requisições não completadas utilizando o algoritmo PriPocess submetido a diferentes cargas de trabalho

Nota-se pela tabela 6.3 que à medida em que aumenta o número de requisições de alta prioridade, aumenta também a média dos tempos de respostas para ambas as classes. Isto ocorre porque com mais processos de alta prioridade presentes no sistema, há uma maior disputa entre estes para conseguir acesso ao processador e outros recursos do sistema. Os processos de baixa prioridade também ficam prejudicados, porque precisam esperar mais tempo para ter acesso aos recursos do sistema, já que muitos outros processos têm privilégios para acessar esses recursos.

Na tabela 6.4 é possível observar um ligeiro aumento no número de requisições não completadas à medida em que se aumenta o número de requisições de alta prioridade. Isso ocorre pelo mesmo motivo explicado anteriormente, ou seja, com mais requisições de alta prioridade, maior o tempo médio de atendimento para ambas as classes de requisições. Com isso aumentam-se as chances de requisições não serem completadas, por excederem o limite de espera pelo cliente por uma resposta do servidor. 


\subsubsection{Considerações sobre o algoritmo}

Assim como mostrado em (Teixeira, 2004), pode-se comprovar através dos experimentos que os algoritmos de escalonamento baseado em prioridades são mais eficientes que os algoritmos de reserva de recursos, pois todas as classes compartilham todos os recursos do sistema, não correndo o risco assim de algum recurso ficar sobrecarregado enquanto outro está ocioso.

No caso do algoritmo proposto nesta implementação, o PriProcess, os resultados foram bons, com as requisições de alta prioridade sempre sendo melhor atendidas que as de baixa prioridade, mesmo variando-se a carga no sistema. No entanto não foi possível manter tempos de respostas relativamente baixos, mesmo para as requisições de alta prioridade, no momento em que o servidor começou a se sobrecarregar e nem garantir o atendimento de todas as requisições dessa classe.

O PriProcess tem o objetivo apenas de garantir melhor atendimento para requisições de alta prioridade, em qualquer caso, mas não tem como criar recursos que o sistema não possui, isto é, a única maneira de evitar a sobrecarga do sistema, e manter os tempos de respostas baixos, é com mais recursos disponíveis. Uma vez que não se podem criar recursos, pode-se evitar que os recursos existentes sejam consumidos no momento em que os tempos de respostas comecem a ficar prejudicados. Para tanto são necessários mecanismos de controle de admissão, para evitar a sobrecarga no sistema, rejeitandose requisições no momento em que isso começa a acontecer. Esses mecanismos serão discutidos na próxima seção.

\subsection{Mecanismos de Controle de Admissão}

\subsubsection{Introdução}

O algoritmo anterior se mostrou eficiente no sentido de prover diferenciação relativa entre as classes, mas não foi capaz de evitar o aumento do tempo de resposta das requisições de alta prioridade e nem que estas não fossem completadas no momento em que o sistema começou a ficar sobrecarregado. Para tentar manter os tempos de respostas estáveis e evitar que requisições de alta prioridade tenham seu atendimento negado ou interrompido, foi implementado também no protótipo um mecanismo de controle de admissão, detalhado no capítulo 5. A seguir serão apresentados os resultados dos experimentos.

\subsubsection{Planejamento dos Experimentos}

Para avaliar o mecanismo de controle de admissão aqui proposto, foi considerado apenas o tipo de carga composta somente por requisições dinâmicas com alto consumo 
de CPU, pois somente com esta é possível sobrecarregar o servidor. O algoritmo de diferenciação de serviços considerado foi o PriProcess.

Nos experimentos, as requisições que chegam ao sistema são divididas em duas classes, de alta e baixa prioridade, pelo módulo Classificador do protótipo, sendo atribuídas aos nós do cluster segundo um esquema de rodízio (round robin), mas, apenas se a carga média no último minuto do nó para o qual ela for designada não tiver ultrapassado um certo limite definido (threshold). Esse limite foi definido como sendo 25.0 para a classe de baixa prioridade e 50.0 para a classe de alta prioridade. Esses valores foram escolhidos porque foi observado através de experimentos, que quando o servidor começa a ficar sobrecarregado, a carga média nos nós do cluster é de 25.0, portanto, esse valor se tornou o threshold para as requisições de baixa prioridade. Como o objetivo desejado é evitar ao máximo o descarte de requisições de alta prioridade, foi definido um thresold duas vezes maior para essa classe, para que só fossem descartadas requisições de alta prioridade em casos extremos.

A taxa de chegada das requisições varia de 100 em 100 requisições por segundo, iniciando com 500 requisições por segundo e indo até o servidor ou a rede ficarem sobrecarregados. Os experimentos foram executados 3 vezes, com duração de 15 minutos cada, para cada valor obtido. As métricas de desempenho utilizadas são a média dos tempos de respostas para o atendimento das requisições e o percentual de requisições completadas com sucesso, para ambas as classes consideradas.

Para analisar sob quais fatores o mecanismo de controle de admissão implementado no protótipo é adequado, foram definidos alguns cenários através da variação da porcentagem de requisições da classe de alta prioridade presentes no sistema. Por meio desse parâmetro especificaram-se várias situações, variando a porcentagem de requisições de alta prioridade presentes no sistema em 10\%, 30\%, 50\%, 70\% e 90\%. O objetivo da variação desse parâmetro foi verificar como o sistema se comporta em situações extremas, como, por exemplo, quando sobrecarregado por requisições de alta prioridade(90\% classe 1 e $10 \%$ classe 2) ou quando sobrecarregado por requisições de baixa prioridade(10\% classe 1 e $90 \%$ classe 2) e também em situações onde há um equilibrio entre as classes (50\% classe 1 e $50 \%$ classe 2$)$. Os resultados apresentados estão dentro de um intervalo de confiança de $95 \%$.

\subsubsection{Carga de trabalho sintética, hipotética, composta $100 \%$ por requisições dinâmicas com alto consumo de CPU}

Para realizar os experimentos foi utilizado o algoritmo PriProcess considerando $50 \%$ de requisições da classe 1 (alta prioridade) e $50 \%$ de requisições da classe 2 (baixa prioridade). Além disso foram considerados dois pontos de corte (Thresholds): um para requisições da classe 1 e outro para requisições da classe 2 . 
Quando a carga média do último minuto, em algum nó do cluster, passar desses pontos, nenhuma requisição da classe para a qual o threshold foi atingido será aceita nesse nó. Os thresholds utilizados foram 25.0 para classe 2 e 50.0 para a classe 1. Os resultados obtidos podem ser vistos nas figuras 6.15 e 6.16 .

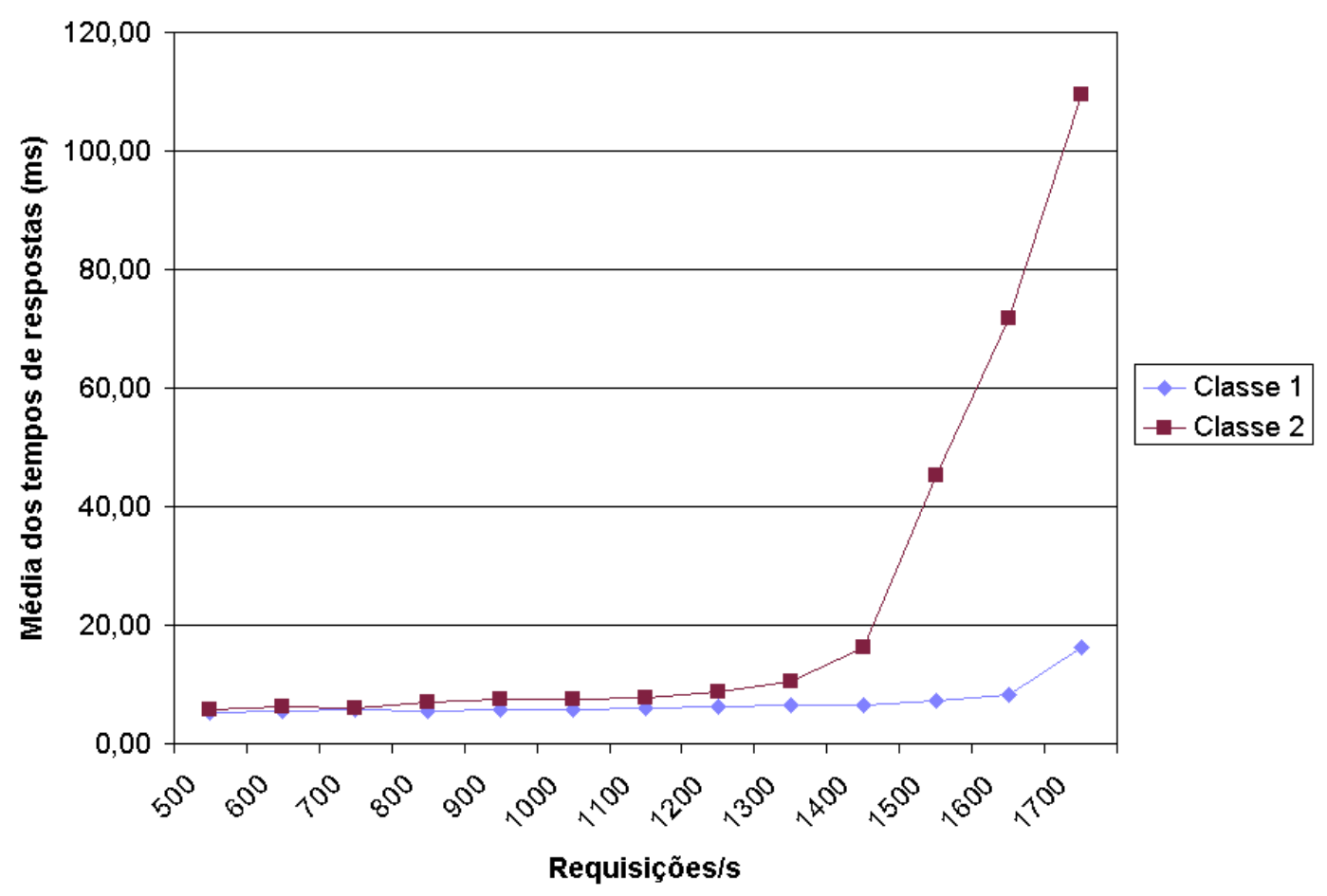

Figura 6.15: Médias dos tempos de respostas para o algoritmo PriProcess com $50 \%$ de requisições de alta prioridade e mecanismos de controle de admissão.

Analisando-se as figuras 6.15 e 6.16 pode-se observar que com o emprego de mecanismos de controle de admissão, foi possível manter a média dos tempos de respostas das requisições de alta prioridade relativamente baixas por mais tempo e também não houve requisições de alta prioridade não atendidas. Isso foi alcançado ao custo de se rejeitarem requisições de baixa prioridade em momentos de sobrecarga no servidor. Em compensação as requisições de baixa prioridade que conseguiram ser atendidas, tiveram também tempos de respostas bem menores.

A fim de comparar como o mecanismo de controle de admissão considerado se comporta variando a porcentagem de requisições de cada classe, foram feitos novos experimentos, considerando 10\%, 30\% 70\% e 90\% de requisições de alta prioridade. Assim como na seção 6.3, foram escolhidas duas taxas de chegada de requisições para ilustrar os resultados, 1500 requisições por segundo e 1700 requisições por segundo. As tabelas 6.5 e 6.6 ilustram os resultados obtidos. Os gráficos correspondentes são apresentados no apêndice A.

Nota-se pela tabela 6.5 que à medida que se aumenta o número de requisições de alta prioridade, aumenta também o tempo de resposta para ambas as classes, pelos mesmos motivos já discutidos anteriormente no caso do algoritmo PriProcess. Percebe-se também 


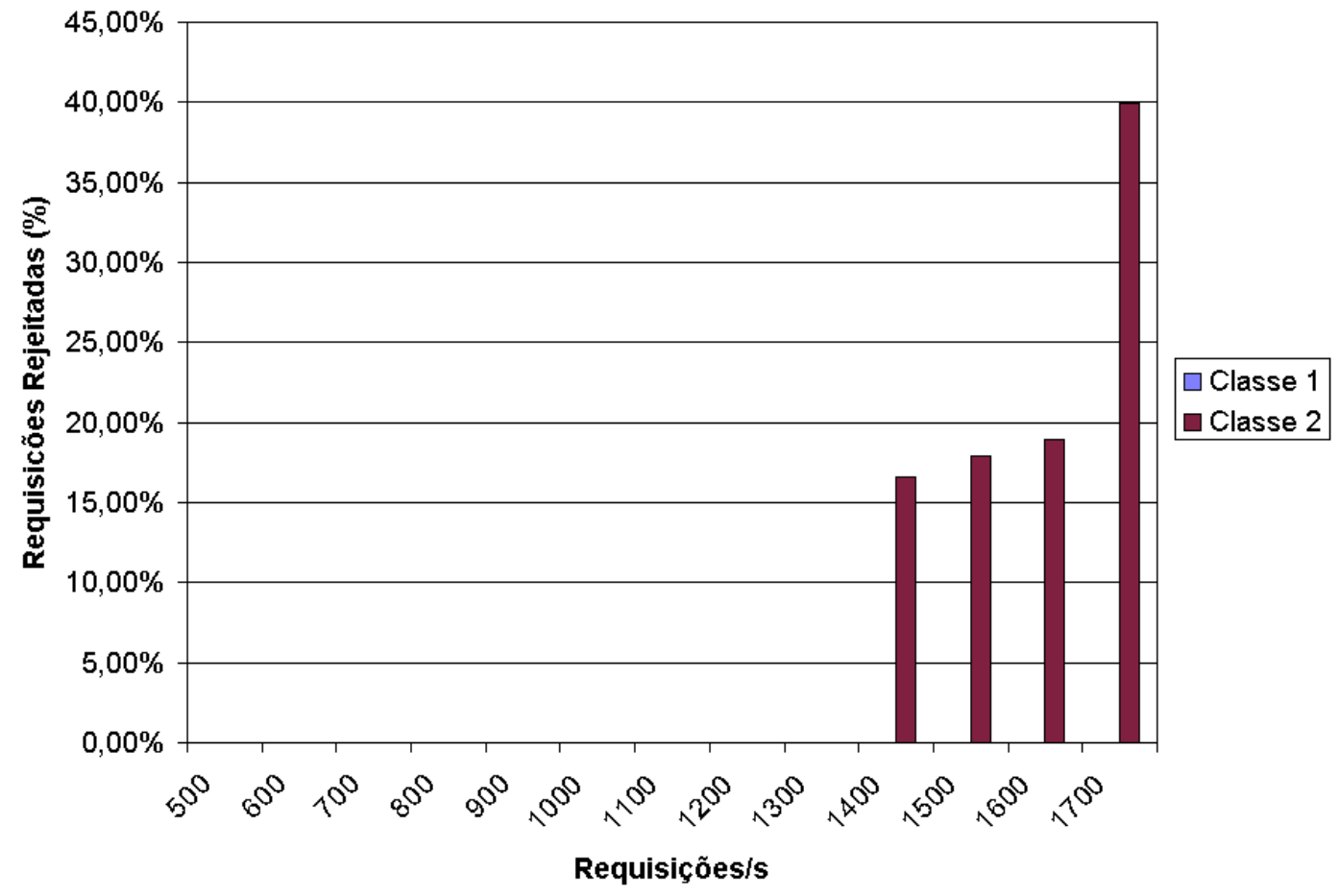

Figura 6.16: Porcentagem de requisições não completadas para o algoritmo PriProcess com $50 \%$ de requisições de alta prioridade e mecanismos de controle de admissão.

\begin{tabular}{|c|c|c|c|c|}
\hline Classe/Taxa de chegada & \multicolumn{2}{|c|}{$1500 \mathrm{reqs} / \mathrm{s}$} & \multicolumn{2}{c|}{$1700 \mathrm{reqs} / \mathrm{s}$} \\
\hline \hline Classe 1/Classe 2 & Classe 1 & Classe 2 & Classe 1 & Classe 2 \\
\hline \hline $10 \% / 90 \%$ & $0,01 \mathrm{~s}$ & $0,03 \mathrm{~s}$ & $0,01 \mathrm{~s}$ & $0,05 \mathrm{~s}$ \\
\hline $30 \% / 70 \%$ & $0,01 \mathrm{~s}$ & $0,03 \mathrm{~s}$ & $0,01 \mathrm{~s}$ & $0,06 \mathrm{~s}$ \\
\hline $50 \% / 50 \%$ & $0,01 \mathrm{~s}$ & $0,05 \mathrm{~s}$ & $0,02 \mathrm{~s}$ & $0,11 \mathrm{~s}$ \\
\hline $70 \% / 30 \%$ & $0,01 \mathrm{~s}$ & $0,12 \mathrm{~s}$ & $0,03 \mathrm{~s}$ & $0,21 \mathrm{~s}$ \\
\hline $90 \% / 10 \%$ & $0,02 \mathrm{~s}$ & $0,11 \mathrm{~s}$ & $0,71 \mathrm{~s}$ & $0,83 \mathrm{~s}$ \\
\hline
\end{tabular}

Tabela 6.5: Comparação das médias dos tempos de respostas (segundos) utilizando o mecanismo de controle de admissão submetido a diferentes cargas de trabalho

que até $70 \%$ de requisições de alta prioridade foi possível manter tempos de respostas relativamente baixos, mesmo com o sistema submetido a uma alta taxa de chegada de requisições $(1700 / \mathrm{s})$. Porém, com 90\% de requisições de alta prioridade os tempos de respostas tiveram um aumento significativo, passando de 3 centésimos para 7 décimos de segundo.

Com $90 \%$ de requisições de alta prioridade, sobram apenas $10 \%$ de requisições de baixa prioridade para serem descartadas, número baixo para evitar que o sistema comece a se sobrecarregar em momentos em que está sendo muito exigido. Como o sistema tenta evitar ao máximo rejeitar requisições de alta prioridade (threshold maior), há um aumento de carga no sistema e isto se reflete nos tempos de respostas.

Na tabela 6.6 é possível observar que com até $70 \%$ de requisições de alta prioridade presentes no sistema, praticamente não houve rejeição destas. No entanto, com $90 \%$ de requisições de alta prioridade, já com uma taxa de chegada de 1500 requisições por 


\begin{tabular}{|c|c|c|c|c|}
\hline Classe/Taxa de chegada & \multicolumn{2}{|c|}{$1500 \mathrm{reqs} / \mathrm{s}$} & \multicolumn{2}{|c|}{$1700 \mathrm{reqs} / \mathrm{s}$} \\
\hline \hline Classe 1/Classe 2 & Classe 1 & Classe 2 & Classe 1 & Classe 2 \\
\hline \hline $10 \% / 90 \%$ & $0,0 \%$ & $20,1 \%$ & $0,0 \%$ & $63,2 \%$ \\
\hline $30 \% / 70 \%$ & $0,0 \%$ & $19,1 \%$ & $0,0 \%$ & $43,1 \%$ \\
\hline $50 \% / 50 \%$ & $0,0 \%$ & $18,0 \%$ & $0,0 \%$ & $39,9 \%$ \\
\hline $70 \% / 30 \%$ & $0,0 \%$ & $15,9 \%$ & $0,3 \%$ & $46,4 \%$ \\
\hline $90 \% / 10 \%$ & $0,9 \%$ & $24,0 \%$ & $17,4 \%$ & $56,8 \%$ \\
\hline
\end{tabular}

Tabela 6.6: Comparação da porcentagem de requisições descartadas utilizando o mecanismo de controle de admissão submetido a diferentes cargas de trabalho

segundo, começou a haver rejeição destas pelo sistema e quando a taxa de chegada passou para 1700 requisições por segundo, essa rejeição aumentou consideravelmente, pois, na falta de requisições de baixa prioridade para serem descartadas (apenas 10\%), a carga média do sistema aumenta e o threshold definido para se começar a descartar requisições de alta prioridade (50.0) é atingido.

\subsubsection{Considerações sobre o mecanismo de controle de admissão}

O mecanismo de controle de admissão proposto neste trabalho se mostrou eficiente em seu objetivo de privilegiar requisições de alta prioridade, mantendo a média dos tempos de respostas relativamente baixos para esta classe de requisições e evitando, ao máximo, que estas tivessem seu atendimento negado ou interrompido.

Para todas as variações de carga experimentadas pelo sistema, sempre as requisições de alta prioridade tiveram melhor atendimento que as requisições de baixa prioridade, tanto na média dos tempos de respostas, quanto na porcentagem de requisições atendidas. Somente quando a porcentagem de requisições de alta prioridade presentes no sistema chegou a 90\%, houve um número significativo de requisições desta classe descartadas, pois com um grande número de requisições de alta prioridade competindo entre si, fica difícil garantir o atendimento a todas.

\subsection{Considerações Finais}

Este capítulo descreveu os resultados obtidos através de experimentos realizados com a implementação do SWDS. Foram discutidos os resultados obtidos com os algoritmos de reserva de recursos (RSV e RSVadap), escalonamento baseado em prioridades (PriProcess) e mecanismos de controle de admissão.

Os algoritmos de reserva de recursos se mostraram eficientes no sentido de diferenciar serviços entre as classes. Com destaque para o RSVadap que consegue se adaptar a variação de carga e manter privilégios para a classe de alta prioridade em relação a classe de baixa prioridade, ao contrário do RSV, que não é sensível a variação de carga, gerando resultados contrários ao esperado quando isto ocorre. 
No entanto, os dois algoritmos baseados em reserva de recursos se mostraram menos eficientes que o algoritmo round robin em determinadas situações. Isto se deve ao fato da arquitetura do Web Switch considerada neste trabalho ser two-way. Os resultados podem ser revertidos utilizando-se outras arquiteturas de Web Switch.

Já o algoritmo de escalonamento baseado em prioridades, o PriProcess, se mostrou eficiente em todos os cenários de variação de carga experimentados, com as requisições de alta prioridade sempre alcançando melhores resultados que as requisições de baixa prioridade.

Finalizando, foi avaliado também o mecanismo de controle de admissão implementado, que se mostrou eficiente no sentido de evitar a sobrecarga do sistema e, com isso, evitar que o atendimento das requisições fosse comprometido, especialmente o atendimento das requisições de alta prioridade.

É importante notar que os mecanismos propostos só obtiveram sucesso no momento em que o servidor começou a se sobrecarregar. O que só foi possível com a utilização de uma carga sintética, hipotética, composta na sua totalidade por requisições dinâmicas com alto consumo de CPU, que fez com que o servidor chegasse a seu ponto de sobrecarga antes da rede.

Na seção seguinte será apresentada a conclusão deste trabalho. 


\section{Capítulo 7 \\ Conclusão}

\subsection{Visão Geral}

A finalidade deste trabalho foi implementar um protótipo de servidor Web com diferenciação de serviços, baseado no modelo proposto por Teixeira (2004), e avaliar seu desempenho. A motivação surgiu a partir da constatação do crescimento exagerado da Web nos últimos anos e desta estar se tornando cada vez mais um ambiente de negócios, tendo que acomodar aplicações cada vez mais complexas que exigem cada vez mais processamento por parte dos servidores. Esses servidores, quase em sua totalidade, atendem às requisições de acordo com a política FCFS, ou seja, primeiro a chegar é o primeiro a ser atendido. Esse tipo de comportamento por parte dos servidores nem sempre é o desejado, pois cada vez mais surgem aplicações e clientes com expectativas diferentes, necessitando então de atendimentos diferenciados.

Pensando nisso, foi proposto por Teixeira (2004) um modelo de servidor Web com diferenciação de serviços (SWDS), que gerou um grande número de trabalhos relacionados desenvolvidos pelo grupo de Sistemas Distribuídos e Programação Concorrente, como (Estrella et al., 2006) (Traldi et al., 2006) (Mourão, 2006), no entanto todos esses trabalhos foram avaliados através de modelagem e simulação. Sendo assim foi definido que seria importante para o grupo propor e implementar um protótipo baseado nesse modelo, onde se pudesse aglutinar não apenas os mecanismos propostos inicialmente por Teixeira (2004), mas também outros que surgiram a partir do SWDS e ainda outros que possam surgir futuramente.

Inicialmente, nos capítulos 2 e 3, fez-se uma revisão de alguns assuntos, como a estrutura da $W e b$ e qualidade de serviço, que juntamente com o modelo proposto por Teixeira (2004) no capítulo 4, formam a base deste trabalho. Também foram apresentados e discu- 
tidos alguns trabalhos que implementam algum tipo de mecanismo de QoS em servidores Web. Em seguida, no capítulo 5, foi apresentada uma arquitetura completa baseada em um cluster de servidores Web para prover diferenciação de serviços entre determinadas classes de usuários, utilizando apenas mecanismos em nível de aplicação.

Várias políticas foram implementadas, tais como reserva de recursos, escalonamento baseado em prioridades e mecanismos de controle de admissão. Foi implementado um Web Switch layer 7 two-way utilizando o Web Server Apache configurado como proxy reverso, através do módulo mod_proxy. Esse Web Switch incorpora as funções de classificador e controle de admissão no protótipo.

Para implementar o classificador, foi utilizado o módulo mod_rewrite que é muito eficiente na reescrita de URLs através de regras baseadas em expressões regulares. Podem ser usadas inúmeras regras condicionais que podem utilizar quaisquer parâmetros contidos no cabeçalho HTTP da requisição, além de variáveis de ambiente do servidor, se tornando assim um classificador muito poderoso e flexível. O controle de admissão foi implementado como um programa multi-thread desenvolvido em linguagem $\mathrm{C}$, que incorpora as funções de escalonamento das requisições, monitoramento do estado do sistema e coleta de carga dos servidores. Esse programa se comunica com o classificador (mod_rewrite) através da leitura e escrita de informações nos descritores de entrada e saída padrão do sistema (stdin/stdout) e é bastante flexível no sentido de que novos parâmetros e políticas de QoS podem ser incorporados ao mesmo sem grandes problemas. Nos nós back-ends, foram utilizados Web Servers Apache padrão e programas responsáveis por monitorar a carga em cada um e enviar essas informações para o Controle de Admissão. O protótipo foi implementado de maneira que possa ter transparência e portabilidade, com mecanismos implementados apenas em nível de usuário, sem ter que alterar o núcleo (kernel) do sistema operacional.

Durante os experimentos, duas cargas de trabalho foram consideradas. Primeiro, uma carga composta majoritariamente por requisições estáticas, que representa de maneira mais próxima o padrão de carga na Web e também um outro tipo de carga, composta 100\% por requisições dinâmicas que exigem uso intenso da CPU. Os resultados apresentados no capítulo 6 mostraram que as políticas utilizadas foram eficientes no sentido de prover diferenciação de serviços entre as classes, em momentos em que o servidor é altamente exigido, chegando perto do seu ponto de saturação. O que só foi possível utilizando o segundo tipo de carga de trabalho proposto, composta somente por requisições dinâmicas com alto consumo de CPU, pois, com a utilização do primeiro tipo de carga, considerada próxima de uma carga real, a rede atingiu seu ponto de saturação antes do sevidor, o que anulou os esforços para fornecer diferenciação de serviços no mesmo. Entretanto, essa situação pode ser revertida se mecanismos de QoS em nível de rede forem utilizados em conjunto com mecanismos em nível de aplicação, o que não é considerado neste trabalho. 
Os algoritmos baseados em reserva de recursos se mostraram eficientes no sentido de prover diferenciação de serviços entre as classes consideradas, mas mostraram deficiências, algumas inerentes à própria natureza do algoritmo e outras devidos à arquitetura em que foram implementados. O algoritmo RSV é eficiente apenas em situações onde a carga de trabalho é bem definida e pouco variável, pois o mesmo não é sensível à variação de carga. Já o algoritmo RSVadap, se mostrou mais flexível quanto à variação da carga de trabalho e manteve a diferenciação desejada. No entanto, ambos apresentaram resultados inferiores ao algoritmo round robin em alguns casos, mesmo para a classe de alta prioridade. Isso se deve ao fato da arquitetura do Web Switch ser uma arquitetura two-way, o que não possibilita um isolamento total dos recursos disponíveis para cada classe. Os resultados apresentados pelos algoritmos podem ser melhorados caso a arquitetura do protótipo utilize um Web Switch one-way, que é mais eficiente que um Web Switch two-way, mas é menos portável e mais difícil de implementar. Para tanto seria necessário alterações no núcleo (kernel) do sistema operacional tanto da maquina que fará o papel do Web Switch como das máquinas que serão os servidores Web, o que estava fora do escopo deste trabalho, que buscou implementar mecanismos apenas em nível de usuário.

O algoritmo de escalonamento baseado em prioridades proposto neste trabalho (PriProcess) difere dos propostos por Teixeira (2004), pois para implementar fielmente os algoritmos propostos por Teixeira, seriam necessárias mudanças em nível de kernel do sistema operacional. Para implementar o PriProcess foi feito um mapeamento de prioridades de requisições para prioridades de processos, utilizando-se apenas mecanismos em nível de usuário. Os resultados mostraram que o PriProcess foi mais eficiente que os algoritmos de reserva de recursos, com as requisições de alta prioridade sempre sendo melhor atendidas que as de baixa prioridade, mesmo variando a carga no sistema. Pode se observar que quanto menor o número de requisições de alta prioridade presentes no sistema, melhor é o atendimento para todas as classes de requisições, pois, com menos requisições de alta prioridade, menor é a concorrência entre estas por recursos do sistema, e menor o tempo de espera das requisições de baixa prioridade para ter acesso a estes recursos.

Com o PriProcess não foi possível manter tempos de respostas relativamente baixos, mesmo para as requisições de alta prioridade, no momento em que o servidor começou a chegar perto do limite de sua capacidade. Para tanto, se faz necessário mecanismos de controle de admissão capazes de evitar a sobrecarga no sistema, rejeitando requisições no momento em que o sistema começa a dar sinais de saturação. O mecanismo de controle de admissão proposto neste trabalho se baseia em informações sobre a média de carga nos servidores obtida através do arquivo /proc/loadavg do linux. Os resultados se mostraram satisfatórios no sentido de privilegiar requisições de alta prioridade mantendo seu tempos de respostas relativamente baixos e evitando, ao máximo, que estas requisições tivessem seu atendimento negado ou interrompido. Para todas as variações de cargas experimen- 
tadas pelo sistema, sempre as requisições de alta prioridade tiveram melhor atendimento que as requisições de baixa prioridade, tanto na média dos tempos de respostas, quanto no número de requisições atendidas. No entanto, no momento em que a porcentagem de requisições de alta prioridade cresceu exageradamente a ponto de quase monopolizar o sistema, não foi possível garantir atendimento a todas, pois, com mais requisições de alta prioridade competindo entre si, fica mais difícil garantir diferenciação de serviços.

\subsection{Principais Resultados e Contribuições}

Os principais resultados deste trabalho estão relacionados a seguir, destacando-se as contribuições feitas ao modelo de Servidor Web com Diferencição de Serviços e, conseqüentemente, relevantes para a área.

1. Revisão Bibliográfica - Foi feita uma revisão crítica da bibliografia existente, a fim de contextualizar o presente trabalho. A revisão foi feita em torno de informações sobre o fornecimento de serviços diferenciados nos servidores web. Revisou-se também o modelo de Servidor Web com Diferenciação de Serviços (SWDS), no qual o presente trabalho teve sua origem, além de maneiras de organização de servidores e de cluster de servidores web. Esta revisão contribui no sentido de facilitar futuros trabalhos e a iniciação de futuros pesquisadores.

2. Protótipo do Servidor Web com Diferenciação de Serviços (SWDS) - Foi implementado um protótipo baseado no SWDS, utilizando-se uma arquitetura de cluster através da utilização do Web Server Apache configurado como proxy reverso, com a utilização do módulo mod_proxy atuando como um Web Switch e um conjunto de outros Web Servers Apache atendendo as requisições da maneira tradicional. O protótipo do SWDS é composto pelos seguintes componentes:

Classificador: Para implementar o classificador foi utilizado o módulo mod_rewrite do Apache que possui mecanismos de reescrita de URLs muito eficientes e flexíveis. A classificação pode ser feita utilizando qualquer campo do cabeçalho HTTP de uma requisição, além de variáveis internas do servidor.

Controle de Admissão: Programa multi-threading implementado em linguagem C responsável pelas políticas de QoS utilizadas pelo sistema.

Mecanismos de Diferenciação de Serviços: Foram implementados alguns dos algoritmos propostos originalmente no modelo do SWDS, além de outros propostos em trabalhos futuros e ainda outros inéditos.

O protótipo de um servidor Web com diferenciação de serviços baseado no SWDS constitui uma contribuição valiosa, pelo fato de existirem poucos servidores com 
estas características implementados. Sua implementação buscou considerar apenas mecanismos em nível de aplicação e de usuário, garantido-lhe portabilidade, pois não são necessárias alterações na rede e nem no kernel do sistema operacional, o que dificultaria sua adoção em uma rede com as dimensões da Internet. A opção por implementar o protótipo em um sistema distribuído (cluster), garante ao mesmo escalabilidade e crescimento incremental, o que o torna um modelo preparado e de fácil adaptação ao crescimento da carga de trabalho.

3. Mecanismo de Controle de Admissão com Diferenciação de Serviços - Foi implementado um mecanismo de controle de admissão com diferenciação de serviços, o qual possui a grande preocupação de que as requisições de alta prioridade no sistema sejam todas atendidas e completadas. Esse mecanismo é baseado na carga média do sistema e define dois thresholds, um para requisições de alta prioridade e outro para requisições de baixa prioridade. O objetivo é descartar primeiro as requisições de baixa prioridade e evitar ao máximo o descarte de requisições de alta prioridade. Nos mecanismos de controle de admissão propostos originalmente no SWDS não há qualquer diferenciação de serviços, ou seja, as requisições de ambas as classes são descartadas a partir de um determinado threshold que é igual para as duas, o que não garante privilégios para a classe de alta prioridade no momento de descartar as requisições. Portanto, o mecanismo considerado neste trabalho contribuiu para flexibilizar o descarte de requisições, podendo priorizar determinada classe (thresholds diferentes) ou manter ambas com a mesma prioridade de descarte (thresholds iguais) se assim for desejado.

4. Algoritmo de escalonamento baseado em prioridades de processos (PriProcess) - Foi implementado um mecanismo de diferenciação de serviços que faz o mapeamento das prioridades das requisições para prioridades dos processos que irão atendê-las, utilizando para tanto apenas mecanismos em nível de usuário. Para tanto foram criadas duas filas de requisições em cada servidor, uma de alta e outra de baixa prioridade. Os processos que irão atender as requisições de alta prioridade têm suas prioridades aumentadas através do comando nice do linux e com isso ganham privilégios no acesso aos recursos do sistema, como o processador por exemplo. Esse algoritmo é uma contribuição valiosa, pois, não requer que sejam feitas alterações no kernel do sistema operacional, o que torna viável sua implementação em servidores $W e b$ que desejam tratar de maneira diferenciada determinadas requisições.

5. Avaliação do protótipo através de submissão de carga sintética - Foi utilizado o Httperf como gerador de carga a fim de avaliar o modelo e os algoritmos propostos e implementados no protótipo. Foram consideradas duas cargas de trabalho: uma composta majoritariamente por requisições estáticas, e outra composta 
apenas por requisições dinâmicas com alto consumo de CPU. Essa contribuição é importante pelo fato de terem sido considerados dois tipos de carga de trabalho e, assim, foi possível perceber quais componentes do servidor são sobrecarregados primeiro dependendo do tipo de carga utilizado.

6. Análise dos resultados e comparação dos mesmos com e sem a utilização dos algoritmos propostos - Vários experimentos foram realizados a fim de analisar a eficiência dos algoritmos propostos e a influência dos componentes do sistema (rede, web switch, servidor, etc) nos resultados, além de uma comparação entre os resultados obtidos com a utilização dos algoritmos de diferenciação de serviços e a utilização do algoritmo round-robin apenas. Esta análise permitiu apontar vantagens e desvantagens dos algoritmos de diferenciação de serviços implementados em uma arquitetura de cluster de servidores Web localmente distribuídos, além de analisar os resultados sob o ponto de vista de dois tipos de carga trabalho.

\subsection{Trabalhos Futuros}

A implementação de um protótipo baseado no SWDS traz consigo várias sugestões para trabalhos futuros relacionados ao oferecimento de serviços diferenciados em servidores web.

Este trabalho contribuiu para uma melhor avaliação do modelo e dos algoritmos propostos no SWDS. No entanto, novos algoritmos poderão ser desenvolvidos e outros já existentes baseados no modelo poderão ser implementados no protótipo e avaliados, como também novos mecanismos de diferenciação de serviços poderão ser incorporados ao protótipo. A seguir, são comentadas algumas sugestões para trabalhos futuros.

- Implementar no protótipo e avaliar outros algoritmos baseados no modelo e já avaliados através de simulação em outros trabalhos do grupo, tais como negociação no módulo de controle de admissão, reconhecimento de sessões no módulo de controle de admissão, entre outros;

- Fazer novos experimentos considerando-se uma carga de trabalho composta por transações comercias na $W e b$, as quais envolvem um grande número de requisições dinâmicas e sessões seguras. Para tanto, teria que haver um estudo aprofundado sobre as características deste tipo de carga;

- Fazer novos experimentos com a utilização dos algoritmos de reserva de recursos e escalonamento baseado em prioridades trabalhando em conjunto. Pode-se, por exemplo, usar os algoritmos de reserva de recursos para reservar recursos para requisições de determinado conteúdo (estáticas ou dinâmicas, por exemplo) e o algoritmo de escalonamento baseado em prioridades para priorizar requisições de determinados clientes; 
- Fazer novos experimentos considerando-se uma rede com suporte a QoS a fim de verificar-se a melhoria alcançada no atendimento das requisições com a soma de QoS aplicada em nível de rede e de aplicação;

- Utilizar o Web Switch também como cache a fim de verificar os resultados da utilização de cache em um Servidor Web com Diferenciação de Serviços. Para tanto poderia ser utilizado o módulo mod_cache do Apache;

- Melhorar a interface do SWDS (swds.conf) para que seja possível especificar todos os parâmetros referentes aos mecanismos de controle de admissão e diferenciação de serviços utilizados, além de requisitos de QoS a serem alcançados;

- Implementar mecanismos no Web Switch capazes de prever a carga de trabalho e auxiliar na tomada de decisões sobre escalonamento e descarte de requisições antes que o servidor esteja sobrecarregado. Para tanto poderia ser implementada uma rede neural adptativa como uma thread no Controle de Admissão. A rede receberia como parâmetro de entrada a ordem de chegada das requisições no sistema, que seria armazenada pela thread responsável pelo escalonamento dessas na área de variáveis globais e lidas pela rede que tentaria com esses dados e outras informações de contexto, prever as próximas chegadas.

- Implementar e realizar novos experimentos considerando um Web Switch One-Way para observar se há ou não ganho de desempenho, para tanto se faz necessário mudanças no kernel do sistema operacional tanto da máquina que fará o papel de Web Switch, quanto das máquinas Back-Ends (Web Servers). 



\section{APÊNDICE \\ $A$ \\ Demais Gráficos}

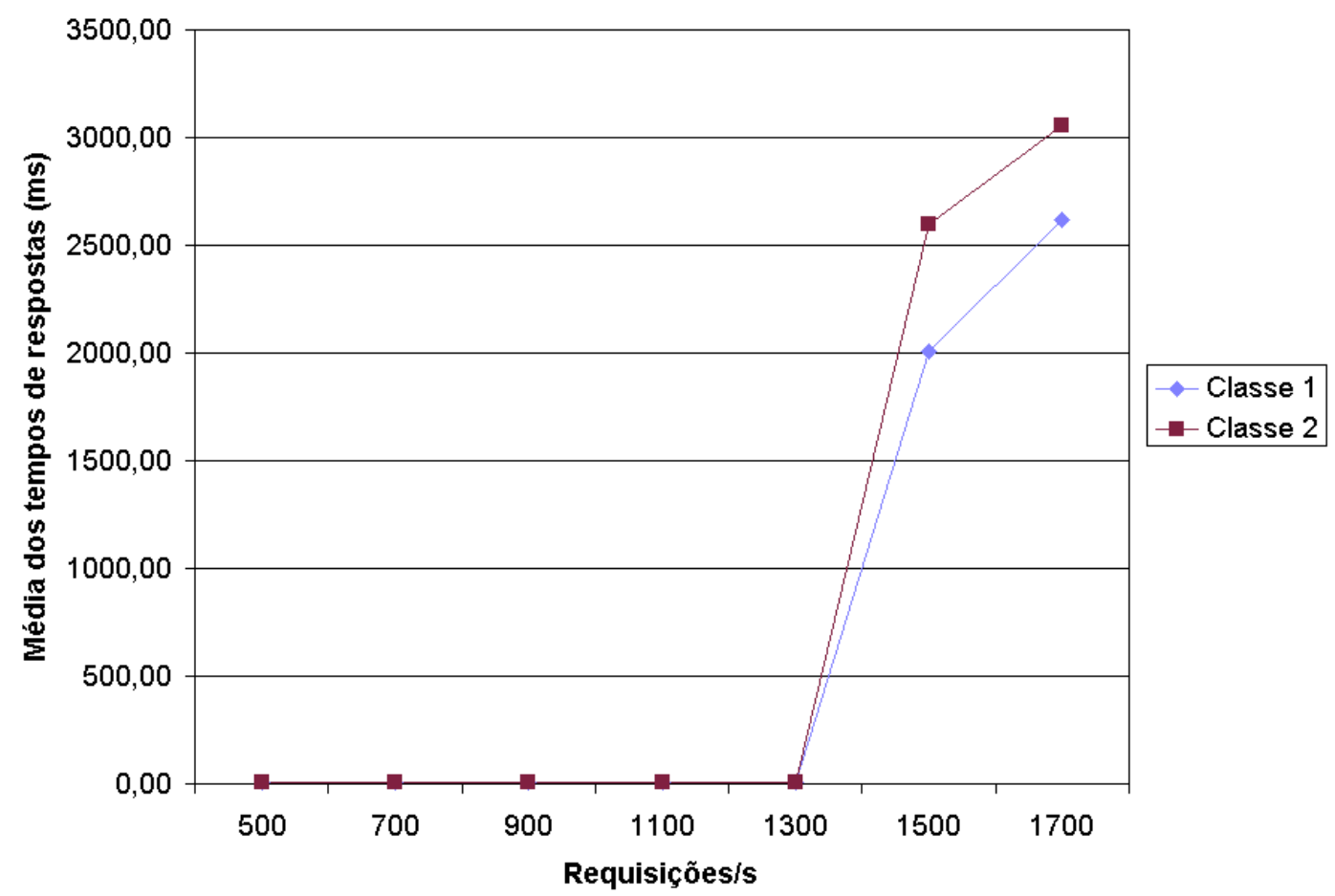

Figura A.1: Médias dos tempos de respostas utilizando o algoritmo PriProcess com 10\% de requisições de alta prioridade (carga hipotética). 


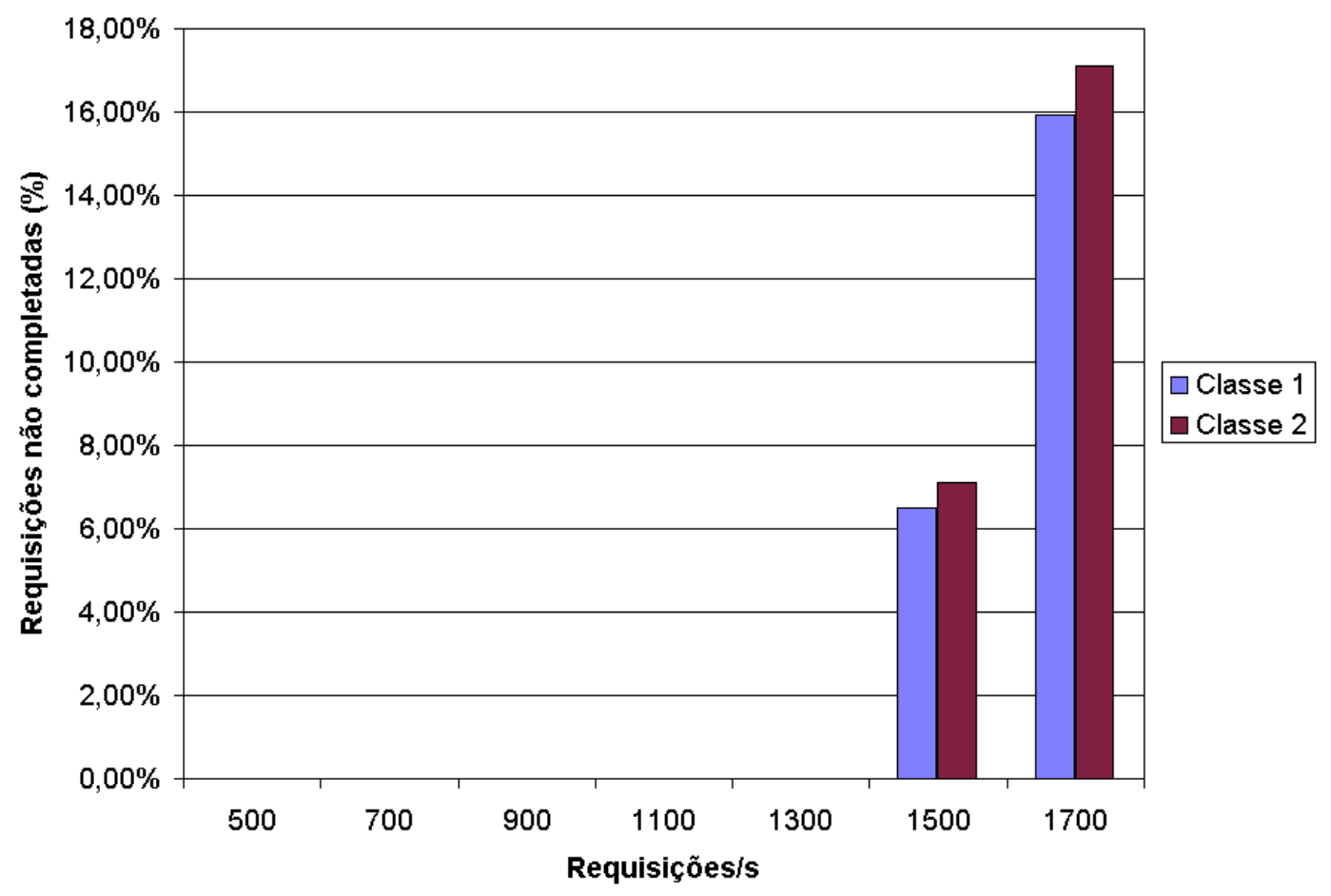

Figura A.2: Porcentagem de requisições não completadas utilizando o algoritmo PriProcess com $10 \%$ de requisições de alta prioridade (carga hipotética).

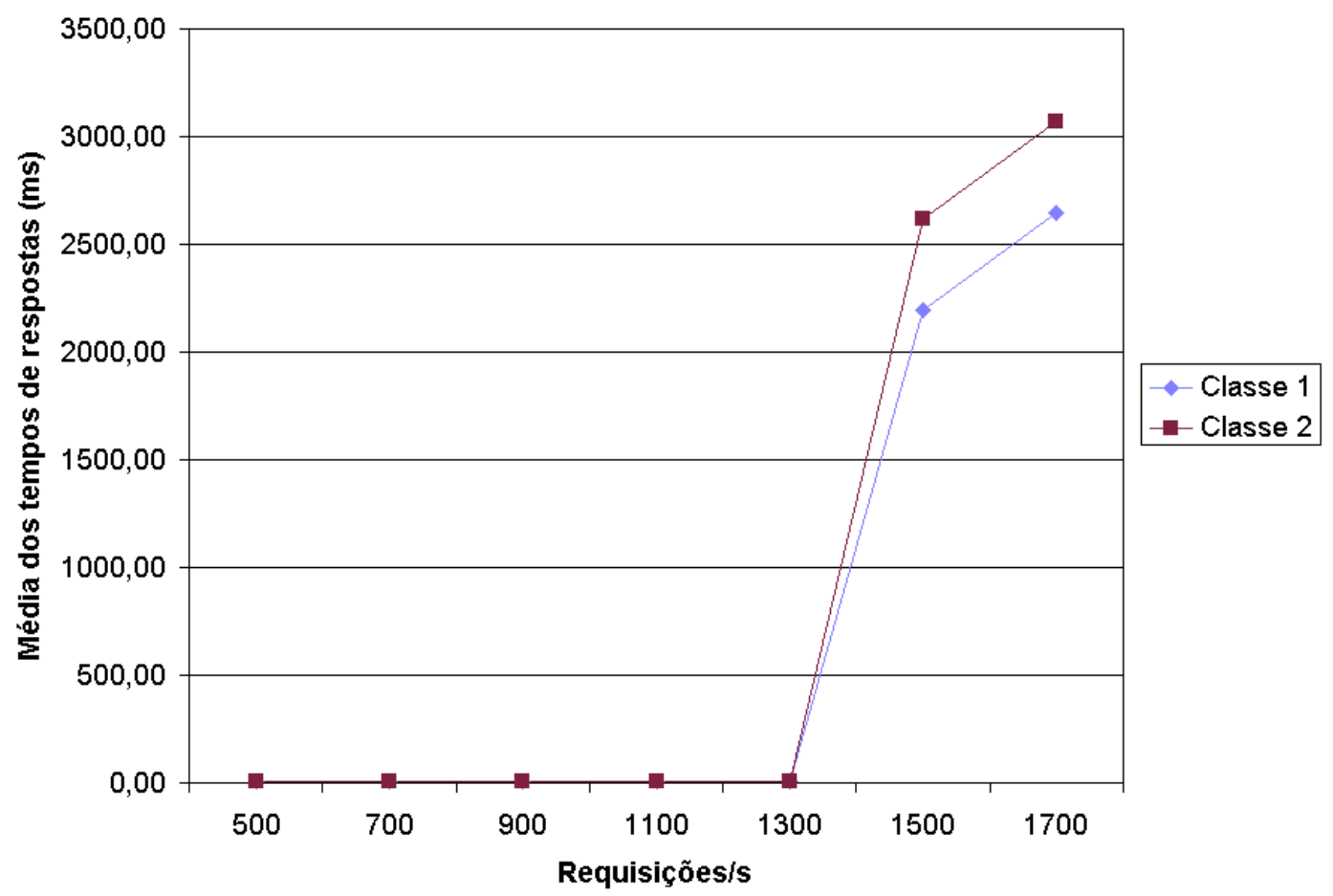

Figura A.3: Médias dos tempos de respostas utilizando o algoritmo PriProcess com 30\% de requisições de alta prioridade (carga hipotética). 


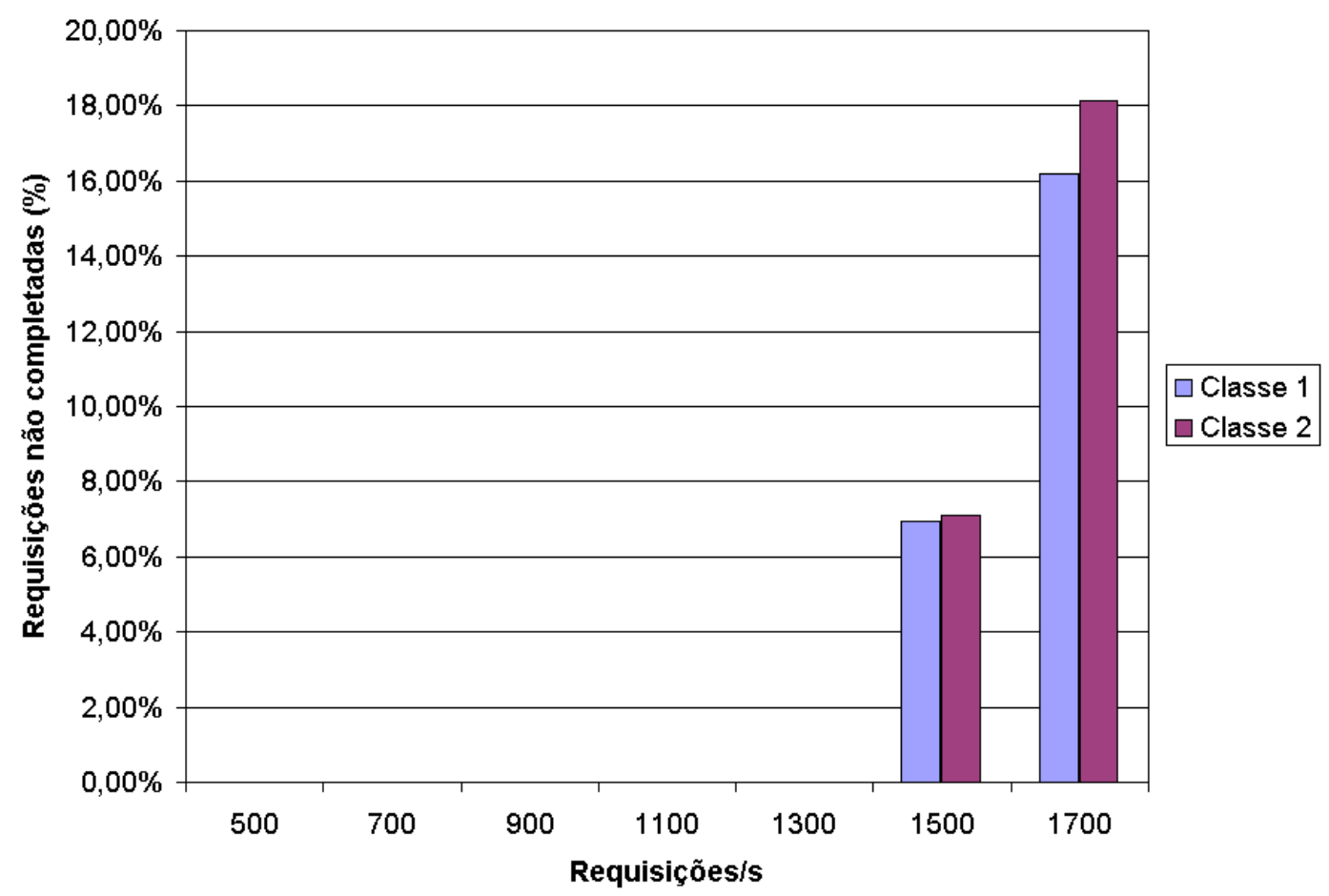

Figura A.4: Porcentagem de requisições não completadas utilizando o algoritmo PriProcess com $30 \%$ de requisições de alta prioridade (carga hipotética).

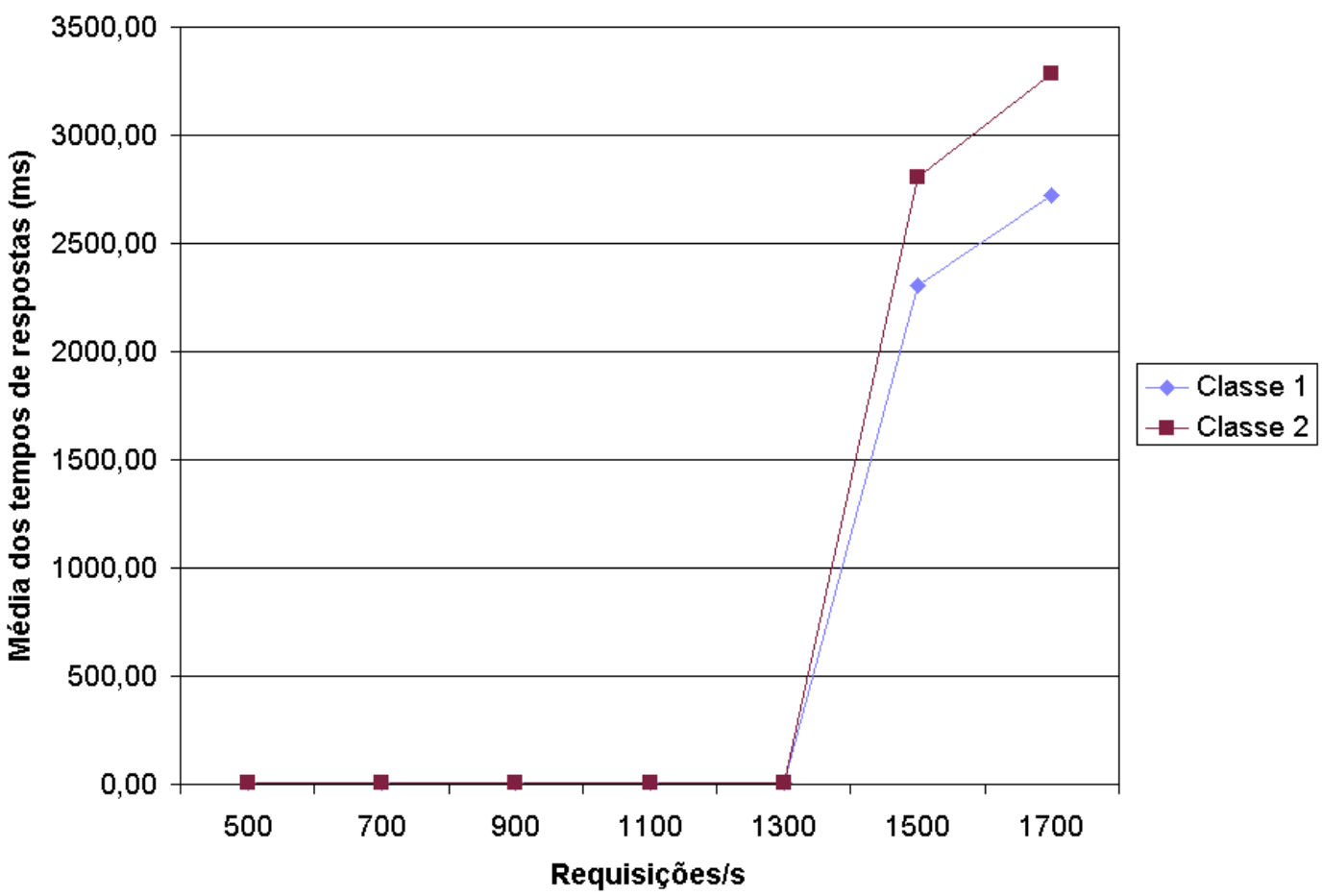

Figura A.5: Médias dos tempos de respostas utilizando o algoritmo PriProcess com $70 \%$ de requisições de alta prioridade (carga hipotética). 


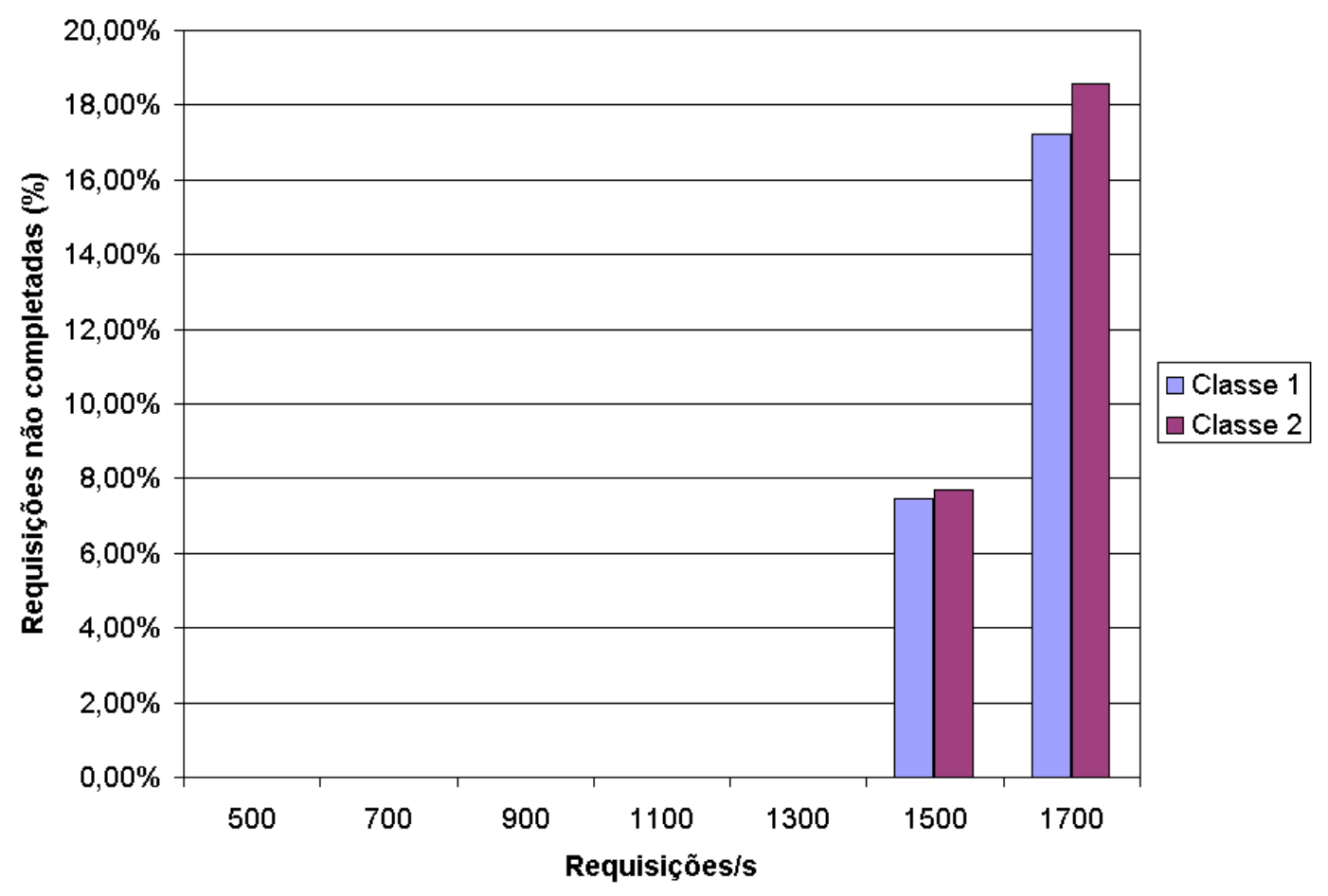

Figura A.6: Porcentagem de requisições não completadas utilizando o algoritmo PriProcess com $70 \%$ de requisições de alta prioridade (carga hipotética).

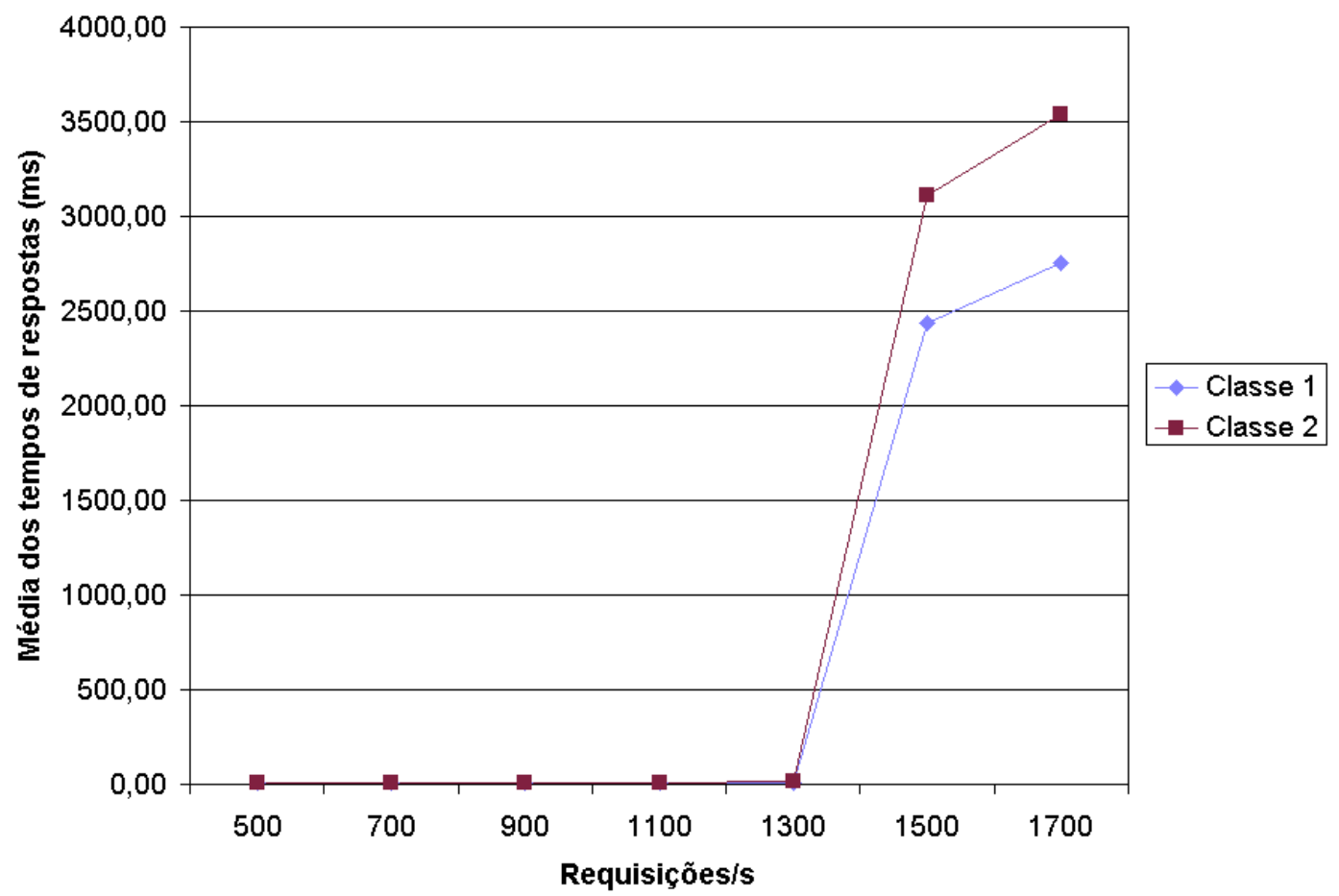

Figura A.7: Médias dos tempos de respostas utilizando o algoritmo PriProcess com 90\% de requisições de alta prioridade (carga hipotética). 


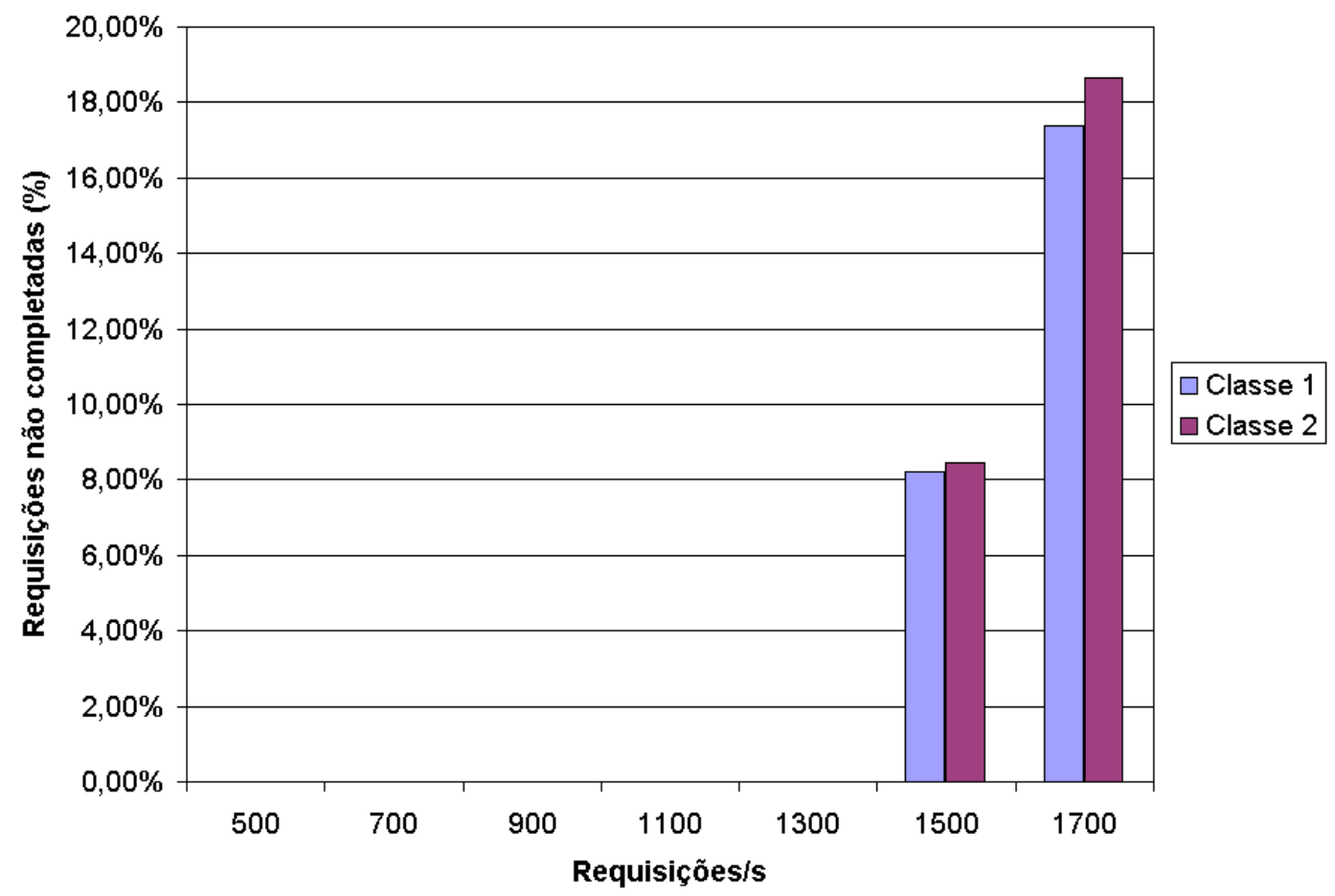

Figura A.8: Porcentagem de requisições não completadas utilizando o algoritmo PriProcess com $90 \%$ de requisições de alta prioridade (carga hipotética).

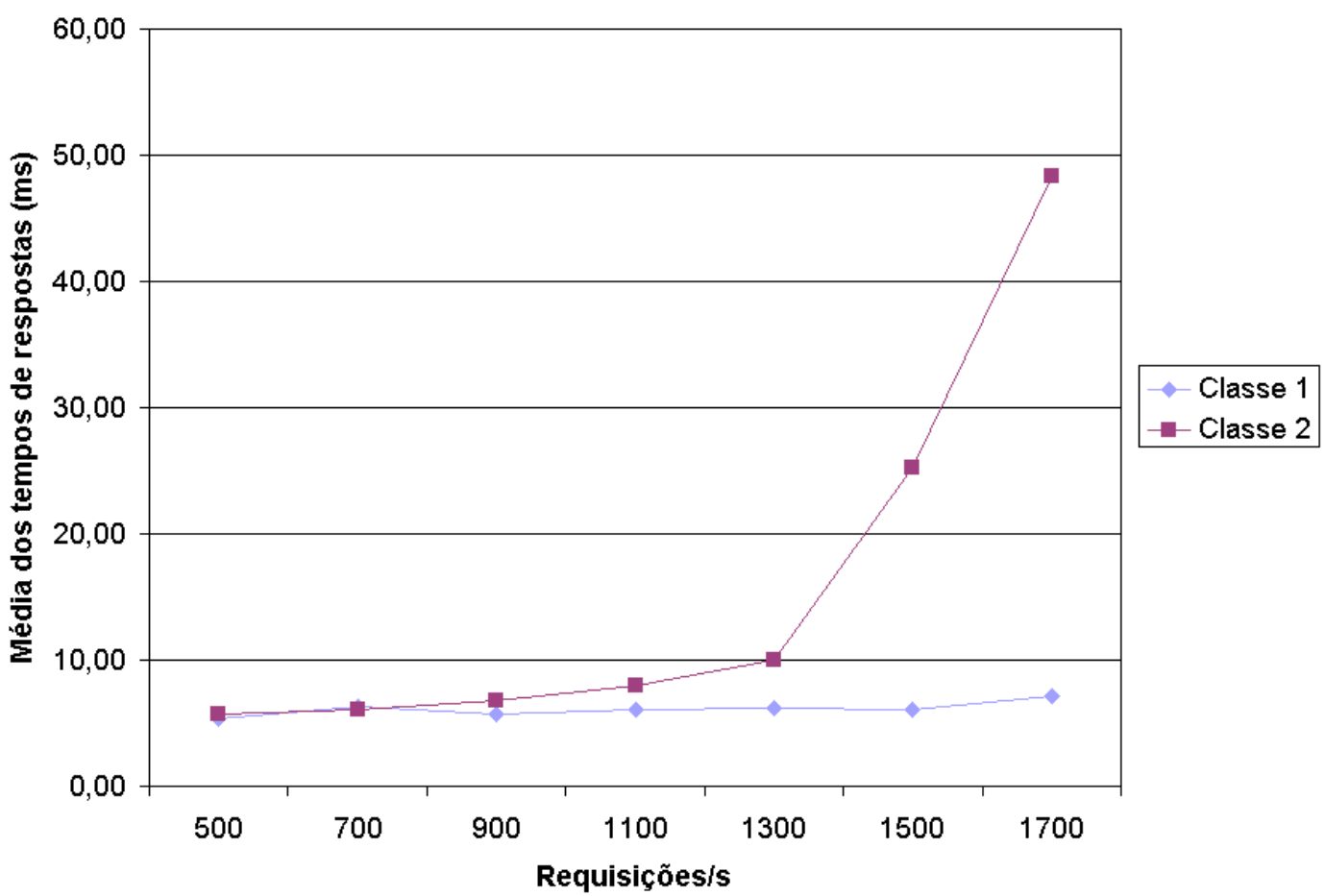

Figura A.9: Médias dos tempos de respostas utilizando o algoritmo PriProcess com 10\% de requisições de alta prioridade e mecanismos de controle de admissão. 


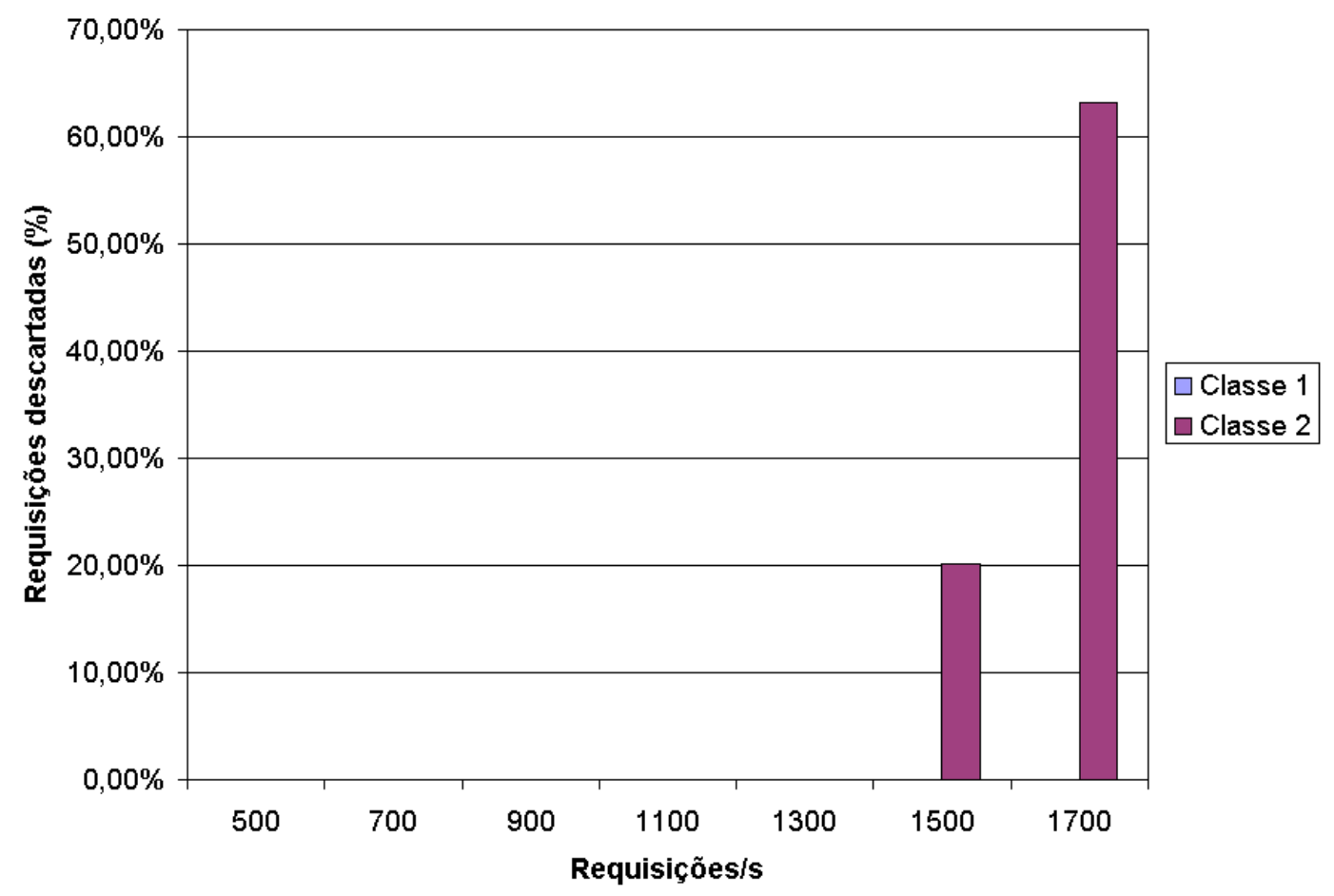

Figura A.10: Porcentagem de requisições descartadas utilizando o algoritmo PriProcess com $10 \%$ de requisições de alta prioridade e mecanismos de controle de admissão.

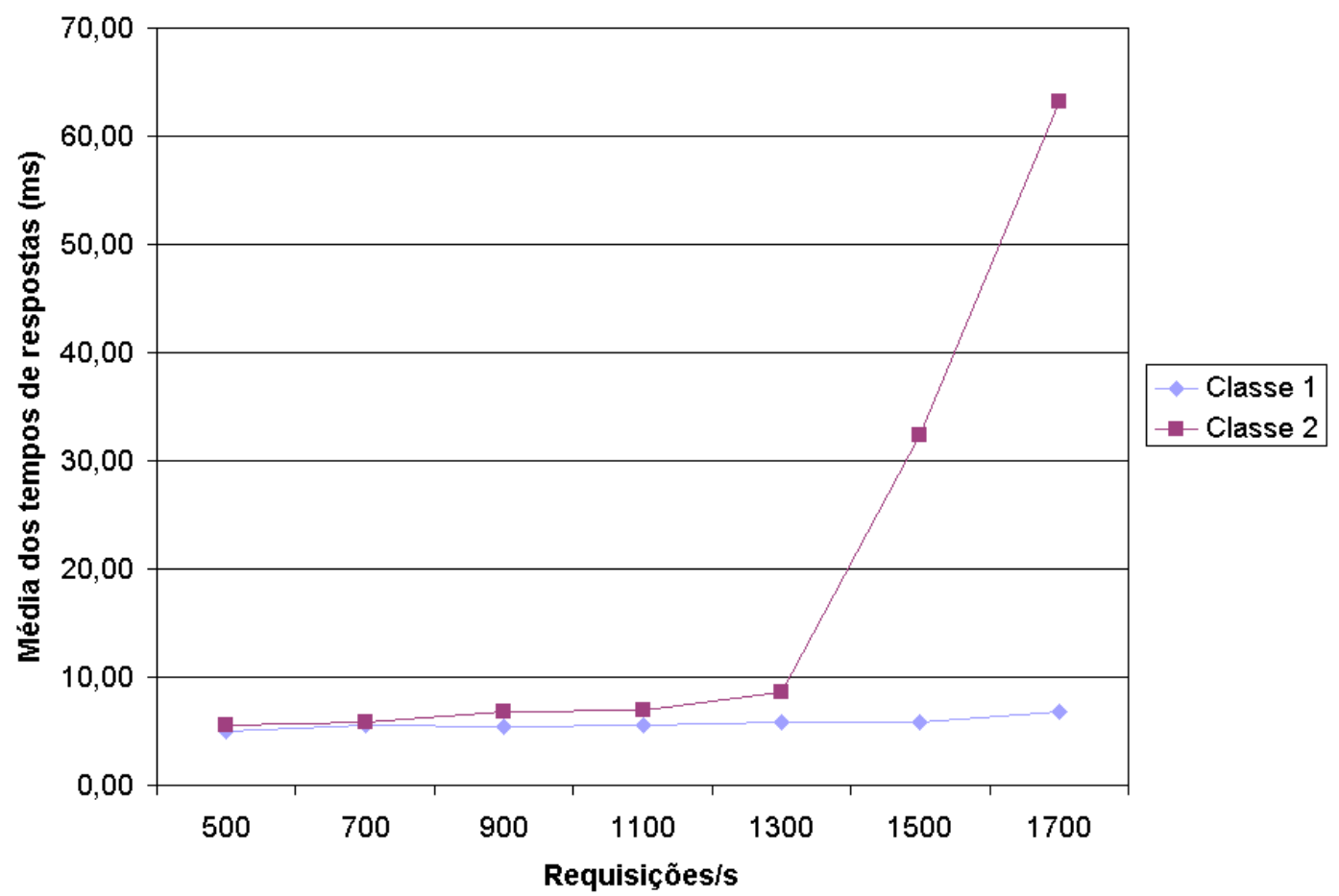

Figura A.11: Médias dos tempos de respostas utilizando o algoritmo PriProcess com 30\% de requisições de alta prioridade e mecanismos de controle de admissão. 


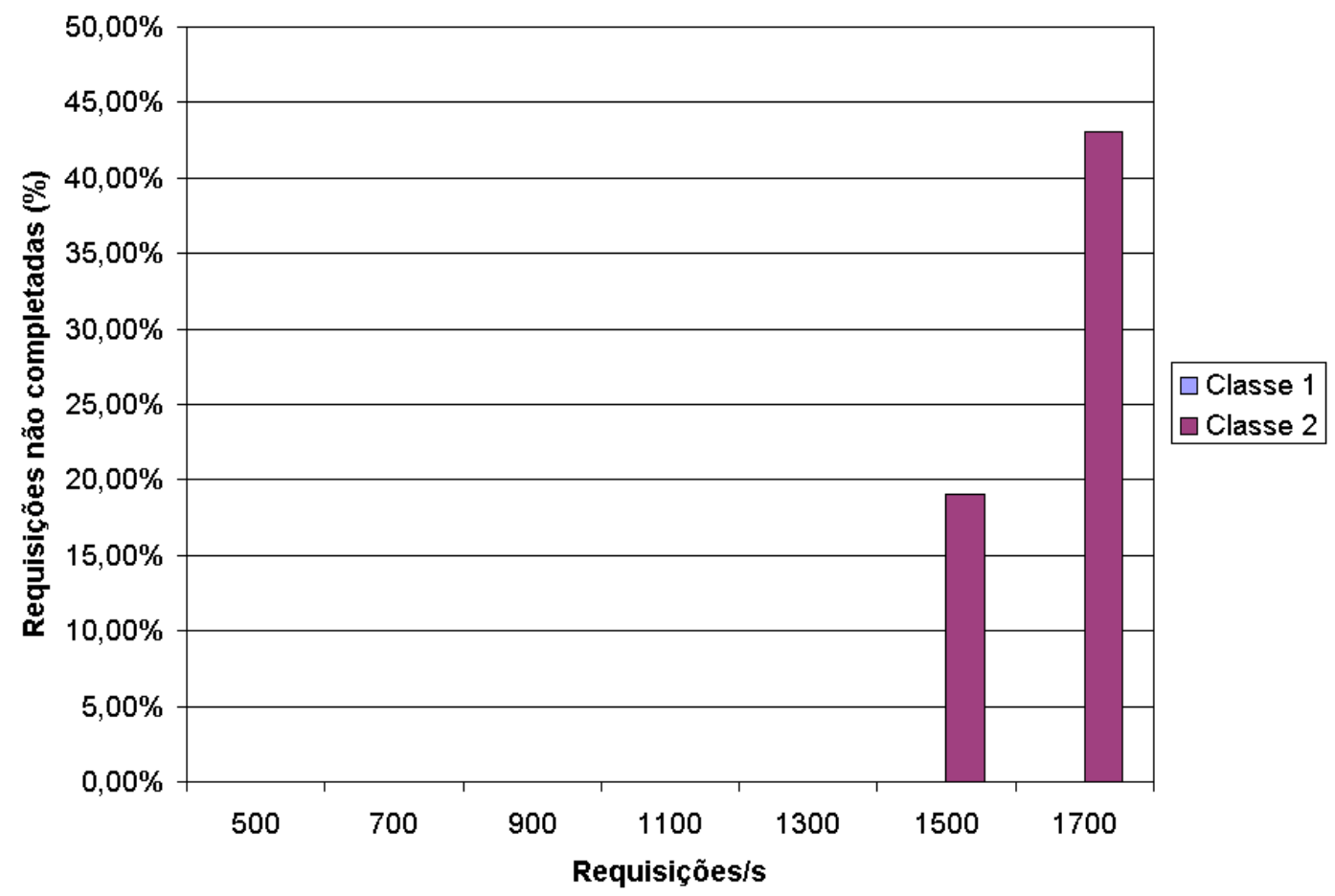

Figura A.12: Porcentagem de requisições descartadas utilizando o algoritmo PriProcess com $30 \%$ de requisições de alta prioridade e mecanismos de controle de admissão.

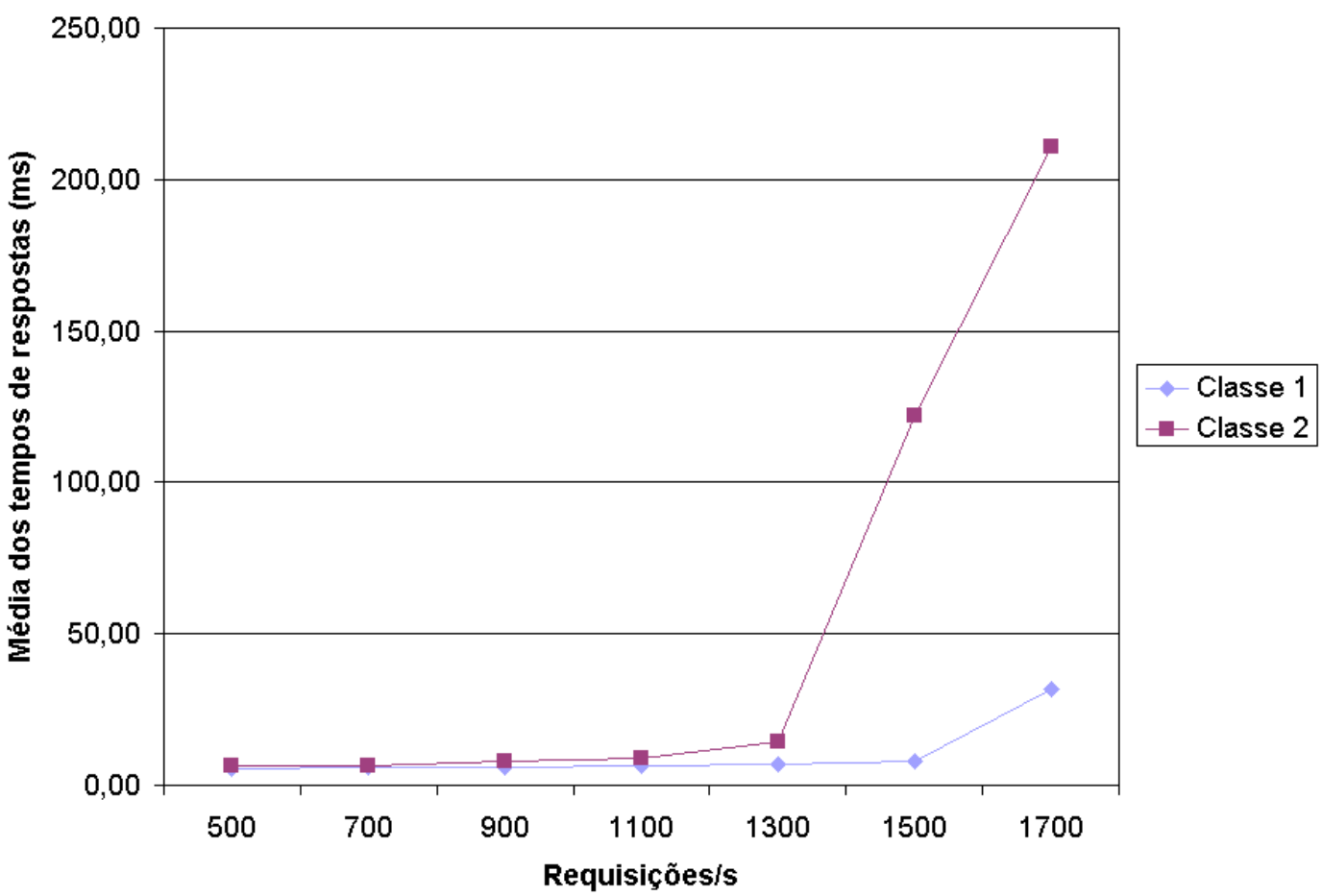

Figura A.13: Médias dos tempos de respostas utilizando o algoritmo PriProcess com 70\% de requisições de alta prioridade e mecanismos de controle de admissão. 


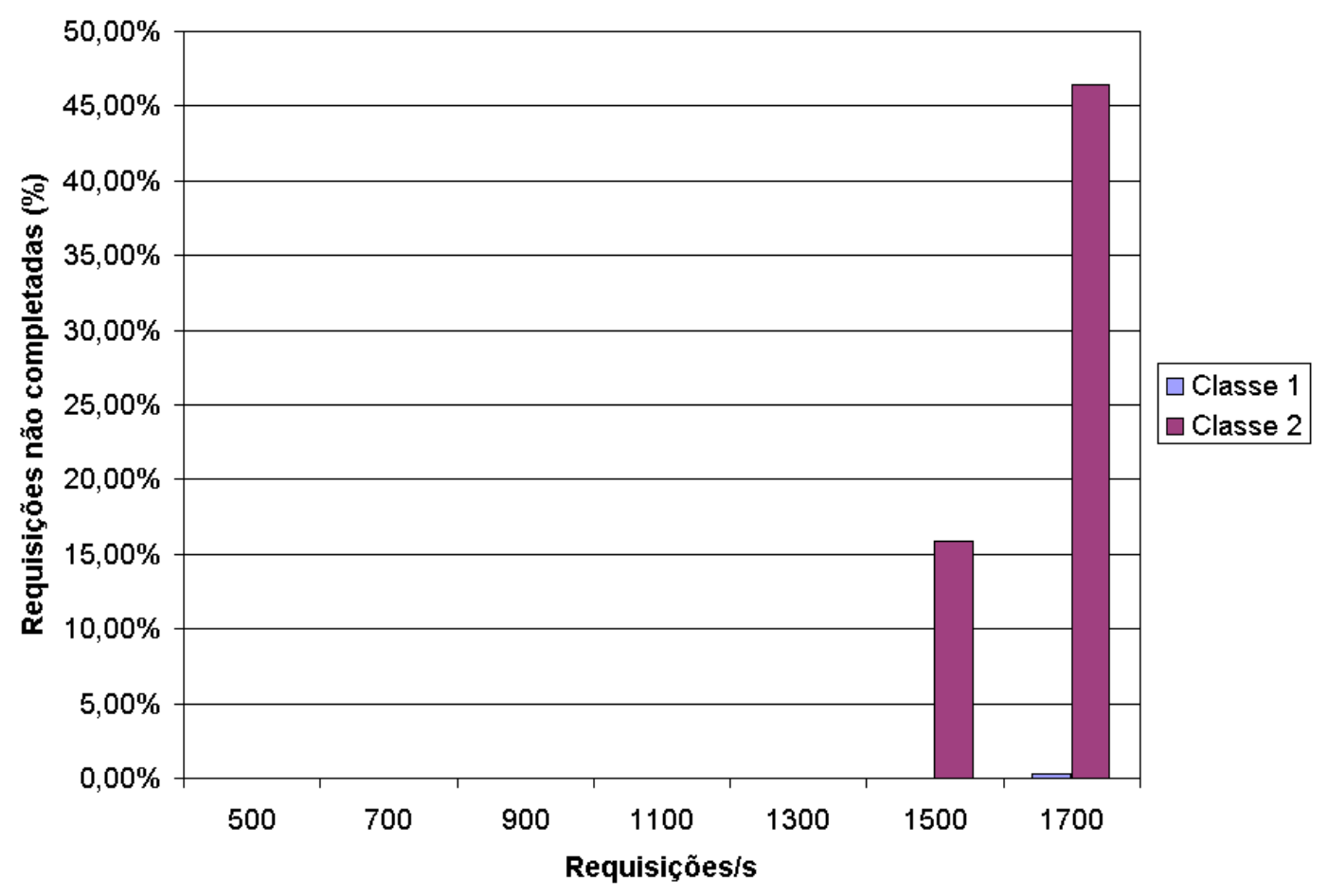

Figura A.14: Porcentagem de requisições descartadas utilizando o algoritmo PriProcess com $70 \%$ de requisições de alta prioridade e mecanismos de controle de admissão.

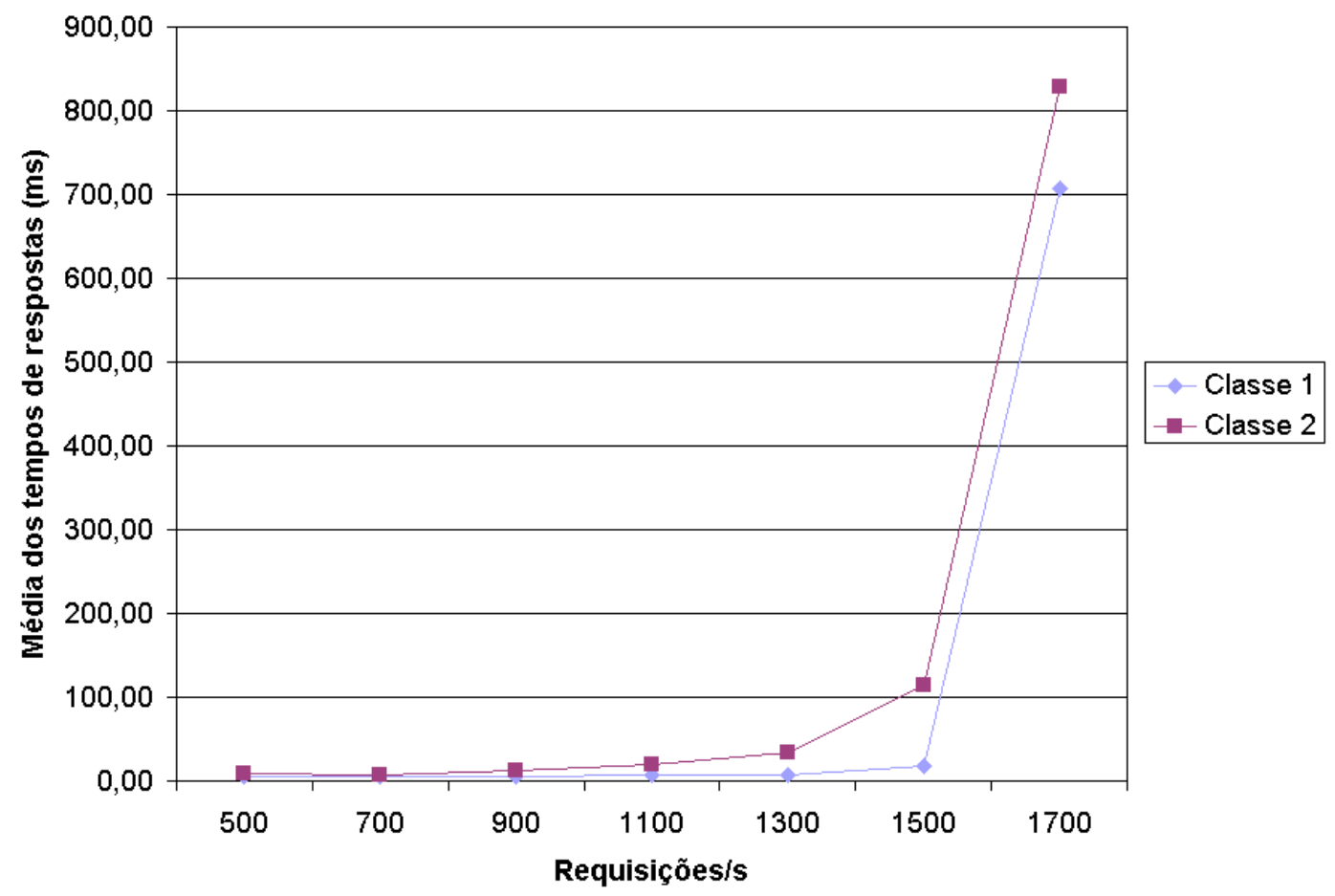

Figura A.15: Médias dos tempos de respostas utilizando o algoritmo PriProcess com 90\% de requisições de alta prioridade e mecanismos de controle de admissão. 


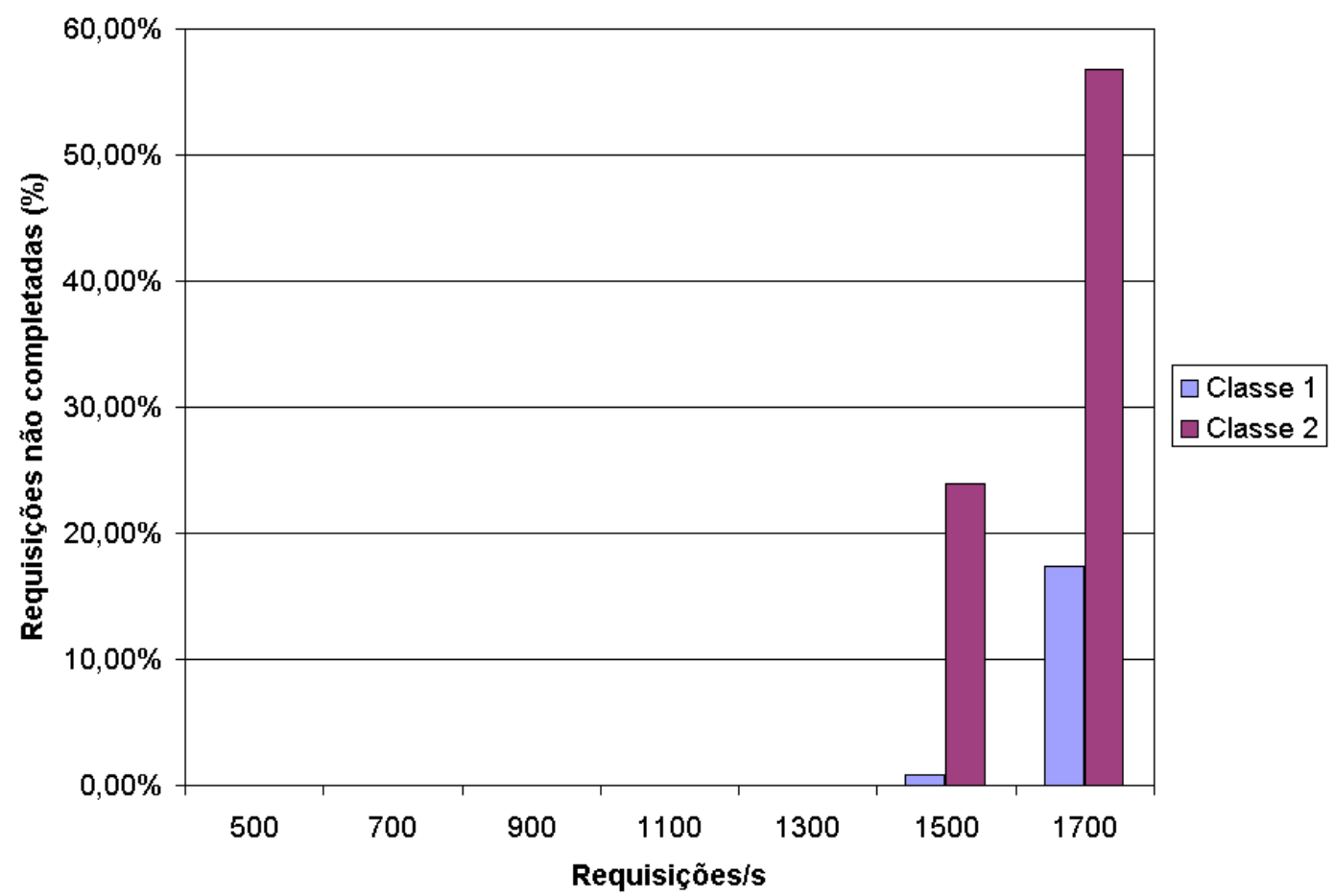

Figura A.16: Porcentagem de requisições descartadas utilizando o algoritmo PriProcess com $90 \%$ de requisições de alta prioridade e mecanismos de controle de admissão. 



\section{Referências Bibliográficas}

Almeida, J.; Dabu, M.; Manikutty, A.; Cao, P. (1998). Providing differentiated levels of service in web content hosting. Proceedings of the 1998 SIGMETRICS Workshop on Internet Server Performance, p. 12. SIGMETRICS.

Andreolini, M.; Casalicchio, E.; Colajanni, M.; Mambelli, M. (2004). A Cluster-based Web System Providing Differentiated and Guaranteed Services. Cluster Computing, v.7, n.1, p.7-19.

APACHE SOFTWARE FOUNDATION (2007). Apache http server project.

Barford, P.; Crovella, M. (1998). Generating Representative Web Workloads for Network and Server Performance Evaluation. Proceedings of ACM SIGMETRICS '98, p. 151-60.

Berners-Lee, T. (1994). World wide web consortium.

Berners-Lee, T.; Fielding, R.; Frystyk, H. (1996). Hypertext Transfer Protocol $\operatorname{HTTP} / 1.0$.

Bhatti, N.; Friedrich, R. (1999). Web server support for tiered services. Techinial report hpl-1999-160, Hewlett-Packard Research Labs, HP Laboratories Palo Alto.

Blake, S.; Black, D.; Carlson, M.; Davies, E.; Wang, Z.; Weiss, W. (1998). An Architecture for Differentiated Services. RFC 2475, IETF.

Braden, R.; Clark, D.; Shenker, S. (1994). Integrated Services in the Internet Architecture. RFC 1633, IETF.

Braden, R.; Zhang, L.; Berson, S.; Herzog, S.; Jamin, S. (1997). Resource ReSerVation Protocol (RSVP) - Version 1 Functional Specification. RFC 2205, IETF.

Cardellinni, V.; Casalicchio, E. (2002). The state of the art in locally distributed webserver systems. v. 34, p. 263-311. ACM Computing Surveys. 
Castilho, L. H. (2006). Caracterização de carga de trabalho para testes de modelos de servidores web. Dissertação (Mestrado), ICMC-USP, São Carlos.

Christin, N.; Liebeherr, J. (2003). A QoS architecture for quantitative service differentiation. IEEE Communications, v.41, n.6, p.38-45.

Comer, D. E. (2000). Internetworking with TCP/IP: Principles, Protocols and Architecture. Prentice Hall, 4 edição.

Dovrolis, C.; Ramanathan, P. (1999). A Case for Relative Differentiated Services and the Proportional Differentiation Model. IEEE Network, v.

Eggert, L.; Heidemann, J. (1999). Application level differentiated services for web servers. World Wide Web Journal, v.2, p.133-142.

Engelschall, P. (1998). Load balancing your web site, web techniques.

Estrella, J. C.; Teixeira, M. A. M.; Santana, M. J.; Santana, R. H. C.; Bruschi, S. M. (2006). Negotiation mechanisms on application level: A new approach to improve quality of service in web servers. IEEE International Workshop on Collaborative Computing, Integration and Assurance (WCCIA 2006), 9th IEEE International Symposium on Object and Component-oriented Real-time Distributed Computing (ISORC 2006), Coréia do Sul.

Fielding, R.; Gettys, J.; Mogul, J.; Frystyk, H.; Masinter, L.; Leach, P.; Berners-Lee, T. (1999). Hypertext transfer protocol - HTTP/1.1.

Finlayson, R.; Mann, T.; Mogul, J.; Theimer, M. (1984). Reverse Address Resolution Protocol. RFC 903, IETF.

Gröne, B.; Knöpfel, A.; Kugel, R.; Schmidt, O. (2004). The Apache Modeling Project.

Haddad, I.; Butler, G. (2004). Experimental studies of scalability in clustered web systems. IPDPS. IEEE Computer Society.

Heinanen, J.; Baker, F.; Weiss, W.; Wroclawski, J. (1999). Assured Forwarding PHB Group. RFC 2597, IETF.

Hu, J.; Pyarali, I.; Schmidt, D. (1997). Measuring the impact of event dispatching and concurrency models on web server performance over high-speed networks.

Jacobson, V.; Nichols, K.; Poduri, K. (1999). An Expedited Forwarding PHB. RFC 2598, IETF.

Kamienski, C. A.; Sadok, D. (2000). Qualidade de Serviço na Internet. 
Kant, K.; Mohapatra, P. (2000). Scalable Internet Servers: Issues and challenges. Proceedings of the Workshop on Performance and Architecture of Web Servers (PAWS). ACM SIGMETRICS.

Klensin, J. (2001). Simple Mail Transfer Protocol. RFC 2821, IETF.

Lee, S. C.; Lui, J. C.; Yau, D. K. (2004). A proportional-delay diffserv-enabled web server: Admission control and dynamic adaptation. IEEE TRANSACTIONS ON PARALLEL AND DISTRIBUTED SYSTEMS, v.15, n.5, p.385-400.

Luo, M.-Y. (2004). Supporting quality of service in web switches. IEEE International Conference on Communications, v.27, n.1, p.2199-2203.

Magalhães, M. F.; Cardozo, E. (1999). Qualidade de serviço na Internet. Relatório técnico, UNICAMP/FEEC/DCA, Campinas, SP.

Mahonen, P.; Riihijarvi, J.; Petrova, M.; Shelby, Z. (2004). Hop-by-Hop toward Future Mobile Broadband IP. IEEE Communications Magazine, v.42, p.138-146.

Masterson, M. (2000). Ethernet Network Performance Monitoring Thresholds. Relatório técnico, M2 Technologies, Wackernheim, Alemanha.

Menascé, D. A.; Almeida, V. A. F. (2003). Planejamento de Capacidade para Serviços na Web. Campus, 1 edição.

Menascé, D. A. (2003). Web server software architectures. IEEE Internet Computing, v.7, n.6, p.78-81.

Mockapetris, P. (1987a). Domain names - concepts and facilities. RFC 1034, IETF.

Mockapetris, P. (1987b). Domain names - implementation and specification. RFC 1035, IETF.

Morrison, G. (2005). Qos for applications. BT Technology Journal, v.23, n.2, p.28-36.

Mosberger, D.; Jin, T. (1998). httperf: A tool for measuring web server performance. First Workshop on Internet Server Performance, p. 59-67. ACM.

Mourão, H. C. B. (2006). Reconhecimento de sessões http em um modelo para servidor web com diferenciação de serviços. Mestrado, ICMC-USP, São Carlos.

Networks, N. (2003). Introduction to quality of service (qos). White paper, Nortel Networks.

Nichols, K.; Blake, S.; Baker, F.; Black, D. (1998). Definition of the Differentiated Services Field (DS Field) in the IPv4 and IPv6 Headers. RFC 2474, IETF. 
Orfali, R.; Harkey, D.; Edwards, J. (1999). Client/Server Survival Guide. John Wiley.

Oyama, C. S. O.; de Lucena, S. C. (2002). Considerações acerca do estabelecimento de qos no rnp2.

Pandey, R.; Barnes, J. F.; Ollsson, R. (1998). Supporting quality of service in HTTP servers. Symposium on Principles of Distributed Computing, p. 247-256.

Paxson, V.; Floyd, S. (2001). Difficulties in Simulating the Internet. IEEE/ACM Transactions on Networking, v.9, n.4, p.392-403.

Plummer, D. C. (1982). An Ethernet Address Resolution Protocol. RFC 826, IETF.

Postel, J. (1980). User Datagram Protocol. RFC 768, IETF.

Postel, J. (1981a). Internet Control Message Protocol. RFC 792, IETF.

Postel, J. (1981b). Internet Protocol. RFC 791, IETF.

Postel, J. (1981c). Transmission Control Protocol. RFC 793, IETF.

Postel, J.; Reynolds, J. (1983). Telnet Protocol Specification. RFC 826, IETF.

Postel, J.; Reynolds, J. (1985). File Transfer Protocol. RFC 959, IETF.

Roberts, J. W. (2004). Internet traffic, qos, and pricing. PROCEEDINGS OF THE IEEE, v. 92, p. 12. SIGMETRICS.

Rosen, E.; Viswanathan, A.; Callon, R. (2001). Multiprotocol Label Switching Architecture. RFC 3031, IETF.

Sabo, C. P. (2006). Avaliação de desempenho com algoritmos de escalonamento em clusters de servidores web. Dissertação (Mestrado), ICMC-USP, São Carlos.

Semprebom, T.; de Oliveira, R.; Montez, C. (2006). Implementing class of service in web server using adaptive scheduling and admission control. WebMedia '06: Proceedings of the 12th Brazilian symposium on Multimedia and the web, p. 273-282, New York, NY, USA. ACM Press.

Serra, A.; Gaïti, D.; Barroso, G.; Boudy, J. (2005). Assuring qos differentiation and load balancing on web servers clusters. Proceedings of the 2005 IEEE Conference on Control Applications, p. 885-890, Toronto, Canada. IEEE Computer Society.

Shan, Z.; Chuang Lin, Y. W. (2005). Prototype implementation and performance evaluation of a qos-based web server. Proceedings of the 2005 IEEE International Workshop on Service-Oriented System Engineering (SOSE 05). 
Shenker, S.; Partridge, C.; Guerin, R. (1997). Specification of Guaranteed Quality of Service. RFC 2212, IETF.

Sit, Y.-F.; Wang, C.-L.; Lau, F. C. M. (2004). Cyclone: A high-performance cluster-based web server with socket cloning. Cluster Computing, v.7, n.1, p.21-37.

Stardust (1999a). White paper - qos protocols \& architectures. Disponível em http://www.qosforum.com.

Stardust (1999b). White Paper - The need for QoS. Disponível em http://www.qosforum.com.

Stevens, W. R.; Fenner, B.; Rudoff, A. (2003). UNIX Network Programming, v. 1. Prentice Hall, 3 edição.

Tanenbaum, A. S. (2002). Computer Networks. Prentice Hall, 4 edição.

Teixeira, M. A. M. (2004). Suporte a serviços diferenciados em servidores web: modelos e algoritmos. Tese (Doutorado), ICMC-USP, São Carlos - SP.

Teixeira, M. A. M.; Santana, M. J.; Santana, R. H. C. (2003). Analysis of task scheduling algorithms in distributed web-server systems. Proceedings of the International Sysmposium on Performance Evaluation of Computer and Telecommunication Systems (SPECTS 2003)., p. 655-663. SPECTS 2003.

Traldi, O. A.; Barbato, A. K.; Santana, R. H. C. (2006). Service differentiating algorithms for qos-enabled web servers. WebMedia '06: Proceedings of the 12th Brazilian symposium on Multimedia and the web, p. 263-272, New York, NY, USA. ACM Press.

Trent, G.; Sake, M. (1995). Webstone: the first generation in http benchmarking.

Vasiliou, N. (2000). Overview of Internet QoS and web server QoS. Relatório técnico, Univ. of Western Ontario, Canadá.

Wen, J.; Lu, X. (2002). The design of QoS guarantee network subsystem. ACM SIGOPS Operating Systems Review.

Wroclawski, J. (1997). Specification of the Controlled-Load Network Element Service. RFC 2211, IETF.

Xiao, X.; Ni, L. M. (1999). Internet QoS: a Big Picture. IEEE Network, v.

Yeager, N. J.; McGrath, R. E. (1996). Web Server Technology: the Advanced Guide for World Wide Web Information Providers. Morgan Kaufmann. 
Zhang, R.; Abdelzaher, T. F.; Stankovic, J. A. (2004). Efficient tcp connection failover in web server clusters. INFOCOM.

Zhao, W.; Olshefski, D.; Schulzrinne, H. (1999). Internet Quality of Service: an Overview. IEEE Network, v.

Zhao, W.; Olshefski, D.; Schulzrinne, H. (2000). Internet quality of service: an overview. http://www.cs.columbia.edu/h̆gs/netbib/.

Zhou, X.; Wei, J.; Xu, C.-Z. (2004). Processing rate allocation for proportional slowdown differentiation on internet servers. Proceedings of the 18th International Parallel and Distributed Processing Symposium, v. 